\title{
Present climate and climate change over North America as simulated by the fifth-generation Canadian regional climate model
}

\author{
Leo Šeparović • Adelina Alexandru • \\ René Laprise · Andrey Martynov • Laxmi Sushama • \\ Katja Winger $\cdot$ Kossivi Tete $\cdot$ Michel Valin
}

Received: 30 July 2012/ Accepted: 11 March 2013/Published online: 5 May 2013

(c) The Author(s) 2013. This article is published with open access at Springerlink.com

\begin{abstract}
The fifth-generation Canadian Regional Climate Model (CRCM5) was used to dynamically downscale two Coupled Global Climate Model (CGCM) simulations of the transient climate change for the period 1950-2100, over North America, following the CORDEX protocol. The CRCM5 was driven by data from the CanESM2 and MPIESM-LR CGCM simulations, based on the historical (1850-2005) and future (2006-2100) RCP4.5 radiative forcing scenario. The results show that the CRCM5 simulations reproduce relatively well the current-climate North American regional climatic features, such as the temperature and precipitation multiannual means, annual cycles and temporal variability at daily scale. A cold bias was noted during the winter season over western and southern portions of the continent. CRCM5-simulated precipitation accumulations at daily temporal scale are much more realistic when compared with its driving CGCM simulations, especially in summer when small-scale driven convective precipitation has a large contribution over land. The CRCM5 climate projections imply a general warming over the continent in the 21 st century, especially over the
\end{abstract}

L. Šeparović · A. Alexandru - R. Laprise - A. Martynov ·

L. Sushama $\cdot$ K. Winger $\cdot$ K. Tete $\cdot$ M. Valin

Centre ESCER (Étude et Simulation du Climat à l'Échelle

Régionale), Montréal, QC, Canada

L. Šeparović $(\varangle) \cdot$ A. Alexandru - R. Laprise - A. Martynov ·

L. Sushama $\cdot$ K. Winger $\cdot$ K. Tete $\cdot$ M. Valin

Département des Sciences de la Terre et de l'Atmosphère,

Université du Québec à Montréal (UQAM), C.P. 8888, Succ.

Centre-ville, Montréal, QC H3C 3P8, Canada

e-mail: leoseparovic@gmail.com

L. Sushama

Canada Research Chair in Regional Climate Modelling, UQAM,

Montréal, QC, Canada northern regions in winter. The winter warming is mostly contributed by the lower percentiles of daily temperatures, implying a reduction in the frequency and intensity of cold waves. A precipitation decrease is projected over Central America and an increase over the rest of the continent. For the average precipitation change in summer however there is little consensus between the simulations. Some of these differences can be attributed to the uncertainties in CGCMprojected changes in the position and strength of the Pacific Ocean subtropical high pressure.

Keywords Regional climate modelling - CRCM5 . CORDEX · Climate change projections over North America $\cdot$ Bukovsky's regionalisation

\section{Introduction}

Coupled Global Climate Models (CGCMs) comprised of an atmospheric general circulation model coupled with the ocean, sea ice and land surface, forced with scenarios of the evolution of concentrations of anthropogenically affected greenhouse gases (GHG) and aerosols, are the most comprehensive tools for climate studies. However, because of their high complexity and the need to perform very long simulations to stabilize the deep ocean, CGCM simulations are very demanding in computational resources and are performed at relatively coarse horizontal resolution. Development of the adaptation and mitigation strategies requires information on spatial scales finer than those provided by CGCMs. One-way nested Regional Climate Models (RCMs) have been increasingly employed as a "magnifying glass" to dynamically downscale coarse-resolution global fields over a region of interest. In this paradigm, information derived from CGCM simulations or 
objective analyses provide the atmospheric lateral boundary conditions (LBC) and Sea Surface Temperature (SST) and Sea-Ice Concentration (SIC) for the integration of atmospheric and land-surface variables over a limited area of the globe using high-resolution computational grids (e.g., McGregor 1997; Giorgi and Mearns 1999; Wang et al. 2004; Laprise 2008; Rummukainen 2010).

When an RCM is forced by a CGCM, the RCM simulations are affected by the combination effect of its own structural biases and of the imperfect boundary conditions. RCM structural biases can be assessed comparing reanalysis-driven RCM simulations with some observational database. The effect of the imperfect boundaries on a RCM simulation can be assessed comparing the CGCM-driven RCM simulations with reanalysis-driven RCM simulations (e.g., Sushama et al. 2006; de Elía et al. 2008; Monette et al. 2012).

In principle, the structural biases of RCM are expected to be smaller than those of CGCMs, due to the higher resolution of RCM and the fact that they are driven by (nearly) perfect reanalysis boundary conditions. When the errors transmitted from the driving CGCMs are considered, the one-way nested RCMs are not intended to considerably change or improve the large-scale atmospheric driving fields imposed as the lateral boundary conditions since large inconsistencies would then arise at the perimeter of the lateral boundaries (von Storch et al. 2000). Further, the RCMs' performance considerably depends on the CGCM skill to reproduce the observed average SST and SIC, as these variables are prescribed as the lower boundary conditions in RCM simulations. The selection of CGCMs for regional downscaling is thus critical for the quality of RCM simulations and is usually based on the quality of CGCM simulations in the region of interest (e.g., Pierce et al. 2009).

Climate-change signal is obtained from RCM simulations by taking the difference between the projected future climate and the simulated current climate considering, for example, statistics computed over 30 years. The credibility of such climate-change signal is of course conditional to the skill of the RCM in faithfully reproducing the current climate. In that respect, RCM structural biases and errors transmitted from the driving CGCM fields via boundary conditions should be both small. If they are of the opposite sign but similar magnitude, they may cancel one another, leading to an apparently high RCM skill in reproducing the current climate, for rather wrong reasons; the cancelation of errors may not necessarily occur in a future climate, thus contaminating the climate-change signal with errors.

Comparing a CGCM-driven RCM simulation with the driving CGCM simulation provides a measure of the "added value" afforded by dynamical downscaling with an RCM. The "added value" may be studied under current climate conditions, for future climate and for the climatechange signal (e.g., Castro et al. 2005; Feser 2006; Laprise 2005; Laprise et al. 2008; Winterfeldt and Weisse 2009; Prömmel et al. 2010; De Sales and Xue, 2011; Di Luca et al. 2012a, b, c).

In order to compare the performance of RCMs and address the uncertainties in RCM climate projections and thus provide valuable high-resolution climate-change information for further impact and adaptation studies, the need of international coordination between RCM downscaling efforts has been early recognized (e.g., PIRCS, Takle et al. 1999; PRUDENCE, Christensen et al. 2007a, b; NARCCAP, Mearns et al. 2009). In 2009, a new World Climate Research Programme (WCRP) initiative-the COordinated Regional climate Downscaling EXperiment (CORDEX, Giorgi et al. 2009) was launched to provide a consistent framework for characterizing the uncertainties underlying regional climate-change projections within the timeline of the Intergovernmental Panel on Climate Change (IPCC) Fifth Assessment Report (AR5). Within the CORDEX framework, the Coupled Model Intercomparison Project-Phase 5 (CMIP5, Taylor et al. 2012) CGCM simulations are downscaled over specified continent-scale regional domains, using specific timeframes for RCM integration (1950-2100) and validation purposes (20 years).

In this manuscript we present an analysis of the two transient climate-change RCM downscaling experiments over the North American CORDEX domain based on the historical and representative future GHGs and aerosol concentrations. These experiments are performed using the fifth-generation Canadian Regional Climate Model (CRCM5) driven at the lateral boundaries and ocean surface by the output from two different CMIP5 CGCMs' simulations. In addition, a reanalysis-driven CRCM5 simulation is performed in order to assess the CRCM5 own structural biases.

The skill of the reanalysis-driven CRCM5 simulation over the North American CORDEX domain in reproducing the observed precipitation and near-surface temperatures is analysed in detail in Martynov et al. (2013). The authors showed that the reanalysis-driven CRCM5 simulation has a comparably high skill in realistically reproducing some key synoptic and mesoscale climatic features of North American climate that were underlined in the IPCC AR4 (Christensen et al. 2007a), such as the North American Monsoon, Great Plains Low-Level Jet and its influence on the precipitation diurnal cycle in summer. In this paper, we first evaluate the ability of the CGCM-driven CRCM5 simulations to realistically reproduce the observed spatiotemporal variability of near-surface temperatures and precipitation, and then we present the projected changes for the 21 st century. Recently, the CRCM5 simulations have 
also been performed over the CORDEX-Africa domain. The skill of the reanalysis-driven CRCM5 simulation at reproducing the key climatic features over Africa is discussed in Hernández-Díaz et al. (2012), and CGCM-driven CRCM5 simulations and climate projections over Africa are analyzed in Laprise et al. (2013).

The paper is organized as follows. A brief description of the CRCM5, driving CGCMs and the experiment design is given in Sect. 2. In Sect. 3 we discuss the uncertainty in the observed climate by considering multiple observation and reanalysis products. Sections 4, 5, 6 discuss the CRCM5 performance in reproducing different aspects of the current climate. Finally, Sect. 7 provides the projected climate changes. Summary and conclusions are presented in Sect. 8.

\section{Experimental setup}

\subsection{CRCM5 configuration}

The CRCM5 (Zadra et al. 2008) is a limited-area version of the Environment Canada Numerical Weather Prediction Global Environmental Multiscale model (GEM, Côté et al. 1998; Yeh et al. 2002). It is a grid-point model based on a two-time-level semi-Lagrangian, (quasi) fully implicit time discretization scheme. The model includes a terrain-following vertical coordinate based on hydrostatic pressure (Laprise 1992) and the horizontal discretization on a rotated latitude-longitude, Arakawa C grid (Arakawa and Lamb 1977). The nesting technique employed in CRCM5 is derived from Davies (1976); it includes a 10-point wide halo zone along the lateral boundaries for the semiLagrangian interpolation and a 10-point sponge zone for a gradual relaxation of all prognostic atmospheric variables toward the driving data along the lateral boundaries. A detailed description of the CRCM5 model used here can be found in Hernández-Díaz et al. (2012) and Martynov et al. (2013).

In the present configuration, the CRCM5 employs KainFritsch deep convection parameterization (Kain and Fritsch 1990), Kuo-transient shallow convection (Kuo 1965; Bélair et al. 2005), Sundqvist resolved-scale condensation (Sundqvist et al. 1989), correlated-K solar and terrestrial radiations ( $\mathrm{Li}$ and Barker 2005), and subgrid-scale orographic gravity-wave drag (McFarlane 1987), the low-level orographic blocking parameterization (Zadra et al. 2003) with recent modifications described in Zadra et al. (2012), and the planetary boundary layer parameterization (Benoit et al. 1989; Delage and Girard 1992; Delage 1997) modified to introduce turbulent hysteresis as described in Zadra et al. (2012). Some important modifications were introduced to the physical parameterization of the model in order to improve its performance for regional climate. This includes a change to the planetary boundary layer parameterization to suppress turbulent vertical fluxes under very stable conditions. The interactively coupled one-dimensional lake model (Flake, Mironov et al. 2010) has been introduced and tested in the CRCM5 (Martynov et al. 2012), for both the resolved- and subgrid-scale lakes following a land-surface type aggregation approach.

The CRCM uses the Canadian Land-Surface Scheme, version 3.5 (CLASS3.5, Verseghy 1991, 2009). The CLASS was set to 26 soil layers, with the maximum depth of $60 \mathrm{~m}$. The ECOCLIMAP bare soil albedo (Masson et al. 2003) is used instead of the default values in CLASS3.5 and the Sturm et al. (1997) parameterization is used for snow thermal conductivity. The geophysical fields representing the distribution and characteristics of vegetation have been modified in order to better reproduce the real vegetation; $50 \%$ of the bare soil fraction has been filled with surrounding vegetation or short grass and forbs and $30 \%$ of bare soil was added in boreal forest and north of it to the following vegetation types: needleleafs, deciduous broadleafs, deciduous shrubs, mixed wood forests. Further, $30 \%$ of "crops" have been converted to "short grass and forbs". Although no organic soils were used in the simulation, peatlands were introduced as a separate soil type.

\subsection{CGCMs}

The CRCM5 simulations use data from two CMIP5 CGCMs. The second-generation Canadian Earth System Model (CanESM2) has evolved from CanESM1 (Arora et al. 2009, 2011). It consists of the fourth-generation atmospheric general circulation model CanAM4 coupled with the physical ocean component OGCM4 developed from the NCAR CSM Ocean Model (NCOM; Gent et al. 1998), the Canadian Model of Ocean Carbon (CMOC; Christian et al. 2010) and Canadian Terrestrial Ecosystem Model (CTEM; Arora and Boer 2010). The CanAM4 evolved from CanAM3, described in detail in von Salzen et al. (2005) and Scinocca et al. (2008) by introducing substantial improvements in the radiative transfer and cloud microphysics parameterizations and adding a prognostic bulk aerosol scheme with a full sulphur cycle, along with organic and black carbon, mineral dust and sea salt. The CanAM4 is a spectral model employing T63 triangular truncation with physical tendencies calculated on a $2.81^{\circ}$ linear grid and 35 levels in the vertical (Arora et al. 2011). The OGCM4 horizontal coordinates are spherical with grid spacings approximately $1.41^{\circ}$ in longitude and $0.94^{\circ}$ in latitude.

The Max Planck Institute for Meteorology's Earth System Model (MPI-ESM) consists of the atmospheric global circulation model ECHAM version 6 (Roeckner 
et al. 2003; Giorgetta et al. 2012) that includes an advanced treatment of terrestrial biosphere using a dynamical land vegetation model (JSBACH; Brovkin et al. 2009). The ECHAM6 is coupled with the global ocean/sea ice model MPI-OM (Marsland et al. 2003) without any flux adjustment (Jungclaus et al. 2006) and the Hamburg Ocean Carbon Cycle model (HAMOCC; Wetzel et al. 2005). In its low-resolution version MPI-ESM-LR, the atmospheric component of ECHAM6 operates at spectral truncation T63, on a $1.87^{\circ}$ quadratic Gaussian grid with 47 levels in the vertical, while the MPI-OM component operates on a $1.5^{\circ}$ grid with 40 levels.

Two CGCM simulations (one member simulation from the CanESM2 and the other from MPI-ESM-LR) are used to drive the CRCM5. These CGCM simulations consist of the historical 1850-2005 period, when GHGs, aerosols and land cover, as well as the natural variability due to solar variability and explosive volcanoes force them. The continuations in the 2006-2100 period are forced with the Representative Concentration Pathway 4.5 future scenario (RCP4.5; Meinshausen and 2011).

\subsection{CRCM5 simulation setup}

Following the CORDEX recommendations, the CRCM5 simulations are performed on a grid mesh of $0.44^{\circ}$; at this resolution CRCM5 uses a 20-min timestep. The integration domain was slightly larger than the minimal one suggested by CORDEX for North America (see for example Fig. 1), consisting of $172 \times 160$ grid points, excluding the halo and sponge zone. In the vertical, 56 hybrid levels were used, with the top level near $10 \mathrm{hPa}$.
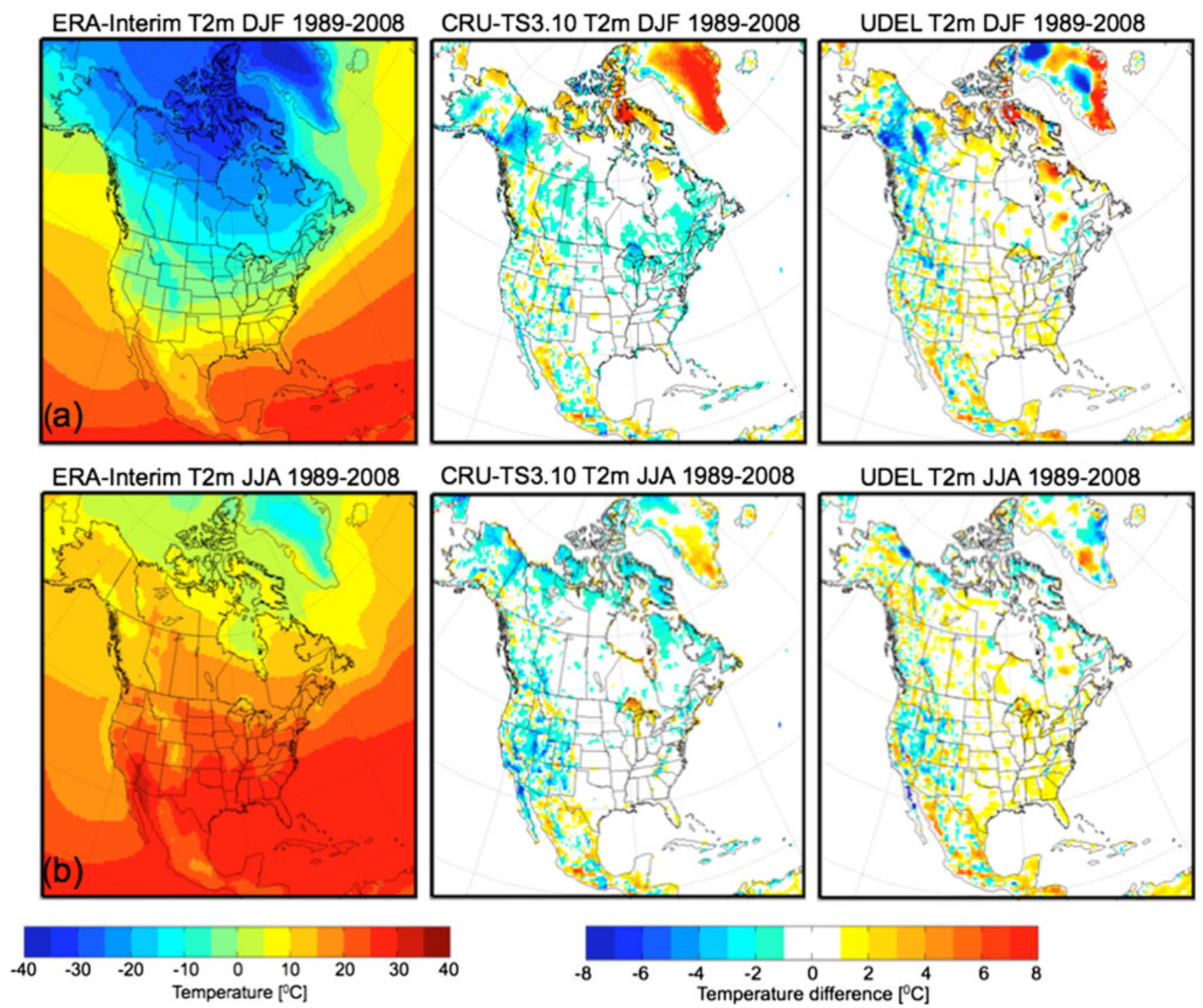

Fig. 1 ERA-Interim 1989-2008 average temperatures and deviations of the CRU and UDEL gridded analyses of observations from ERAInterim temperatures for a DJF and $\mathbf{b}$ JJA 
Following the CORDEX recommendations, the simulations were driven at the lateral boundaries only, with no nudging in the interior of domain; thus the large-scale spectral nudging option was turned off in all simulations reported here.

Three CRCM5 simulations were carried out. The first simulation spanned a 50-year period and was driven by the ERA40 reanalysis and AMIP II SST and SIC (Kanamitsu et al. 2002) for 1959-1988 and by the ERA-Interim reanalysis data during the period 1989-2008 for atmospheric and ocean surface conditions. Air temperature, horizontal wind components and specific humidity lateral boundary conditions on pressure levels were used for driving this simulation.

In order to spin up the CLASS for the CGCM-driven CRCM5 integrations, the soil temperature profiles are first taken from Stevens et al. (2008); they were obtained by forward modelling with a simple soil model using forcing data from a millennial CGCM integration. Next, these profiles were used as an input to a 300-year long CRCM5 integration on a grid mesh of $1^{\circ}$ over North America, driven with the ERAINT reanalysis for a selected representative year. The final soil temperature profiles from this integration served as the initial profiles for the CGCMdriven CRCM5 simulations.

The two continuous CGCM-forced CRCM integrations were carried out for the period 1950-2100, driven from the lateral boundaries and ocean surface by the data from CanESM2 and MPI-ESM-LR, and forced with the historical and representative future GHG and aerosol concentrations from the RCP4.5. For these two simulations, the CGCM-derived lateral boundary conditions were interpolated on the model levels, with the same driving variables, except in the case of MPI-ESM-driven simulation where the available cloud data were also prescribed at the lateral boundaries. When unavailable in the driving CGCM due to the different land-use definitions arising from the very different model resolutions, the SST and SIC fields on the CRCM5 grid were derived using the linear and nearestneighbour extrapolation, respectively. For diagnostic analysis the simulated fields were interpolated to 22 pressure levels. Most variables were archived at three hourly intervals, except for precipitation that was accumulated and archived at hourly intervals.

In what follows we will use the acronyms CRCM-ERA, CRCM-Can and CRCM-MPI for the reanalysis-, CanESM2- and MPI-ESM-LR-driven CRCM5 simulations. Prior to analysing these simulation results, we briefly discuss the current-climate near-surface temperature and precipitation over North America. We will compare various observation-based gridded datasets and reanalysis in order to assess the uncertainty in the observed climate and select the datasets for model validation.

\section{Observed present-day climate}

Figure 1 shows the 1989-2008 climatological-average $2 \mathrm{~m}$ temperatures from ERA-Interim (ERAINT) reanalysis for winter (DJF, Fig. 1a) and summer (JJA, Fig. 1b), interpolated on the CRCM5 grid. In addition, the central and right columns in Fig. 1 display the deviations from ERAINT values of corresponding fields from two other observational datasets that are only available over land: the University of East Anglia Climate Research Unit (CRU, version TS3.1; Mitchell and Jones 2005) and the University of Delaware (UDEL, version 2.01; Willmott and Matsuura 1995). It can be seen in Fig. 1 that, with the exception of Greenland and northern parts of the Canadian Archipelago, the differences among these datasets over central and eastern parts of the continent are generally not large. The CRU values tend to be somewhat cooler than ERAINT while UDEL values tend to be warmer; the absolute differences are, however, mostly confined to $\pm 1{ }^{\circ} \mathrm{C}$. Over the western part of the continent and Mexico, characterized with complex topography, there is somewhat less agreement between the three datasets, giving rise to differences locally as large as $\pm 4{ }^{\circ} \mathrm{C}$. Part of these differences might arise because of a somewhat coarser resolution of ERAINT reanalysis. It is produced with an assimilation system operating on a $0.75^{\circ}$ reduced Gaussian grid with spectral truncation T255 (Dee et al. 2011) but the publicly available ERAINT $2 \mathrm{~m}$ temperatures are provided on the $1.5^{\circ}$ latitude-longitude grid, which could result in some smoothing of the original data. The UDEL and CRU datasets $\left(0.5^{\circ}\right)$, might more accurately represent the local differences in elevation. On the other hand, the latter two datasets might suffer problems related to the localization of station data (valleys and mountains).

The first column of Fig. 2 shows the climatologicalaverage precipitation for 2001-2008 in winter (Fig. 2a) and summer (Fig. 2b) from the Global Precipitation Climatology Project global daily merged precipitation analysis (GPCP, 1DD; $1^{\circ}$; Huffman et al. 2001). The other three columns on Fig. 2 display seasonal-average deviations of CRU, UDEL and Tropical Rainfall Measuring Mission (TRMM, 3B42, 0.25, 1998-2009; Huffman et al. 2007) datasets, respectively. The TRMM dataset is defined over land and oceans, but only for latitudes below $50^{\circ} \mathrm{N}$ and for a shorter time frame. Very large deviations from the other three sets having been noted in the TRMM seasonal means in the period $1998-2000$ in the $40^{\circ} \mathrm{N}-50^{\circ} \mathrm{N}$ range (not shown), we decided to exclude these years and to use only 2001-2008. The same period is used in Fig. 2 in order to compare the four datasets.

The deviations of each of the three datasets in Fig. 2 are normalized with the arithmetic mean between that dataset and GPCP. In winter (Fig. 2a), CRU and UDEL have 

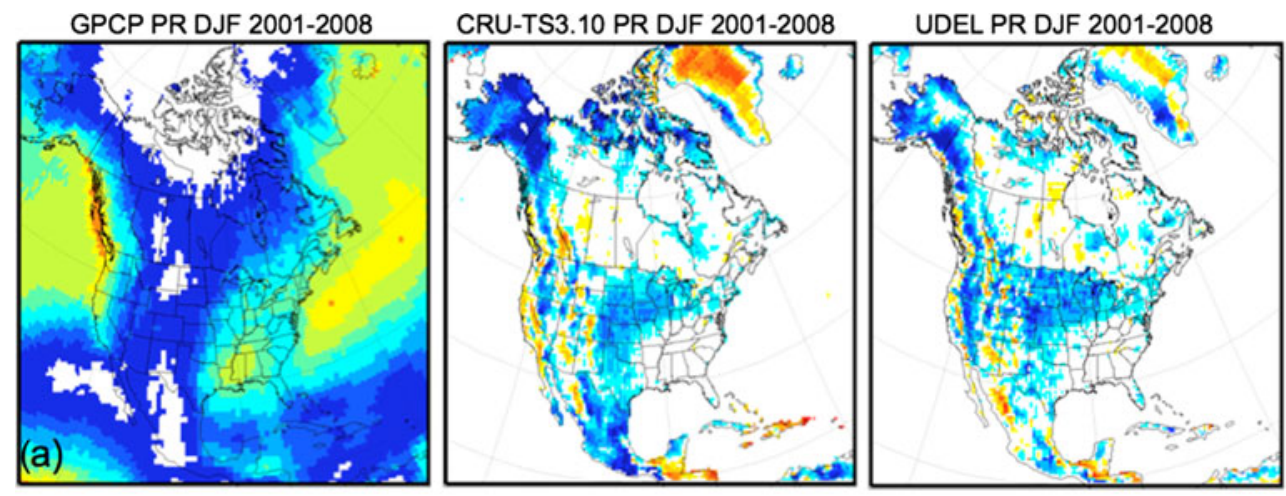

TRMM PR DJF 2001-2008

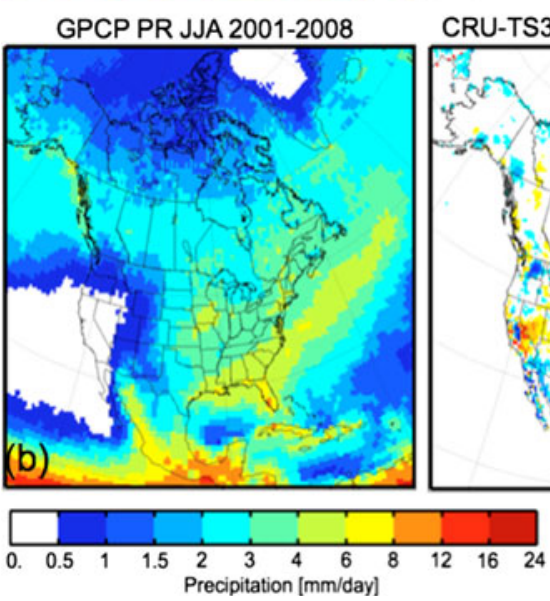

CRU-TS3.10 PR JJA 2001-2008
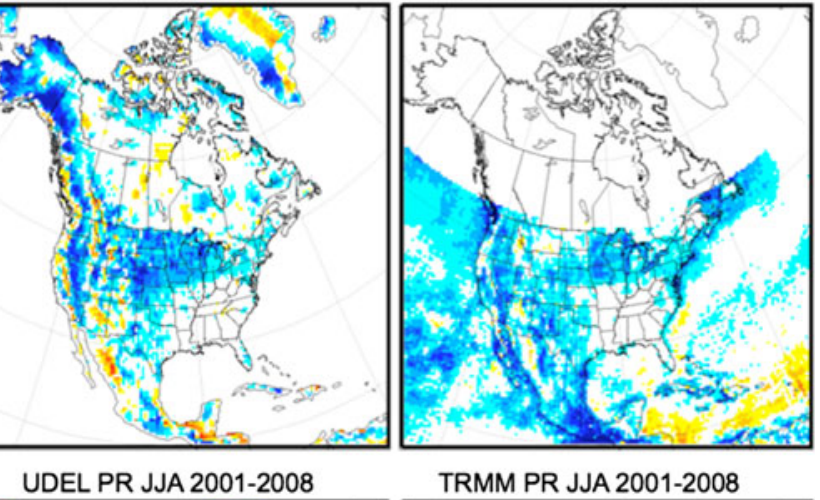

TRMM PR JJA 2001-2008
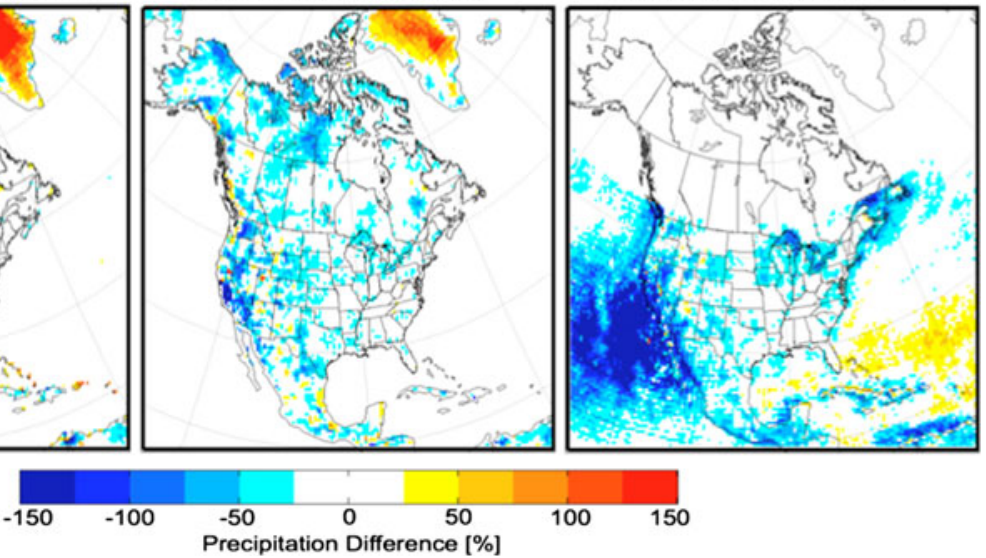

Fig. 2 GPCP 2001-2008 average observed precipitation and the deviations of the CRU, UDEL and TRMM mean precipitation from the GPCP observations in a DJF and b JJA

considerable dry deviations over Alaska and northern Pacific Coast. Another important feature of these sets is a dry deviation in the US central plains. A careful examination of this feature shows that the gradient of precipitation difference closely follows the US-Canada border. This cross-border discontinuity in winter precipitation has been attributed to snowdrift treatment and differences in catch characteristics between the national gauges (Yang et al. 2005). It is present in both CRU and UDEL datasets that are purely based on ground observations. On the other hand, GPCP and TRMM combine satellite and gauge data, which likely diminishes the cross-border discontinuity in winter. In summer, there is no such discontinuity and, in general, the relative differences among different datasets become considerably smaller. It is also worth noting that TRMM dataset exhibits a general dry deviation with respect to GPCP in both summer and winter, especially in the western-most regions of the continent and over the Pacific Ocean, locally as large as $100 \%$, which implies three times lower values in TRMM than in GPCP. A more thorough discussion of the TRMM bias and other observation uncertainties can be found in Nikulin et al. (2012) for CORDEX-Africa domain.
For validation of CRCM5-simulated spatially averaged precipitation, such as, for example, when evaluating the precipitation annual cycles over aggregated regions, the $1^{\circ}$ GPCP set will be used as a reference in order to avoid the systematic differences associated with the snowdrift treatment. However, for grid-point validations of the CRCM5 precipitation the $0.5^{\circ} \mathrm{CRU}$ set will be used instead, because its higher spatial resolution matches more closely that of CRCM5. It can be seen in Fig. 4a that in winter over Mountainous West there are relatively large local differences between the GPCP as compared to CRU or UDEL sets. The latter two yield more precipitation on the western slopes of mountains, exposed to the westerly flow, but less over eastern slopes in the lee of mountains (such as the Okanagan Valley and Alberta Foothills). These local differences are likely due to the coarseness of the GPCP dataset. Finally, for the purpose of comparison of CRCM5 precipitation at higher temporal resolution, such as daily accumulations time series, we decided to utilize the highresolution TRMM set $\left(0.25^{\circ}\right)$ since it can potentially better represent heavy precipitation events; for a comparison of GPCP and TRMM daily precipitation distributions, see Martynov et al. (2013). 
For validation of CRCM5 seasonal $2 \mathrm{~m}$ temperatures we will use CRU data. Finally, for comparison of CRCM5 daily temperature time series ERAINT reanalysis will be utilized. Daily temperatures are not so fine-scale dominated as precipitation and we do not expect the choice of the reference dataset to have a large impact on the assessment of CRCM5 skill in reproducing daily temperature distributions, except in regions with complex topography, such as the Pacific Coast or Mountainous West, where deviations of the ERAINT reanalysis from UDEL and CRU datasets were noted (Fig. 1).

In the next section we begin the evaluation of CRCM5 simulations of the present climate by first considering seasonal-average variables.

\section{Evaluation of CRCM5 seasonal averages}

Among the CGCM variables used to force the CRCM5 simulations it appears that the SST have a large impact on the CRCM5 skill in reproducing present climate. Figure 3 shows the DJF- and JJA-average SST biases in CRCM-Can and CRCM-MPI simulations. The SSTs shown in Fig. 3 are identical to those of the corresponding CGCM simulations, except in regions where they are not defined and hence needed to be extrapolated, such as, in the case of CanESM2, the Canadian Archipelago and the Gulf of California. It can be seen in Fig. 3 that both CRCM-Can and CRCM-MPI exhibit a cold bias of $2-6{ }^{\circ} \mathrm{C}$ off the midlatitude Pacific Coast in winter and a warm bias off the subtropical Pacific Coast in all seasons. This warm bias is exceptionally large in CRCM-MPI in summer when it reaches $6{ }^{\circ} \mathrm{C}$ and also extends farther northward. Both models also have considerable SST biases in the Atlantic, warm bias off the East Coast and a strong cold bias in north-central Atlantic, implying that the Gulf Stream is not well represented. It is worth noting that these biases are quite a bit larger than the interannual variability; the standard deviation of seasonal average SSTs is mainly confined to $1-2{ }^{\circ} \mathrm{C}$ (not shown).

The biases of CGCM-driven CRCM5 simulations can be thought of as originating from: (1) the CRCM5's own
Fig. 3 Deviation of the 1989-2008 average SST in the CRCM-Can (a, b) and CRCMMPI (c, d) from the ERA-Interim 1989-2008 mean, for DJF $(\mathbf{a}, \mathbf{c})$ and JJA $(\mathbf{b}, \mathbf{d})$

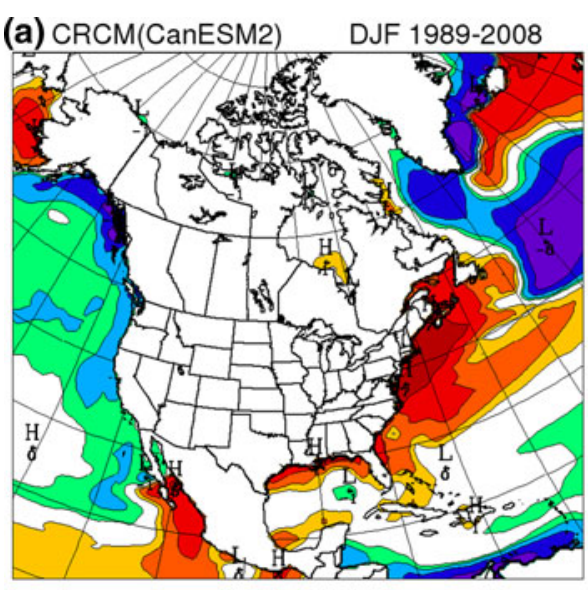

(c) CRCM(MPI-ESM-LR) DJF 1989-2008

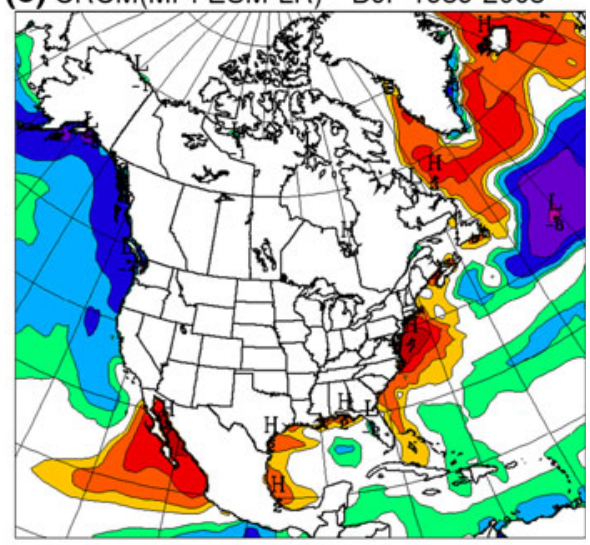

(b) CRCM(CanESM2) JJA 1989-2008

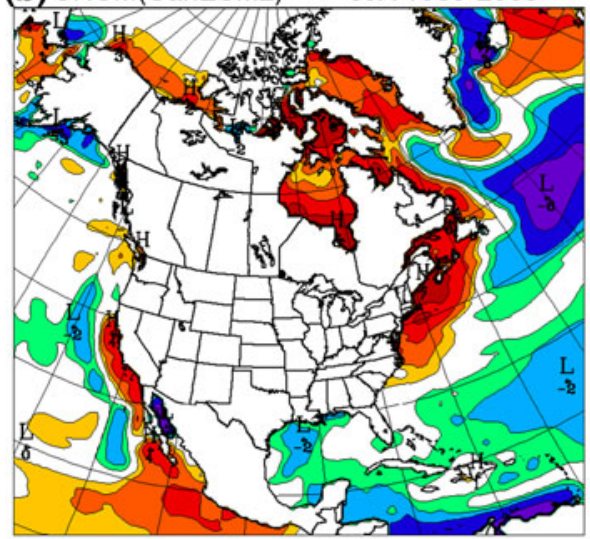

(d) CRCM(MPI-ESM-LR) JJA 1989-2008

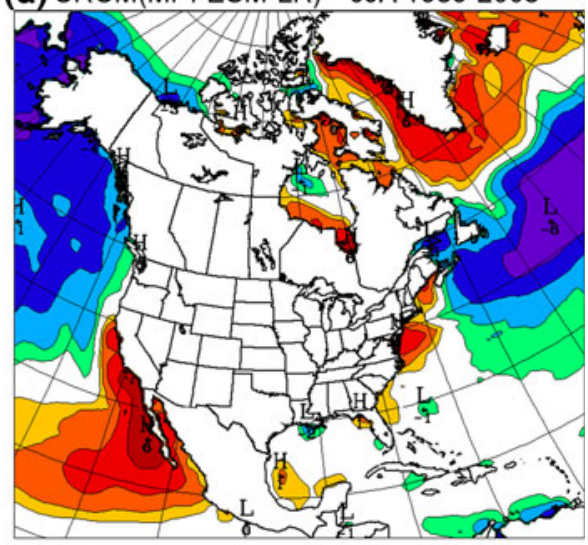

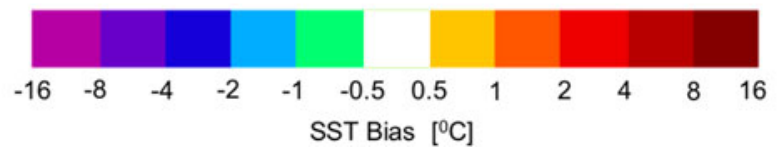


structural errors that are present even when driven with perfect lateral and lower boundary conditions, and (2) the effect of errors in the lateral boundary conditions and lower boundary forcing over ocean (SST and SIC) that are "inherited" from the driving CGCM, as well as due to the internal variability of the CGCM. Upon assuming that the reanalysis and observation errors are negligible, the CRCM5 structural bias (denoted as SB) can be quantified as the deviation of the reanalysis-driven simulation from observations. The lateral and lower boundary conditions effect (denoted as LLBCE) can then be assessed as the deviation of a CGCM-driven CRCM5 simulation from the reanalysis-driven CRCM5 simulation.

Figure $4 \mathrm{a}, \mathrm{b}$ show the 1989-2008 DJF-average $2 \mathrm{~m}$ temperature biases in CRCM-Can and CRCM-MPI simulations with respect to CRU observations. These biases are each decomposed in (1) the CRCM5 SB that is quantified by the CRCM-ERA deviation from CRU, which is displayed in Fig. 4c and is common to both CRCM-Can and CRCM-MPI simulations, and (2) the LLBCE, displayed in Fig. 4d, e for CRCM-Can and CRCM-MPI, respectively. Finally, for the purpose of the comparison, we show the CGCMs' own DJF 2 m-temperature structural biases in Fig. 4f, $g$ for the CanESM2 and MPI-ESM-LR simulations, respectively.

It can be seen in Fig. 4a, $\mathrm{b}$ that both CGCM-driven runs exhibit moderate to strong cold biases of -2 to $-8{ }^{\circ} \mathrm{C}$ in DJF over most of the continent, except in the northeastern parts where the biases are near zero in CRCM-MPI and about +2 to $+4{ }^{\circ} \mathrm{C}$ in CRCM-Can. Inspection of Fig. $4 \mathrm{c}$ shows that the cold bias over the western US and Mexico is also present in CRCM-ERA, though with somewhat smaller magnitude. It is however still much larger than the interannual standard deviation of DJF 2 m temperatures in these regions that takes values around $1-2{ }^{\circ} \mathrm{C}$ over the western US and smaller than $1{ }^{\circ} \mathrm{C}$ over Mexico (not shown). It appears that the cold bias over these regions in CGCM-driven runs is to a large degree due to the CRCM5 own structural errors. However, Fig. 4d shows that over the southwestern part of the continent the LLBCE also contributes to the cold bias when the CRCM5 is forced with the CanESM2. On the other hand, the warm bias over eastern Canada in CRCM-Can in Fig. 4a is mostly due to the LLBCE (Fig. 4d) since is absent in CRCM-ERA (Fig. 4c). When the CRCM5 is forced with the MPI-EMSLR (Fig. 4e), the LLBCE has a considerable contribution to the cold bias over the entire west and central part of the continent; this is very likely due to the cold SST bias in Northern Pacific in MPI-EMS-LR (see Fig. 3c). Finally, Fig. 4f shows that the winter temperature bias pattern in the CanESM2 is similar to that in CRCM-Can, although CanESM2 tends to be warmer by a few degrees. The MPIESM-LR appears to have the best overall skill in reproducing winter temperatures over North America (Fig. 4g), with the exception of a strong cold bias over Pacific Northwest, which it has in common with the CRCM-MPI (Fig. 4b).

Figure 5 displays the corresponding analysis for summer. In general, the CRCM5 performs better in summer. The CRCM-Can summer temperatures (Fig. 5a) exhibit a relatively uniform warm bias of up to $4{ }^{\circ} \mathrm{C}$ in the interior of the continent. The exception is Mexico where there is a cold bias of similar magnitude. There is also a narrow region stretching over the northern-most Pacific Coast with strong cold biases with magnitude as large as $-8{ }^{\circ} \mathrm{C}$. Comparison of Fig. 5a with Fig. 5c shows similar patterns in CRCM-ERA over the northern-most Pacific Coast as well as over Mexico, implying that these features are due to the CRCM5 SB. The LLBCE in CRCM-Can (Fig. 5d) is considerable over northern Canada where it reaches of $2-4{ }^{\circ} \mathrm{C}$. It is worth noting here that the standard deviation of JJA average $2 \mathrm{~m}$ temperatures is confined to $1{ }^{\circ} \mathrm{C}$ over most of the continent. This implies that the summer bias, despite being smaller in absolute terms than the bias in winter, is still large with respect to the interannual variability. CRCM-MPI summer temperatures (Fig. 5b) are, in general, quite close to the observations, with the exception of a cold bias over the West Coast and Mexico that is due to the CRCM5 SB (Fig. 5c). Comparison of Fig. 5c, e shows that a relatively high skill of CRCM-MPI over the central parts of the continent (Fig. 5b) is a consequence of the cancelation of the CRCM5 SB and LLBCE; the CRCM5 SB and LLBCE in CRCM-MPI summer temperatures are of similar magnitude but of the opposite sign. A negative LLBCE in Fig. 5e might be partly due to the cold SST biases over the northern Pacific and mid-latitude Atlantic in summer (Fig. 3d). Figure 5f shows that the CanESM2 has a very strong warm bias over central part of the continent with values as large as $10^{\circ} \mathrm{C}$. As it can be seen in Fig. 5a, CRCM5 substantially improves summer CanESM2 $2 \mathrm{~m}$ temperatures. On the other hand, CRCMMPI has biases roughly similar to those in MPI-ESM-LR but each of these have less than half of the amplitude of those found with CanESM2.

Next we consider seasonal precipitation. Figure 6 displays the bias for 1989-2008 winter precipitation using the CRU data as a reference. The biases are normalized with the arithmetic average between the model and observed precipitation, and are expressed in percentage. Figure $6 \mathrm{a}-\mathrm{c}$ as well as $6 \mathrm{f}$ and $\mathrm{g}$ show that all simulations exhibit a wet bias of 50-100\% over the Great Plains, south of the USCanada border. Similar biases are present over Alaska and the Arctic Archipelago. As it was discussed earlier, despite being large these biases are of the order of magnitude of differences among the observations sets (see Fig. 2) and for this reason will not be pursued further. In other regions the 
Fig. 4 Differences between a CRCM-Can, b CRCM-MPI, c CRCM-ERA, f CanESM2, g MPI-ESM-LR and CRU 1989-2008 DJF-mean 2 m temperatures; $\mathbf{d}$ difference between CRCM-Can and CRCM-ERA 1989-2008 DJFmean $2 \mathrm{~m}$ temperatures; $\mathrm{e}$ the same as in $\mathbf{d}$ but between CRCM-MPI and CRCM-ERA
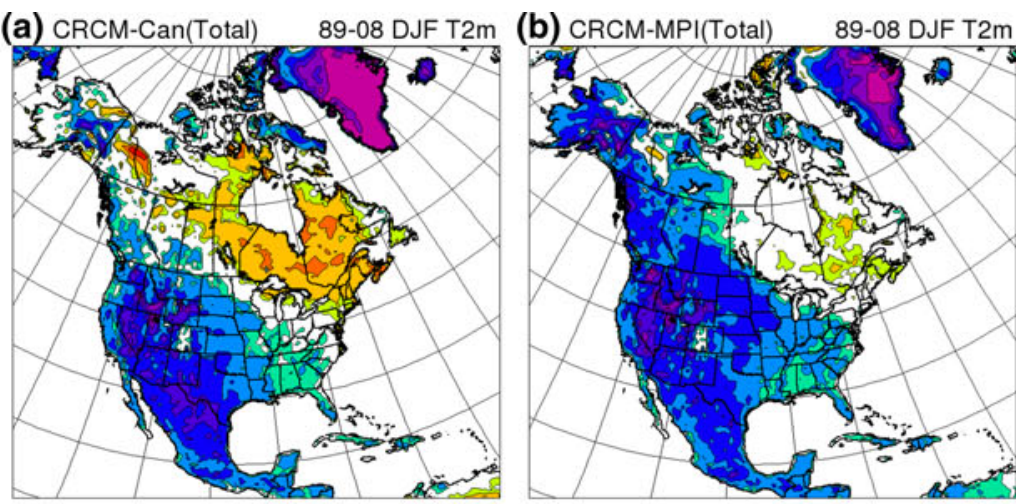

(c) $\mathrm{CRCM}-\mathrm{ERA}(\mathrm{SB})$

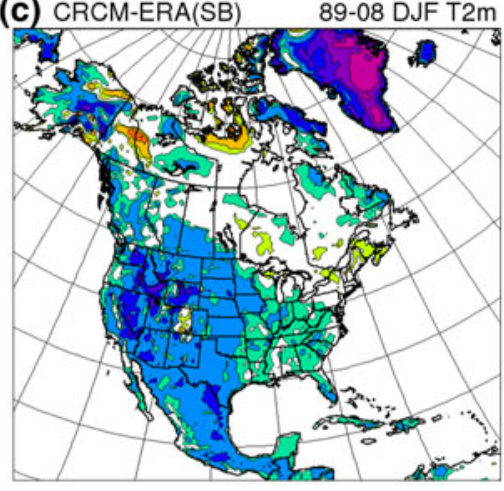

(d) CRCM-Can(LLBCE) 89-08 DJF T2m

(e) CRCM-MPI(LLBCE) 89-08 DJF T2m
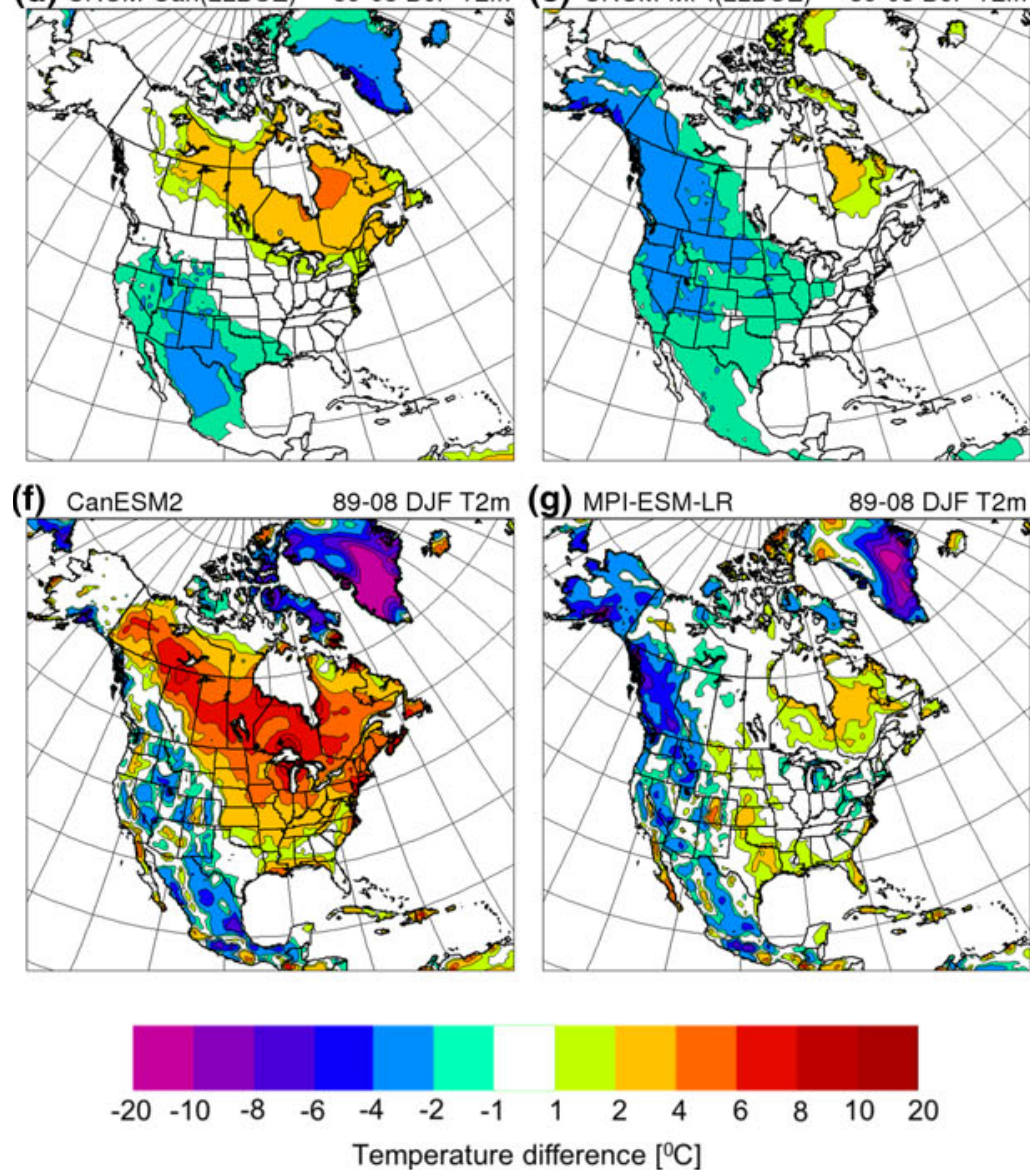
Fig. 5 Same as in Fig. 4 but for JJA $2 \mathrm{~m}$ temperatures
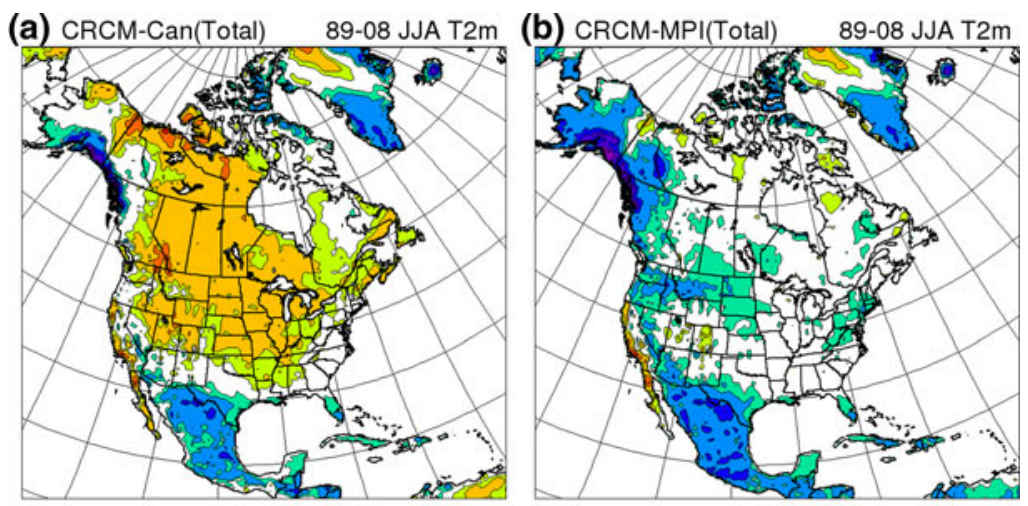

(c) CRCM-ERA(SB)

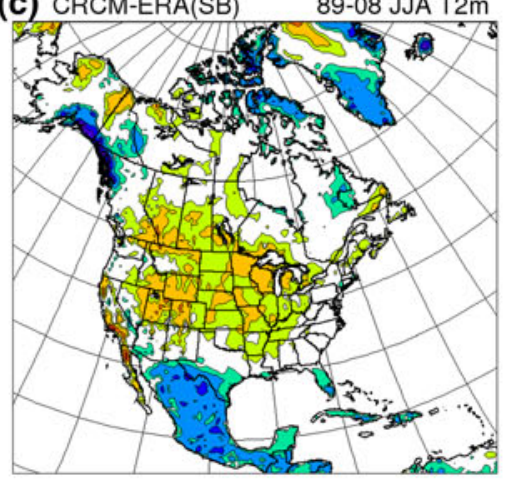

(d) CRCM-Can(LLBCE) 89-08 JJA T2m
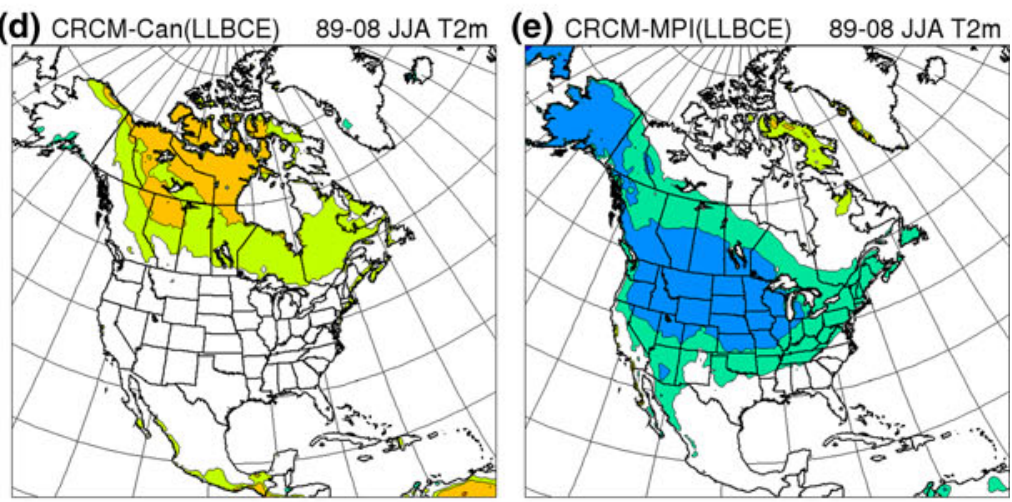

(f) CanESM2 89-08 JJA T2m

(g) MPI-ESM-LR 89-08 JJA T2m
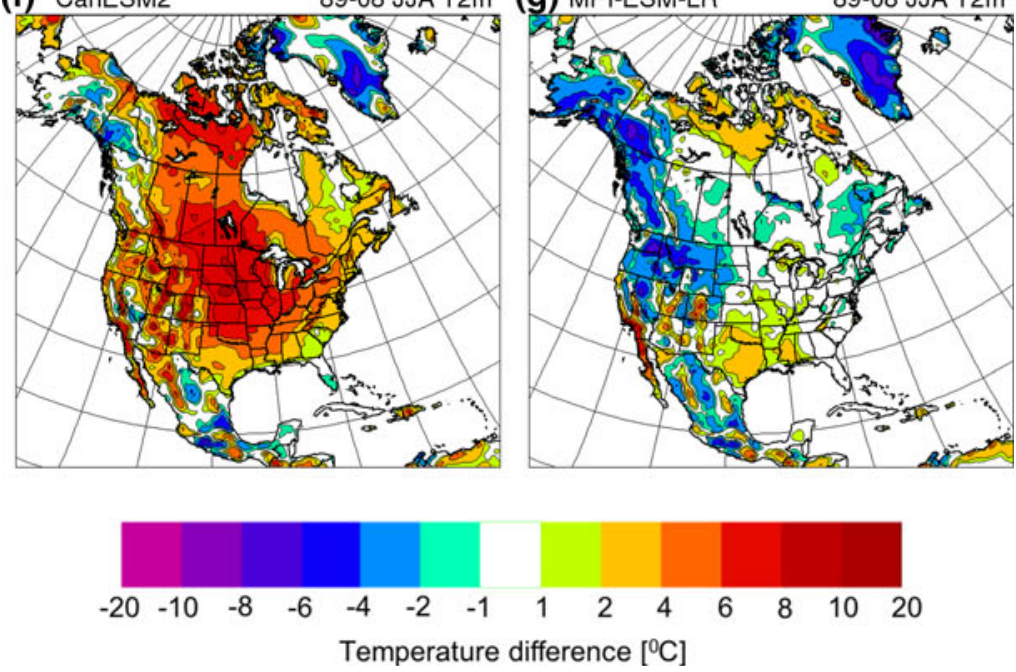

Temperature difference $\left[{ }^{\circ} \mathrm{C}\right]$ 
CRCM simulations exhibit relatively small differences with respect to CRU observations. However, as it can be seen in Fig. 6a, b, the exception is Mexico, where the CRCM-Can and CRCM-MPI winter precipitation is strongly overestimated. Figure 6d, e show that the wet bias over central and western Mexico is mainly due to the LLBCE, since it has no counterpart in the CRCM-ERA simulation (Fig. 6c). The warm SST bias over subtropical Pacific in the CRCM-Can and CRCM-MPI (Fig. 3c, d) may contribute to this wet bias. Figure $6 \mathrm{~d}$ also shows that the LLBCE in the CRCM-Can winter precipitation contributes to the wet bias over the southern and eastern coastal regions of the continent, likely due to the warm SST biases off the coast in these regions in the CRCM-Can simulation (Fig. 3b). Comparison of Fig. 6f,g with Fig. 6a, b shows that CGCMs' bias patterns are relatively similar to those in the corresponding CRCM simulations, except over the mountainous regions over the western parts of the continent. The both CGCM simulations exhibit common strong biases, locally larger than $100 \%$ in magnitude, which can be associated with a poorly resolved topography in the CGCMs' simulations. The most notable feature in Fig. 6f, $g$ is a long stretch of positive bias in lower basins between the Rocky Mountains and Coastal Range. This bias is however absent in the corresponding CRCM-Can and CRCM-MPI simulations (Fig. 6a, b), demonstrating the CRCM added value in the simulated winter precipitation due to a better resolved topography.

We complete this section with the corresponding analysis for summer. CRCM-Can summer precipitation (Fig. 7a) exhibits relatively good agreement with the observations over the northern parts of North America. Over Central Plains and the Rocky Mountains there is a dry bias from 25 to $75 \%$. Similar bias patterns are found in the CRCM-ERA precipitation (Fig. 7c), implying that they are mainly due to CRCM5 SB. Further, CRCM-Can precipitation exhibits strong dry bias over the Pacific Coast, stretching from Mexico to Southern California as well as over the US Southwest. It is also worth noting that there is a strong dry bias over Greater Antilles and northern Gulf of Mexico. These features partly originate in the CRCM5 SB (Fig. 7c) and the LLBCE (Fig. 7d). The CRCM-MPI summer precipitation (Fig. 7b) is quite close to observations over most of the continent. It is worth noting however that the CRCM5 SB (Fig. 7c) is negative over Central Plains while the LLBCE has a positive contribution there (Fig. 7e), yielding a cancelation of errors and a good skill of CRCM-MPI in reproducing summer precipitation, as it was the case for summer temperatures. The largest positive deviation of CRCM-MPI summer precipitation from CRU occurs in the North American monsoon region, from the southern tip of Baja California, northward, into northwest Mexico and the US Southwest (Fig. 7b). The position of this pattern corresponds very well with the LLBCE displayed in Fig. 7e, implying that it is "inherited" from the driving MPI simulation. It is however very difficult to understand the nature of this wet bias in the CRCM-MPI simulation since the monsoon precipitation is a result of adverse effects. There is a strong positive SST bias of up to $4{ }^{\circ} \mathrm{C}$ in the driving MPI simulation off the coast of this region (Fig. 3d). The SST bias may have enhanced the evaporation and hence increased the precipitation over the adjacent coastal regions, yielding a wet bias in CRCMMPI. On the other hand, the warm SST bias also implies a smaller land-sea temperature contrast and may weaken the monsoon; negative correlations between the SST anomalies off the northern Baja California and monsoon precipitation have been documented in the literature (e.g., Vera et al. 2006). Other LLBC effects may include the moisture flow via the synoptic-scale circulation as well as the soil moisture The CRCM-MPI simulation exhibits a wet bias over the US Southwest and Mexico in winter (Fig. 5b).

Now we proceed to a more detailed evaluation of CRCM5 $2 \mathrm{~m}$ temperature and precipitation by first considering the annual cycles of monthly means and then the daily time series distributions. For this purpose the NARCCAP regions of North America, proposed in Bukovsky (2011), will be used. In any regionalization there is a trade-off between selecting either smaller, quasi-homogeneous or larger, aggregated regions; we decided to use the latter approach. The ten Bukovsky's regions that will be used here are displayed in Fig. 8. Following Martynov et al. (2013), we introduced two additional regions situated in the US Southwest, in order to analyze the precipitation related to the North-American monsoon. These two regions are denoted as CORE and Arizona-New Mexico (AZNM) in Fig. 8.

\section{Evaluation of annual cycles}

For the sake of brevity we will evaluate the annual cycle of CRCM5 precipitation over selected regions; we omit the temperature as the evaluation of 2 m-temperature annual cycles in the reanalysis-driven CRCM-ERA simulation can be found in Martynov et al. (2013). The authors showed that the annual cycle of 2 m-temperature was in most cases generally well reproduced by the model as well as the interannual variability of this variable. Figure 9 displays the annual cycles of regional-average 1997-2008 monthlymean precipitation in each of the 12 regions, for CRCMERA, CRCM-Can and CRCM-MPI. The GPCP precipitation is used as the reference. We also show the precipitation simulated by the two driving CGCMs: CanESM2 and MPI-ESM-LR.

The first row in Fig. 9 displays the results for regions that are characterized with cold-season minimum and 
Fig. 6 Same as in Fig. 4 but for 1989-2008 DJF-average precipitation with CRU observations as reference

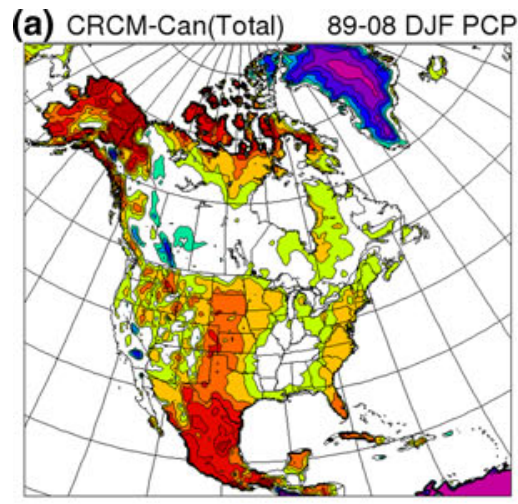

(b) CRCM-MPI(Total) 89-08 DJF PCP

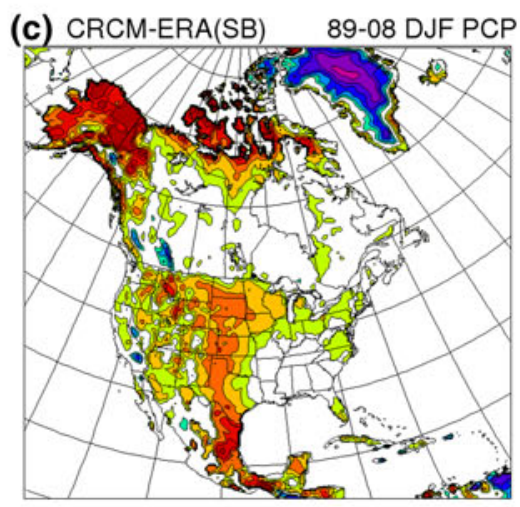

(d) CRCM-Can(LLBCE) 89-08 DJF PCP (e) CRCM-MPI(LLBCE) 89-08 DJF PCP
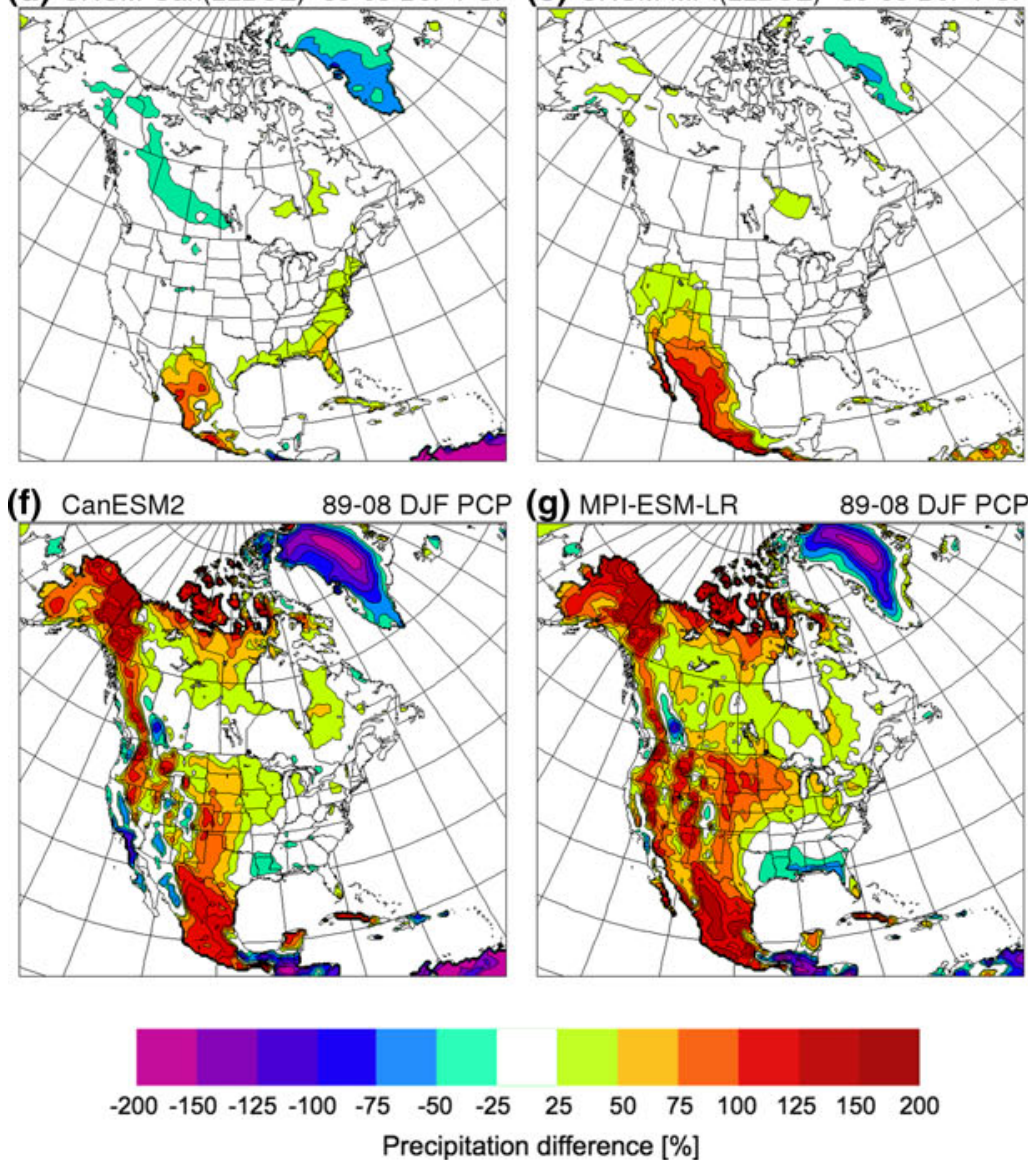

Precipitation difference [\%] 
Fig. 7 Same as in Fig. 6 but for JJA precipitation
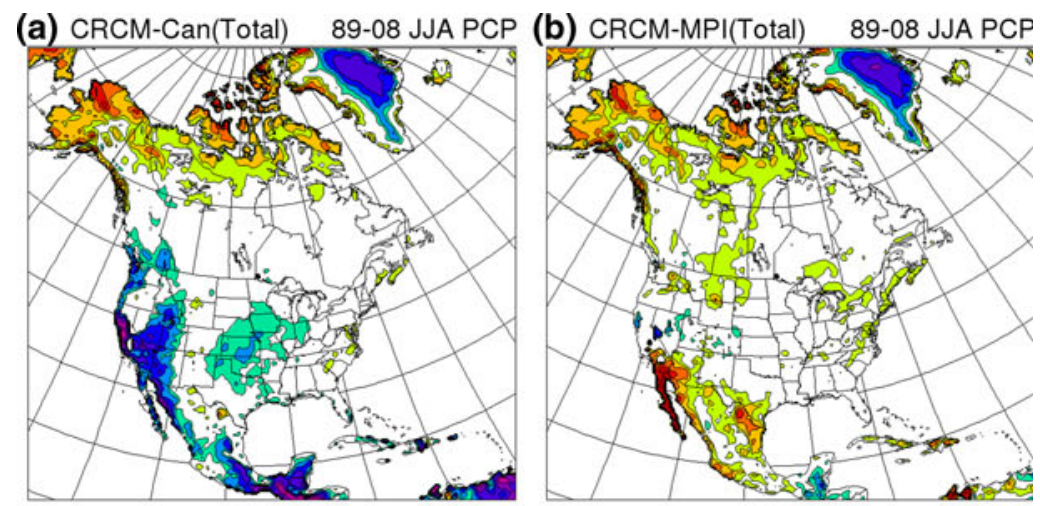

(c) CRCM-ERA(SB)

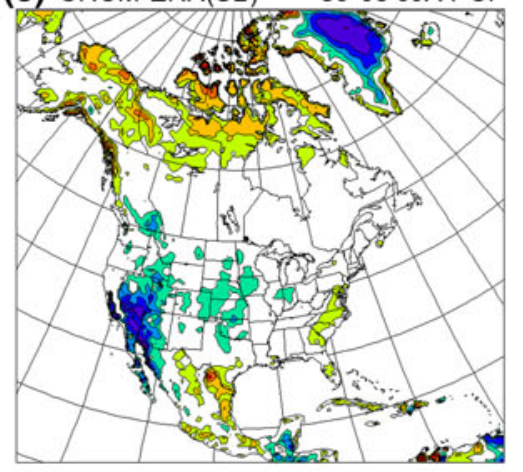

(d) CRCM-Can(LLBCE) 89-08 JJA PCP

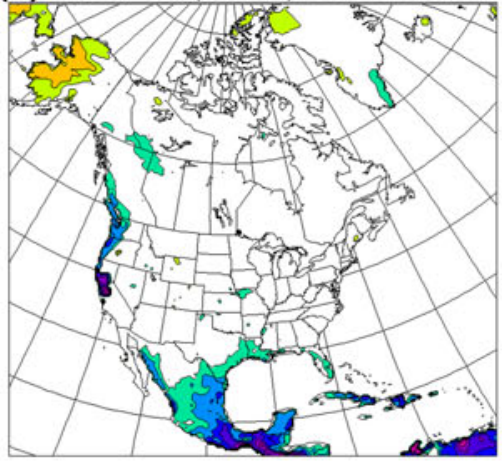

(e) CRCM-MPI(LLBCE) 89-08 JJA PCP
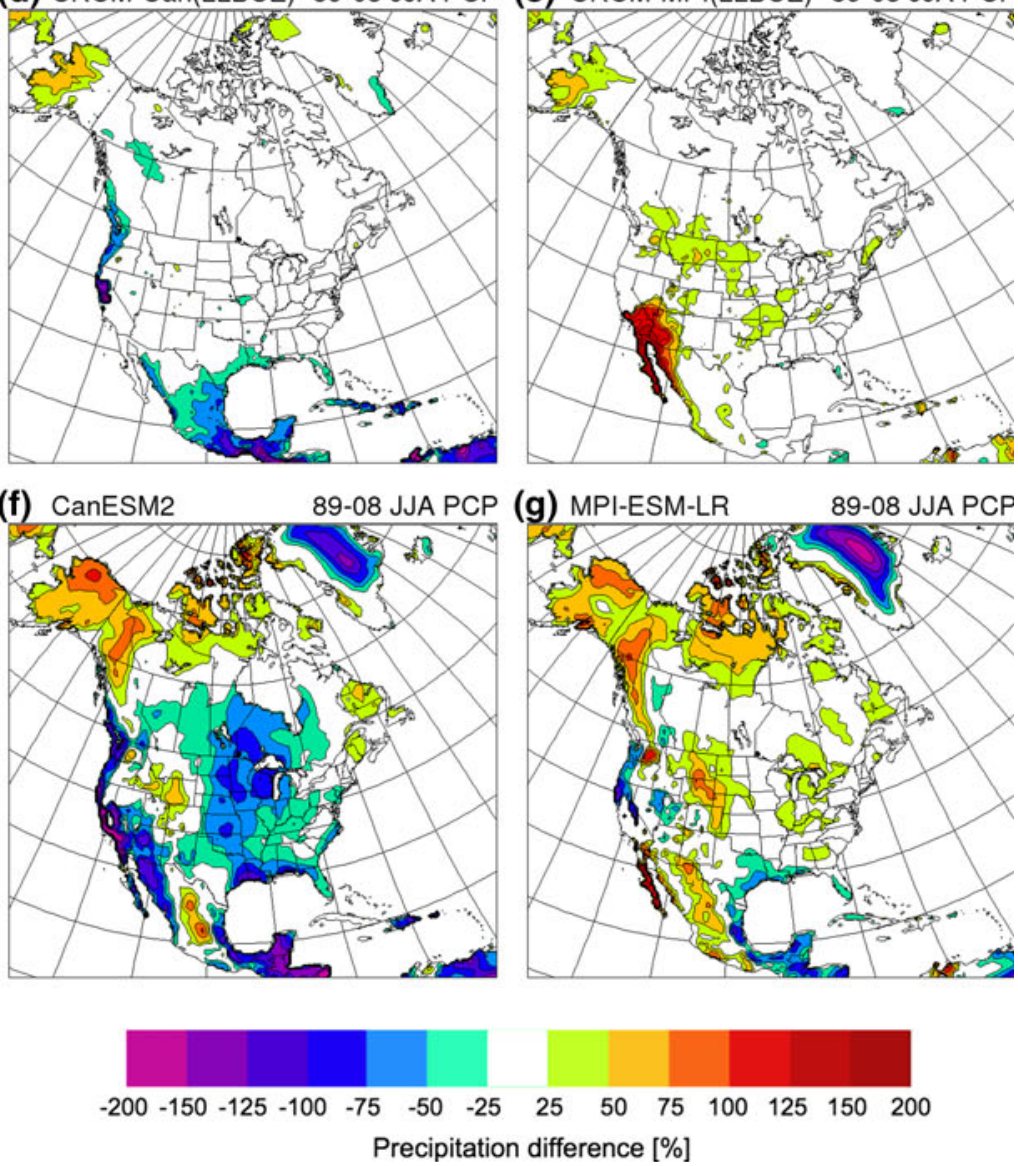


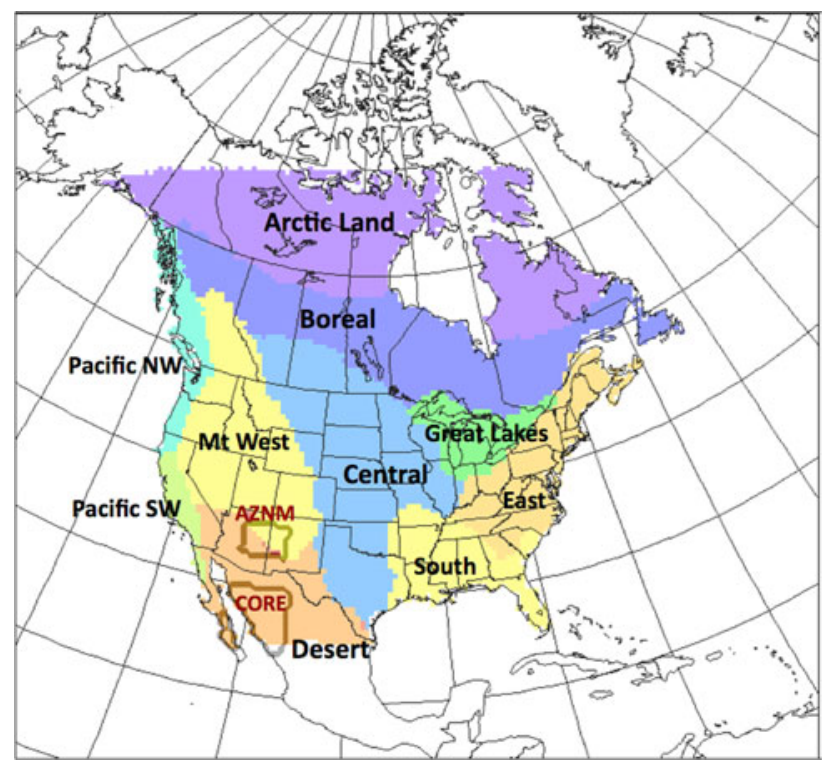

Fig. 8 Map of regionalization adopted from Bukovsky (2011)

warm-season maximum precipitation (Arctic Land, Boreal and Central). Over Arctic Land all simulations tend to somewhat overestimate precipitation in all seasons but, at the same time, they represent the annual cycle relatively well. The reanalysis-driven simulation CRCM-ERA has the strongest wet bias in late summer (Aug-Oct) of about $0.5 \mathrm{~mm} /$ day. The maximum precipitation in CRCM-ERA is in August, which is in accord with the GPCP observations. On the other hand in both CRCM-Can and CRCMMPI, the maximum is shifted to September; this is also the case with the CanESM2 precipitation. Over Arctic Land the MPI-ESM-LR has a strong wet bias in spring but the CRCM5 simulation forced with MPI-ESM-LR tends to be much closer to the GPCP values in this season. Over Boreal forest region the GPCP precipitation has a maximum in July due to the peak in convection and another maximum in September. The CRCM-ERA reproduces this feature, although the convective maximum occurs too early, in June. The CRCM-Can precipitation has the same behaviour as the CRCM-ERA. On the other hand, the CRCM-MPI has some wet bias over Boreal forest region in summer, as is the case in MPI-ESM-LR, and in addition exhibits a single maximum in August. The observed precipitation cycle in the Central region is characterized with a single peak in June and minimum in January. The CRCM-ERA run performs quite well in Oct-May but not in Jun-Sep, when it has a pattern quite a bit different from the observations; instead of June maximum the CRCM-ERA precipitation decreases from May, having a minimum in July, when it has a dry bias of about $1 \mathrm{~mm} / \mathrm{day}$, and then increases until October, when it again gets close to the observations. The same holds for CRCM-Can and
CanESM2 precipitation, the latter also having a dry bias in all seasons. The best results are obtained with Can-MPI that accurately reproduces the precipitation annual cycle over Central regions. However, as it was noted when discussing Fig. 7 in the case of Can-MPI summer precipitation over this region, the CRCM5 SB is balanced by the LLBCE, resulting in the cancelation of the two errors and a small CRCM-MPI bias. Interestingly, the same holds for the CRCM-MPI precipitation annual cycle.

The second row in Fig. 9 displays the precipitation annual cycles for the Great Lakes, East and South regions that are characterized with a more uniform precipitation throughout the year. Over the Great Lakes the GPCP curve shows an increase in precipitation in May-Sep, with respect to other months. In the CRCM-ERA this increase occurs much earlier and, in disaccord with the observations, the precipitation rate decreases in mid-summer. This also characterizes the CRCM-Can and CanESM2. However, CRCM-Can improves quite a bit the precipitation of its driving CGCM. Can-MPI more closely follows the GPCP curve, with some overestimation in early summer; this simulation also appears to improve its driving CGCM, which has a strong wet bias in summer over the Great Lakes. Next, over the East region, the CRCM-ERA precipitation is relatively close to GPCP, though there is some wet bias of up to $0.5 \mathrm{~mm} /$ day in almost all seasons. The CRCM-Can and CRCM-MPI both overestimate precipitation in the East and this is likely to the warm SST bias off the East Coast in the two simulations (see Fig. 3a-d). In the South region, the GPCP shows multiple maxima and minima. The CRCM-ERA very well captures the May and October minima, but not the minimum in August, when it overestimates the precipitation by about $0.5 \mathrm{~mm} /$ day. It is however close to the observed values during June and September maxima. CRCM-MPI variations are quite close to the GPCP in summer and autumn months, while in winter and spring its variations do not agree with the observations. The CRCM-Can annual cycle over the South deviates the most from the GPCP values, having a more pronounced annual variation with a maximum in winter and minimum in summer. The CanESM2 and MPI-ESMLR also have too pronounced annual variations, the first with a dry bias in summer and the latter with a dry bias in winter; their CRCM5 counterparts, are still closer to the observations in the South.

Next we consider the Pacific NW, Pacific SW and Mountainous West (Mt West) regions characterized with summer minimum and winter maximum in the precipitation annual cycle (third row in Fig. 9). In the Pacific NW all CRCM5 simulations display the annual cycle similar to the observed one but tend to be too wet, by a few $\mathrm{mm} /$ day, especially in early winter. The driving CGCMs appear to have better results, especially the CanESM2 whose native 


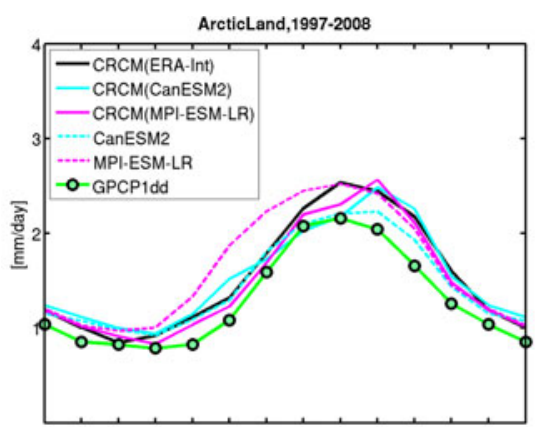

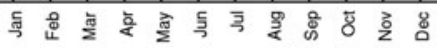
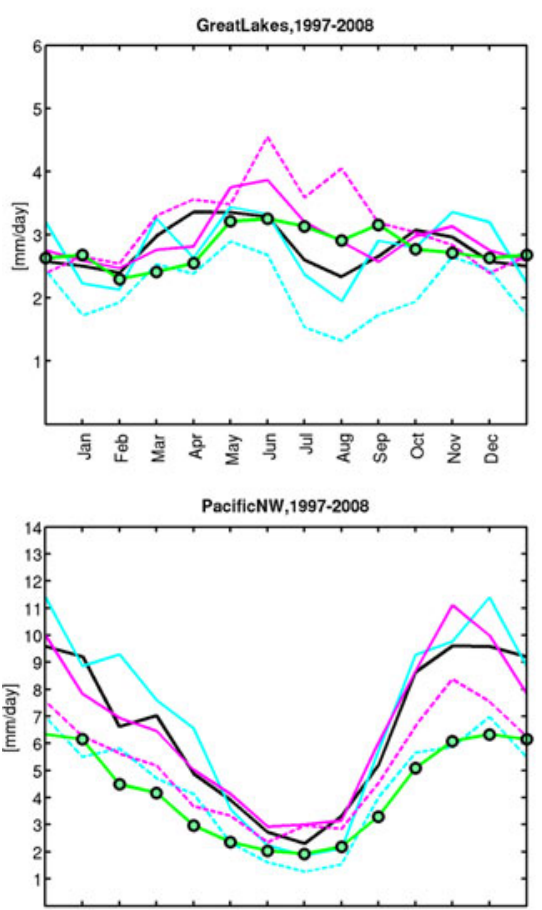

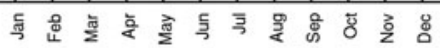

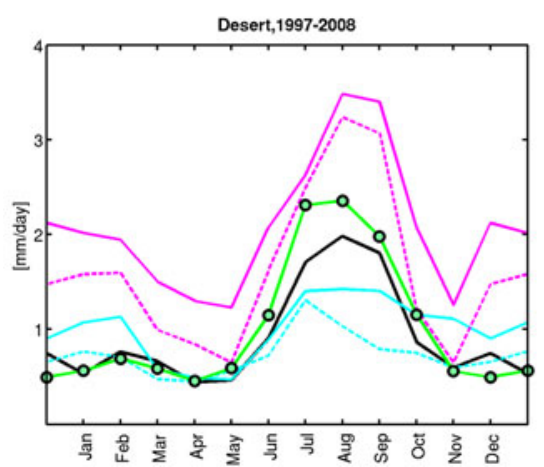

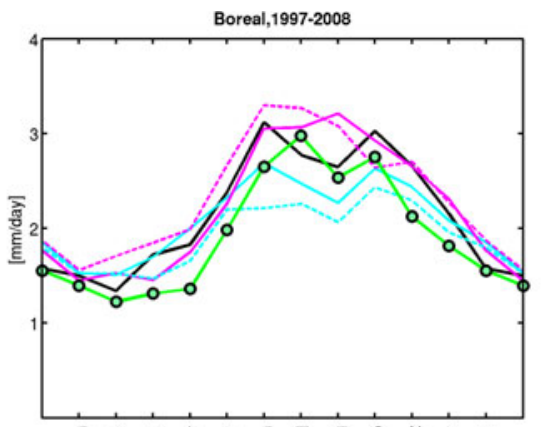

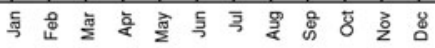
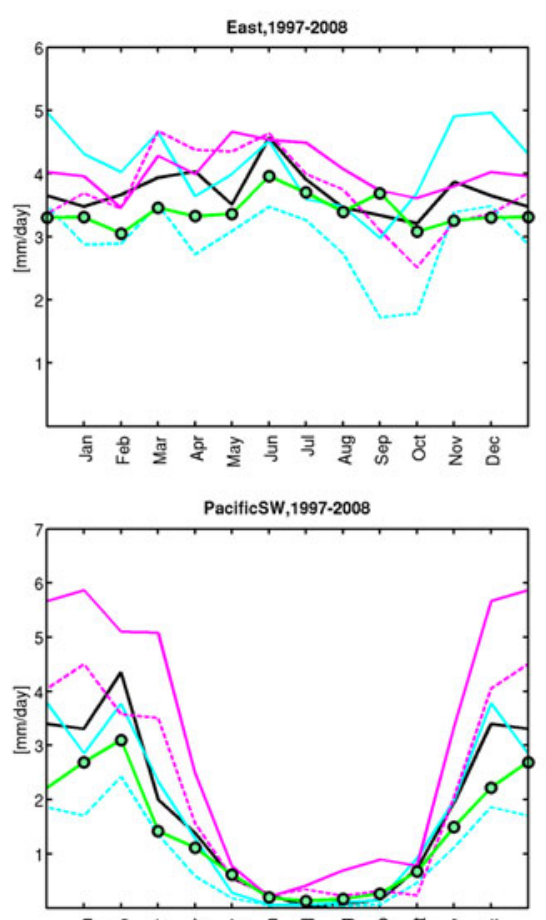

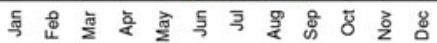

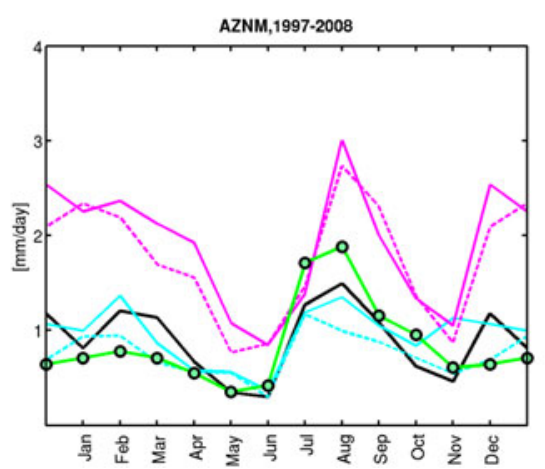

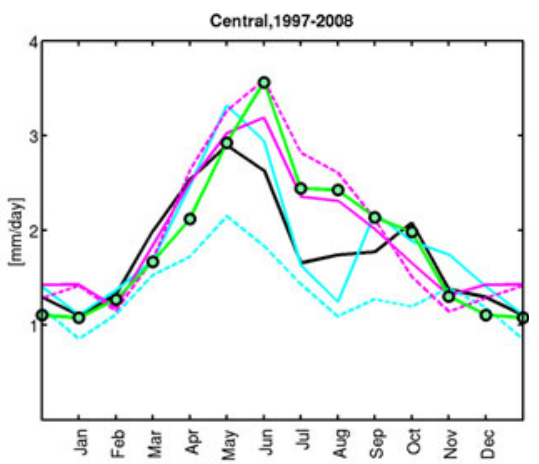
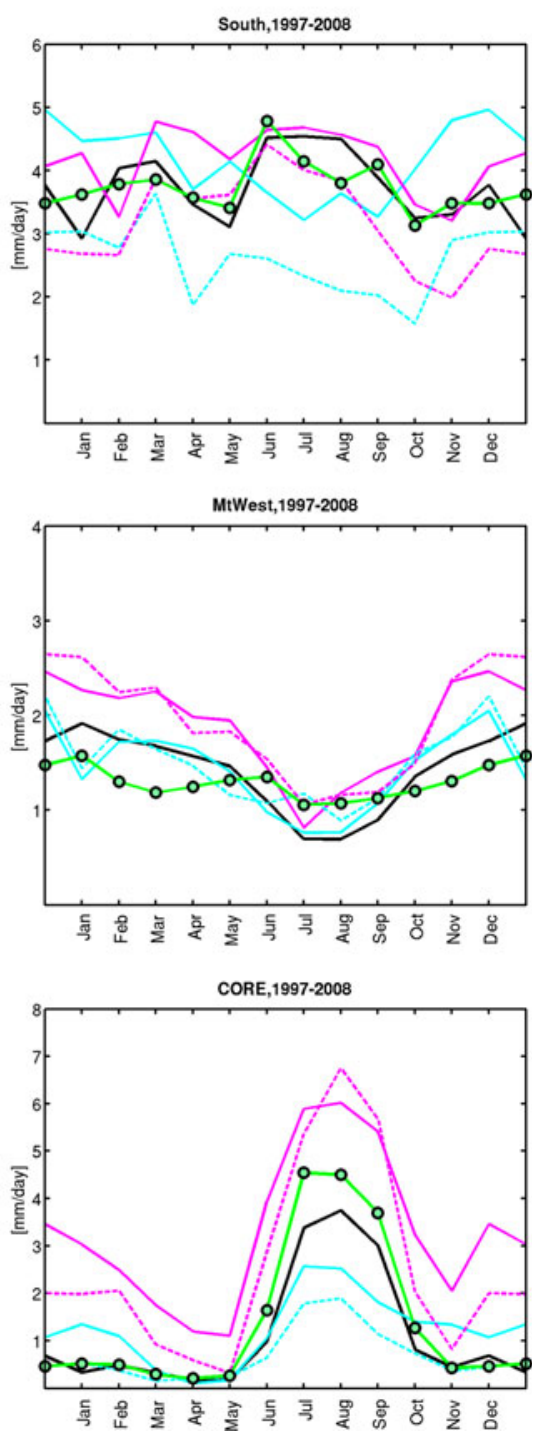

Fig. 9 Annual cycles of 1997-2008 monthly mean precipitation for the GPCP observations (green), CRCM-ERA (black-full), CRCM-Can (cyan-full), CanESM2 (cyan-dashed), CRCM-MPI (pink-full) and MPI-ESM-LR simulations (pink-dashed line)

region is the Pacific NW. Over the Pacific SW, both the CRCM-ERA and CRCM-Can are able to reproduce the annual cycle of precipitation. The CRCM-MPI, however, is too wet by $2 \mathrm{~mm} /$ day in winter-spring and produces considerable precipitation in Aug-Sep, while in the GPCP there is almost no precipitation in these months. This implies that the North American monsoon propagates to the southern-most portions of the Pacific SW region (see also Fig. 7b, e), which in nature does not happen (e.g., Adams and Comrie 1997). Note also a strong warm SST 
bias in the CRCM-MPI simulation in the subtropical Pacific (Fig. 3c, d). Interestingly the driving MPI-ESM-LR simulation produces no such wet bias in summer. In the Mt West the GPCP shows a weak annual variation with a general minimum in summer and two maxima in January and June. None of the models represents this behaviour well; they all tend to have a too pronounced annual variation, with a dry bias in summer and a wet bias in winter, the latter being especially strong in the CRCM-MPI and MPI-ESM-LR.

Finally we turn our attention to the Desert region (the bottom row in Fig. 9) and the two joint subregions AZNM and CORE, where the summer precipitation is governed by the North American Monsoon regime. In the Desert and CORE regions, the CRCM-ERA follows closely the GPCP curve in Sep-June period, but it does not represent well the Jul-Aug maximum; it is too dry in summer and the maximum is lagged more towards Aug-Sep. The CRCM-Can exhibits a similar behaviour but has a stronger dry bias in summer and also a wet bias in winter. The CRCM-MPI simulation strongly overestimates precipitation in all seasons. In the northern-most part of the Desert region (AZNM), the CRCM-ERA and CRCM-Can somewhat better represent the summer precipitation, being able to reproduce the correct timing of the monsoon-related maximum in August. They have, however, still a dry summer bias and some wet bias in winter-spring in AZNM.

In summary of Fig. 9, the two CGCM-driven CRCM5 simulations reproduce the most general features of the precipitation regional annual regimes but they disagree with observations in finer details. Some of these differences could be generated by the CGCM natural variability. Apart from the annual variation, in all season in the western parts of the continent and Mexico, the RCM simulations tend to overestimate precipitation, especially the CRCM-MPI that has a too warm subtropical Pacific SST. The CGCM-forced CRCM5 simulations also exhibit a relatively high skill in the monsoon timing but do not reproduce the precipitation amounts as accurately as the reanalysis-driven simulation CRCM-ERA.

\section{Evaluation of spatiotemporal distributions}

We now move to the investigation of the spatiotemporal distributions of temperature and precipitation. Spatiotemporal distributions were obtained by treating each archival times and grid points within each region as individual data that are then pooled in a large single set, which is then used to assess the empirical distribution of a climate variable for that region.

Figure 10 summarizes the results for 1989-2008 dailymean $2 \mathrm{~m}$-temperature series for ERAINT, the three
CRCM5 simulations and two driving CGCM simulations, for each of the ten Bukovsky's regions. Panels a-c display the distribution mean, the 5th and 95th percentile, respectively, as a function of region for winter, and panels d-f show the same for summer. We begin the discussion by analysing the winter mean temperature (Fig. 10a). In Arctic Land, Boreal, Great Lakes and East regions, the reanalysis-driven CRCM-ERA (black circles) has a high skill in reproducing the ERAINT (green circles). In these regions the MPI-ESM-LR simulation (pink diamonds) is also very close to ERAINT, while the CanESM2 (cyan diamonds) has a warm bias of $2-6{ }^{\circ} \mathrm{C}$. Clearly, the two CGCM-forced CRCM5 simulations (CRCM-Can as cyan squares and CRCM-MPI as pink squares) have smaller biases than the corresponding CGCM runs in these regions. In the other regions (Central, South, Pacific NW and SW, Mt West and Desert) the CRCM5 has a cold structural bias (SB), measured by the deviation of the CRCM-ERA from ERAINT, of $2-4{ }^{\circ} \mathrm{C}$. Due to this CRCM5 SB, winteraverage temperatures are generally underestimated in CRCM-Can and CRCM-MPI in these regions.

Next we consider the 5th percentile of daily-average temperatures in winter (Fig. 10b). It can be seen that results are very similar to those obtained when the mean was considered. Again in Arctic Land, Boreal, Great Lakes and East regions, the reanalysis-driven CRCM-ERA is very close to the reference ERAINT. The CGCM-driven CRCM5 simulations produce generally substantially better results than the driving CGCM runs. Note also that over Arctic Land, all models appear to perform very well, when compared to ERAINT. However, ERAINT data are obtained in a process by which model information and observations are combined to produce consistent global parameters (Dee et al. 2011). Since the observations are very sparse over Arctic Land, ERAINT data are less constrained by the observations and more rely on model information. Thus it is possible that ERAINT suffers from common biases as the present CRCM5 and CGCM simulations. As of the rest of regions, it can be seen that the biases of the 5th percentile (Fig. 10b) tend to be of the same sign but of a somewhat larger magnitude when compared to the biases in the mean (Fig. 10a). The largest deviations from ERAINT are found for CRCM-MPI and MPI-ESM-LR over the Pacific NW, where they both have a cold bias of almost $10{ }^{\circ} \mathrm{C}$. It is worth recalling the cold bias in CRCM-MPI SST over the North Pacific (Fig. 3c).

When the 95th percentile of winter daily $2 \mathrm{~m}$-temperature is considered (Fig. 10c), it can be seen that the three CRCM5 simulations tend to show better performance than for the 5th percentile. This implies that models have generally more difficulties to reproduce the observed left tails of daily-temperature distribution. One exception is the Central region where the cold bias in the 95th percentile is 
Fig. 10 The mean (a, d), 5th (b, e) and 95th percentiles (c, f) of daily-mean temperatures for 1989-2008, as a function of Bukovsky's regions, in a-c DJF and d-f JJA; ERAINT (green circles), CRCM-ERA (black circles), CRCM-Can (cyan squares), CanESM2 (cyan diamonds), CRCM-MPI (pink squares), MPI-ESM-LR (pink diamonds)
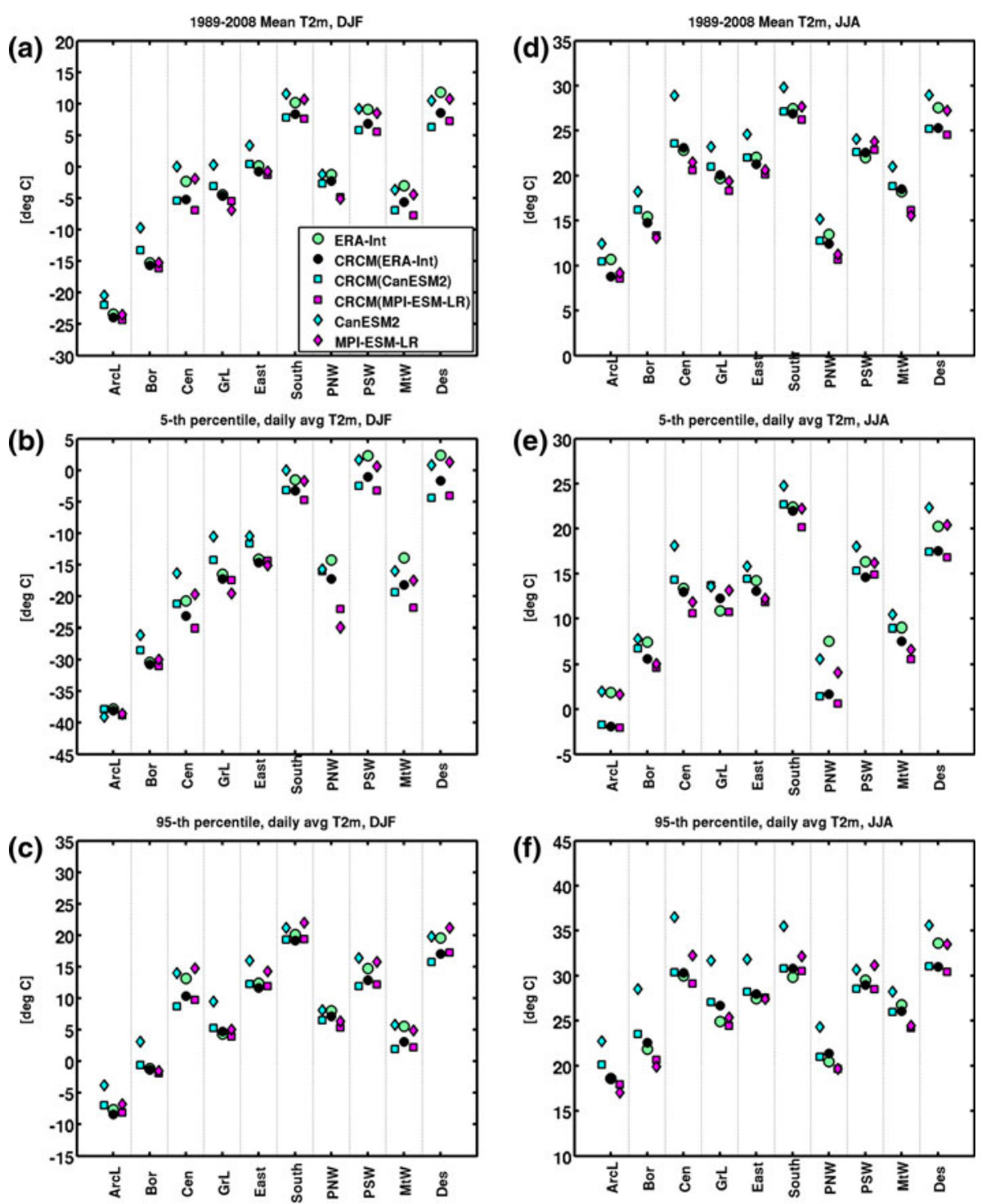

similar to that in the 5 th percentile and the mean, implying that the entire distribution is shifted to lower temperatures.

We now turn our attention to the corresponding summer data, summarized in Fig. 10d-f. When the mean is considered, it can be seen that, with the exception of Arctic Land and Desert, the CRCM-ERA summer temperatures are very close to ERAINT, implying that there is little SB in the CRCM5. At the same time the CGCMs' biases are quite large in some regions, especially in the case of the CanESM2. For example, in Central region, the CanESM2 summer mean is warmer than ERAINT by more than $10{ }^{\circ} \mathrm{C}$. However, the CRCM-Can is also close to ERAINT. This, along with the fact that there is no considerable SB, implies that the improvement of summer temperatures in the CRCM-Can simulation relative to CanESM2 is achieved for good reasons and not as a result of a simple cancelation of biases. On the other hand MPI-ESM-LR temperatures tend to be somewhat colder than ERAINT, but in general rather good in both the mean and percentiles; this is also the case for the CRCM-MPI temperatures. The largest biases of CRCM5 simulations are found in the Pacific NW in the 5 th percentile (Fig. 10e) for which the underestimation is about $6-8{ }^{\circ} \mathrm{C}$ in this region. Contrary to that, for the 95th percentile (Fig. 10f) the CRCM5 temperatures are in accord with ERAINT. It is possible that part of the apparent cold bias in the 5th percentile in Pacific NW originates from the coarser resolution of the ERAINT data. In this topographically complex region the CRCM5 grid points can consequently lie on a higher elevation than ERAINT allowing for lower temperatures to enter the spatiotemporal distribution in summer. However, the difference in the resolution of the model $\left(0.44^{\circ}\right)$ and ERAINT $\left(1.5^{\circ}\right)$ is likely too small to explain such large differences.

Comparison of Fig. 10d-f shows that in Arctic Land there is a cold bias in excess of $5{ }^{\circ} \mathrm{C}$ in the three CRCM5 simulations in the 5 th percentile, while there is almost no 
bias in the 95th percentile. This implies that the cold bias in the mean is largely due an underestimation of temperatures during cold days. To put it simply, cold days are too cold in the CRCM5, while warm days are well reproduced. This can be interpreted as that there is a leftward shift of the temperature distribution's left tail. We found a similar situation in Boreal region, though the cold bias in the 5th percentile is smaller there. On the other hand, in Desert region, in summer, there is a cold bias of a similar magnitude in the mean, 5th and 95th percentiles, implying that the entire CRCM-ERA temperature distribution is leftshifted with respect to that of ERAINT.

In summary, it should be noted that, with the exception of a few cases, the reanalysis- and CGCM-driven CRCM5 simulations exhibit a relatively good skill in reproducing regional near-surface temperature means. This skill is not considerably deteriorated in the limit of lower and higher percentiles of the distribution, which is a necessary condition for a realistic representation of the natural variability of daily temperatures in the present-day climate.

We now move to spatiotemporal distributions of dailymean precipitation. Evaluation of precipitation distributions is conducted using the regridded TRMM daily means. Since the TRMM data are defined at latitudes below $50^{\circ} \mathrm{N}$, we modified the Bukovsky's regions (Fig. 8) in order to fit within this constraint; Arctic Land and Boreal are excluded from considerations, while Pacific NW, Mt West and Central regions are reduced to southward of $50^{\circ} \mathrm{N}$. Note also that the CRCM5 grid mesh is coarser by about factor of two than that of the TRMM data. The effect of the CRCM5 lower spatial resolution is to potentially shift distributions towards smaller intensities, since the local heavy precipitation events that might occur in TRMM would be smoothed in the CRCM5. However, averaging in time acts in the same way, by reducing differences due to the spatial resolution (e.g., Di Luca et al. 2012a). Using daily averages is expected to reduce the differences caused by different spatial resolutions of TRMM and CRCM5. This, however, may not be the case with CGCM simulations, because their spatial resolution differs from that of TRMM by a much larger factor.

The frequency-intensity precipitation distributions are obtained by pooling 2001-2008 gridded seasonal time series of daily means from every grid point within a region in a large single set, treating each grid point as an individual data. We then computed the relative frequency of values smaller than $0.1 \mathrm{~mm} /$ day in this large set; this frequency is interpreted as the relative frequency of dry days. The values above this threshold are sorted and binned over intervals $0.1,1$ and $2^{n}$ $\mathrm{mm}$, where $n=1,2$, etc. Finally, the sum of accumulations falling into each individual bin is normalized with the sum of accumulations over all bins, i.e., the total 2001-2008 accumulated precipitation. The resulting normalized distribution will be referred to as the relative daily-accumulations distribution (RDAD). Because of the normalization of accumulations collected in individual intensity ranges (bins) with the total accumulation, deviation of the simulated total accumulation over a region from the observed value has no effect on RDAD; the RDAD only quantifies the portion of the total precipitation over a region that is collected at that daily intensity range. The bias in the mean is thus to be considered separately as well as the frequency of wet/dry days.

Figure 11 shows the RDADs, for DJF 2001-2008, from CRCM-Can, CRCM-MPI, CanESM2 and MPI-ESM-LR simulations in the 10 regions. For every set (model or observations) the RDADs at each intensity range are expressed in percentage of the total accumulation within that set. Also printed are the relative frequency of dry days, spatiotemporal average and maximum daily precipitation. Note that this figure should really be shown as histograms; it is shown as curves for ease of comparing different datasets. It can be seen that in Central, Great Lakes, East, South and Mt West, all simulations depart from the TRMM observations in a quite similar manner by having: (1) a wet bias in the mean, which can be seen by inspecting the printed values of the regional averages, and (2) a leftward displacement of the RDAD, especially in the left tail, implying that the accumulations at lower precipitation rates have a too large contribution to the total accumulation. The overestimation of the accumulations at lower rates comes at the expense of dry days, which are strongly underestimated in these regions. For example, over the Great Lakes, in TRMM on average $84 \%$ of all days in DJF 2001-2008 are dry days, while their frequency is only $23-35 \%$ in all simulations, including both the CRCM5 and the two CGCM simulations.

In the case of the Pacific NW and SW, there is a strong wet bias in the average in all simulations (see printed values), but at the same time, the RDADs in the three CRCM5 simulations are quite close to the TRMM. Despite the bias in the mean, the partitioning of accumulations is still close to the observations. In Pacific SW and NW, however, the CGCM simulations have less bias in the total accumulations but exhibit some leftward shift in their RDADs (toward lower-intensity bins), especially for the coarser-resolution CanESM2. The CGCM-forced CRCM5 simulations improve the RDADs of the driving CGCMs, possibly because they better represent the topography than the coarser-resolution CGCM simulations. Finally, over the southernmost regions Desert, AZNM and CORE, the CRCM-ERA and CRCM-Can RDADs are quite close to the TRMM, while the MPI-ESM-LR and especially the CRCM-MPI exhibit a shift towards higher intensities, which can be attributed to the warm SST bias in the vicinity of these regions (Fig. 3). In summary, the differences between CGCM and CRCM5 simulations in winter 

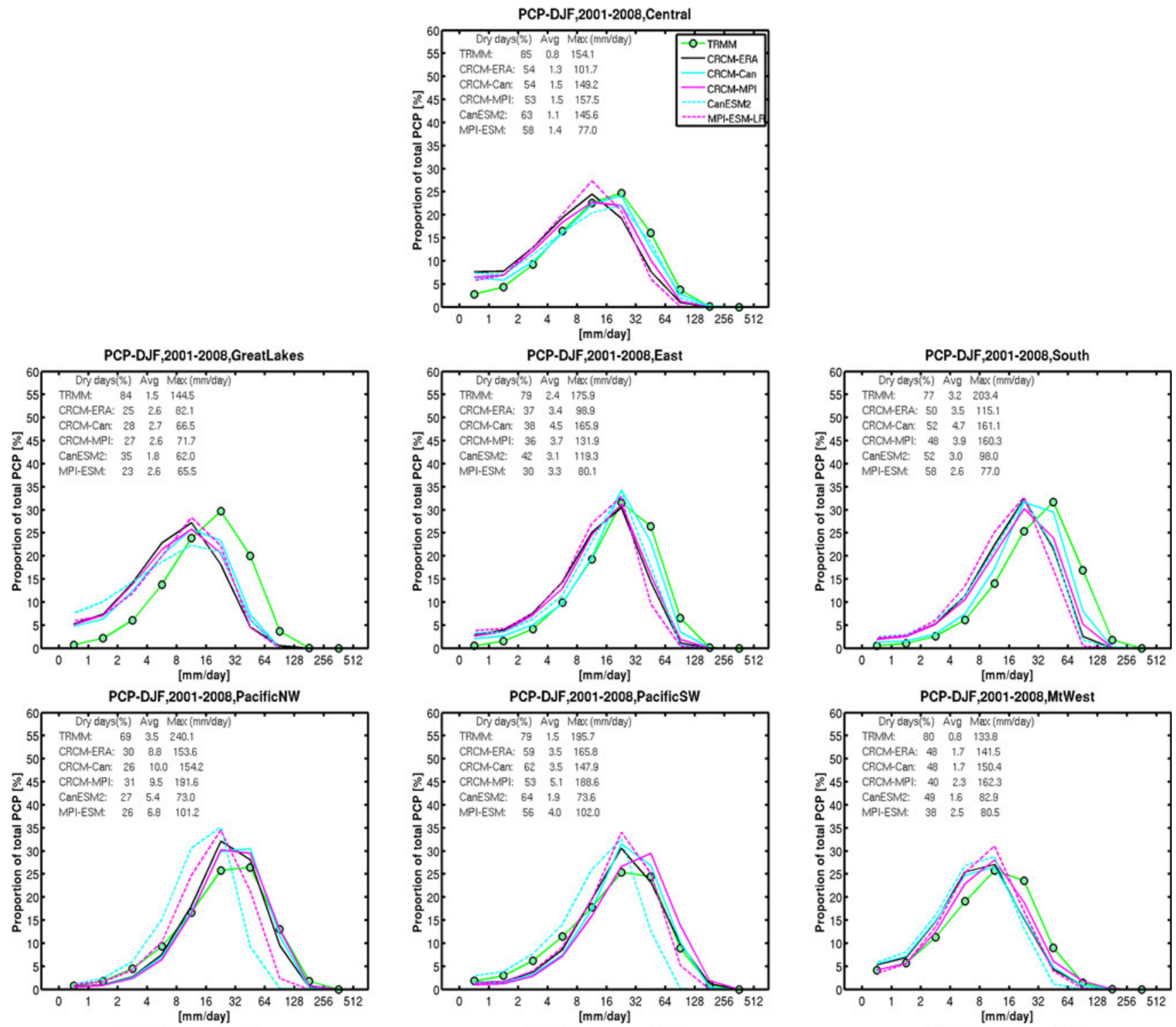

PCP-DJF,2001-2008,AZNM
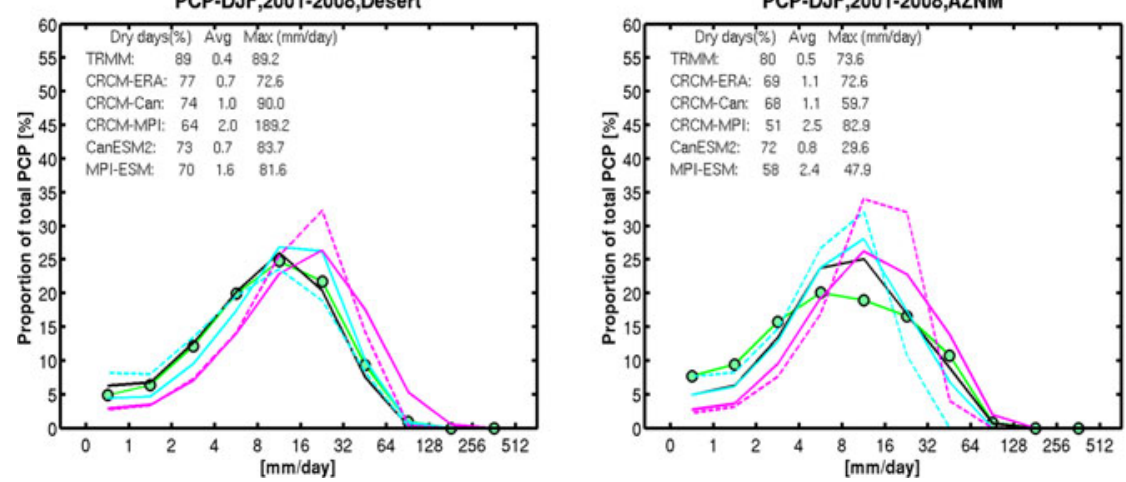

PCP.DJF, 2001-2008,CORE

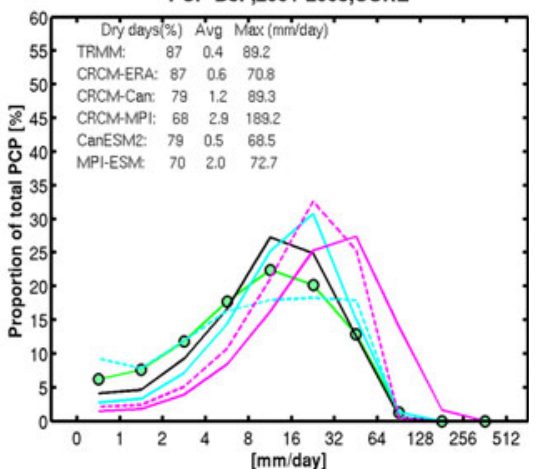

Fig. 11 The relative daily accumulation distributions (RDAD) for 2001-2008 DJF daily precipitation series; TRMM observations (green), CRCM-ERA (black-full), CRCM-Can (cyan-full), CanESM2

are not very large, possibly because winter precipitation is dominantly of the large-scale grid-resolved stratiform type that is adequately represented in CGCMs. (cyan-dashed), CRCM-MPI (pink-full) and MPI-ESM-LR simulations (pink-dashed line)

In summer, on the other hand, the subgrid convective precipitation has a dominant contribution over land and CGCM simulations underestimate it, which is the most 
striking feature of summer RDADs, displayed in Fig. 12 . The exception is the Southwestern regions (Pacific SW, AZNM) where the MPI-ESM-LR produces larger relative accumulations than observed in the heavy precipitation range. The summer precipitation RDADs of the three CRCM5 simulations in Fig. 12 are in most of the regions quite close to the TRMM observations. The exceptions are the Central, Great Lakes and South regions where the CRCM5-simulated RDADs are slightly shifted towards the lower intensities. Over the Pacific SW, the CRCM-ERA and CRCM-Can do capture the specific shape of the TRMM RDAD but have a considerable shift towards the large intensities. Over all southern and western regions the CRCM-MPI systematically overestimates the average and exhibits a strong rightward shift in RDAD, thus strongly overestimating the relative contribution of heavy precipitation events in the total. Finally, in the North American Monsoon regions, the CRCM-ERA is quite close to the TRMM data in terms of the average, dry days and distribution of relative accumulations, especially in AZNM. In these regions CRCM-Can is also quite good, while the CRCM-MPI exhibits strong wet biases. The large SST biases inherited from the driving MPI-ESM-LR simulation (Fig. 3) coincide with a considerably deteriorated performance of the corresponding CRCM5 simulation, not only in terms of bias in the mean precipitation, but also in terms of the partition of the accumulations over the intensity ranges.

The analysis of the RDADs shows that, at regional and daily temporal scale, both the reanalysis- and CGCM-driven CRCM5 simulations exhibit a quite high skill at partitioning the simulated total precipitation accumulations across the range of intensities. This holds despite the fact that there are considerable biases in the total precipitation over regions and large biases in the frequency of wet and dry days. A similar conclusion was found in Leung et al. (2003) for a reanalysis-driven RCM simulation over the western U.S. This is not the case for CGCM simulations that cannot adequately represent the partition of accumulations in the range of heavy precipitation, especially in summer, when the convective precipitation has a large contribution over land.

In summary, the CRCM5 simulations are satisfactory in reproducing $2 \mathrm{~m}$ temperatures and precipitation climatology. The exception is the Can-MPI simulation that has large biases over the western and southern parts of the continent, especially in summer precipitation, which can be attributed to large SST biases in the Pacific Ocean in the MPI-ESM-LR. At the same time however the CRCM-MPI performs quite well over the central and eastern North America, partly due to the cancelation of the CRCM5 SB and the LLBCE in the CRCM-MPI.

This concludes the discussion of the CRCM5 simulations' skill in reproducing the present climate. We next move to examine the projected climate changes over North America.

\section{Climate projections}

Climate projections will be discussed starting with $2 \mathrm{~m}$ temperatures. Figure 13 shows the projected changes in the mean $2 \mathrm{~m}$ temperatures between periods $2071-2100$ and 1981-2010, for DJF (Fig. 13 a-d) and JJA (e-h), in the CRCM5 simulations (left column) and the corresponding driving CGCM simulations (right column). In winter, the CRCM-Can and CanESM2 simulations project large temperature increases, reaching 13 and $16^{\circ} \mathrm{C}$, respectively, over parts of the Arctic Ocean. On the other hand, the CRCM-MPI and MPI-ESM-LR both display quite a bit smaller values, especially over the northern regions where the projected change is limited to $7{ }^{\circ} \mathrm{C}$ over the Arctic. All four simulations do agree on a strong south-to-north gradient of the temperature increase over land in winter, with the smallest temperature increase over the US Southeast, by about $1{ }^{\circ} \mathrm{C}$. The patterns of the projected changes in the CRCM5 simulations and their driving CGCM simulations are generally very similar in winter. The exception is the higher-elevation regions in the western parts of the continent where the CRCM5 simulations add to the climatechange signal some fine-scale details that are absent in the CGCMs. For higher elevations, such as the Cascades and the Rocky Mountains in the Pacific NW and British Columbia, the CRCM simulations indicate less warming than the corresponding CGCM simulations. On the other hand, over lower elevations such as the Columbia Basin, the CRCM shows warming of similar magnitude as the CGCM simulations. Salathe et al. (2008) obtained fairly similar results and attributed these warming differences to the fact that the snow-albedo feedback is more realistically represented in RCMs due to better-resolved elevations of the regional topography and mesoscale distribution of snow.

In summer (Fig. $13 \mathrm{e}-\mathrm{h}$ ), the projected changes vary from $1{ }^{\circ} \mathrm{C}$ over the central Arctic to about $2-4{ }^{\circ} \mathrm{C}$ over most of North and Central America and locally up to $6{ }^{\circ} \mathrm{C}$ over the Canadian Prairies and Pacific NW. The projected summer changes in the CRCM-MPI and MPI-ESM-LR are somewhat smaller than in CRCM-Can and CanESM2 simulations. While the latter two simulations are quite similar, the former two simulations exhibit more differences; the projected changes of summer temperature over the Canadian Archipelago are up to $5{ }^{\circ} \mathrm{C}$ in the CRCMMPI and below $3{ }^{\circ} \mathrm{C}$ in MPI-ESM-LR simulation. A disagreement between the two simulations is also present over the Southern Great Plains, where the CRCM-MPI projects a warming smaller by about $1-2{ }^{\circ} \mathrm{C}$ than the MPI-ESMLR. 

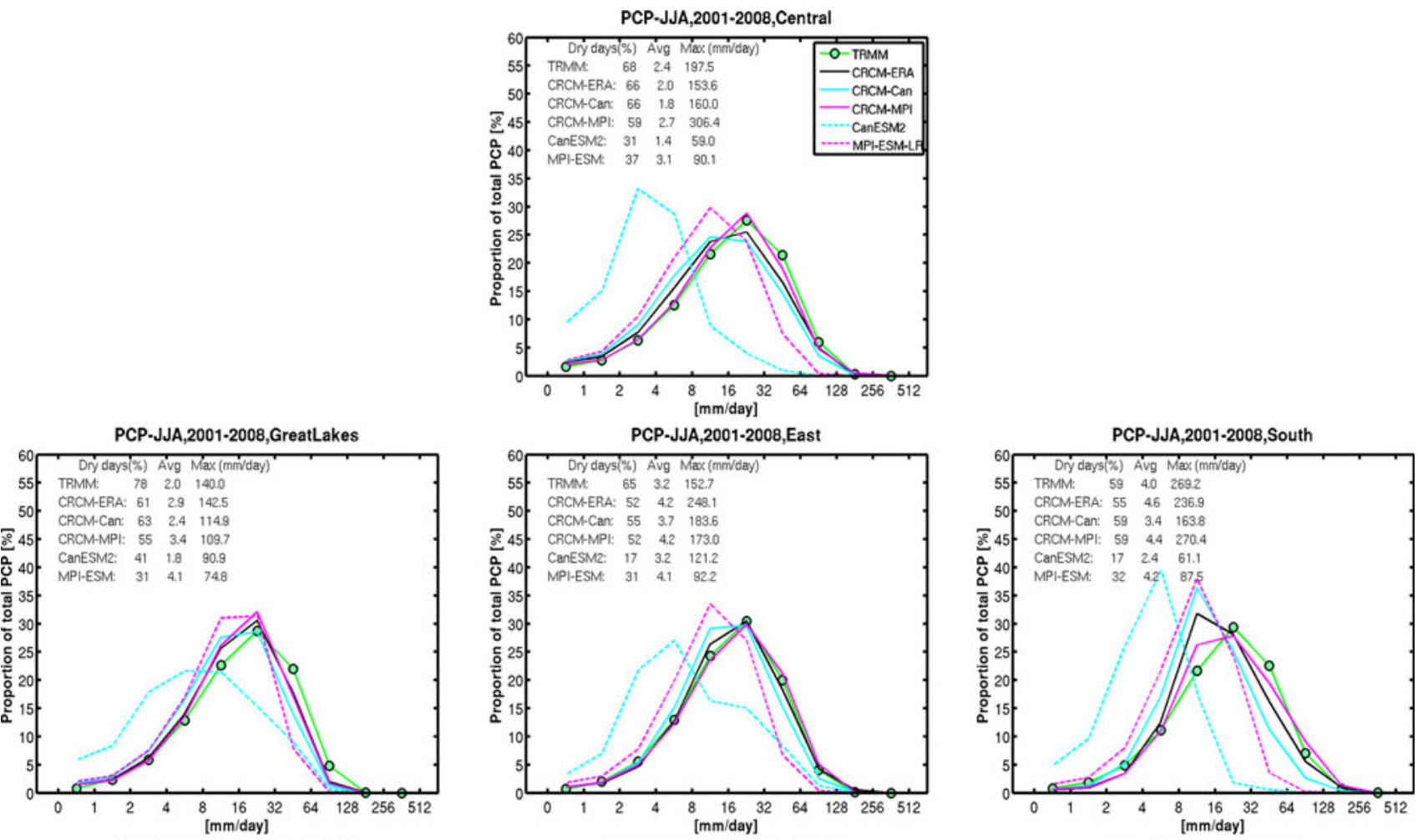

PCP-JJA,2001-2008,PacificNW

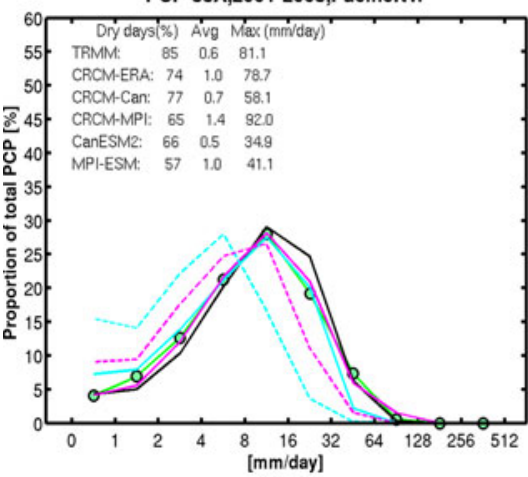

PCP-JJA,2001-2008,Desert

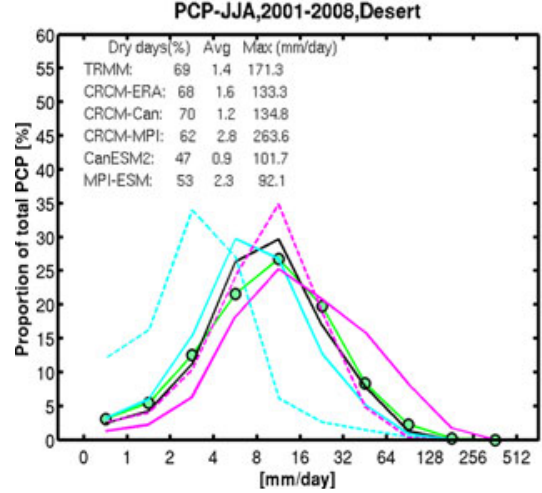

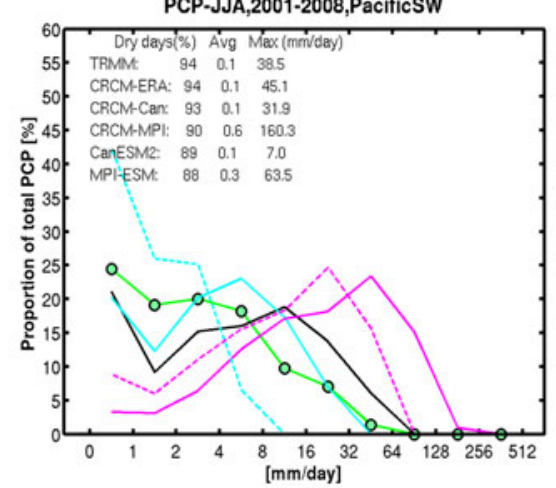

PCP-JJA,2001-2008,AZNM

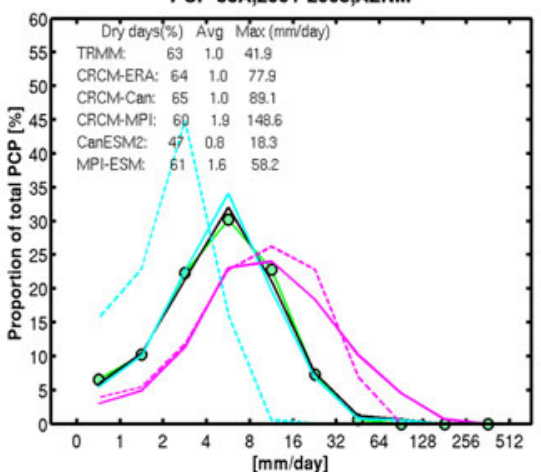

PCP-JJA,2001-2008,MtWest

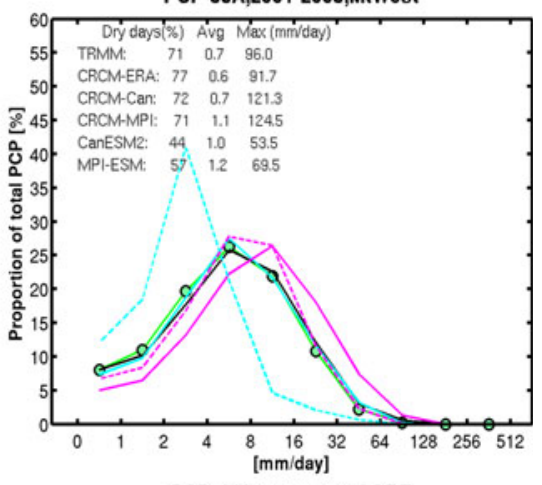

PCP-JJA,2001-2008,CORE

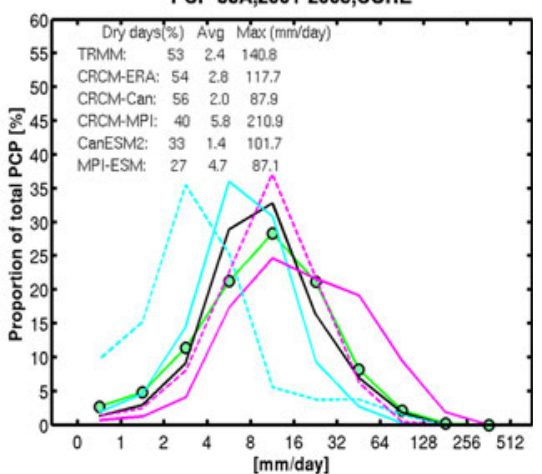

Fig. 12 Same as in Fig. 11 but for JJA precipitation

It is worth noting that the CRCM-Can projected warming in both summer and winter, despite being large, appears not to exceed the 75th percentile of the multimodel distribution when compared to the IPCC AR4 projected temperature changes over different regions under the A1B scenario (Christensen et al. 2007a). When compared to the same reference, the CRCM-MPI projected warming rather lies in the lower percentiles. 
Fig. 13 Change in the a-d DJF and $\mathbf{e}-\mathbf{h} \mathrm{JJA}$ average $2 \mathrm{~m}$ temperature in the period 2071-2100 compared to 1981-2010, for CRCM-Can (a, e), CanESM2 (b, f), CRCM-MPI $(\mathbf{c}, \mathbf{g})$ and MPI-ESM-LR (d, h)
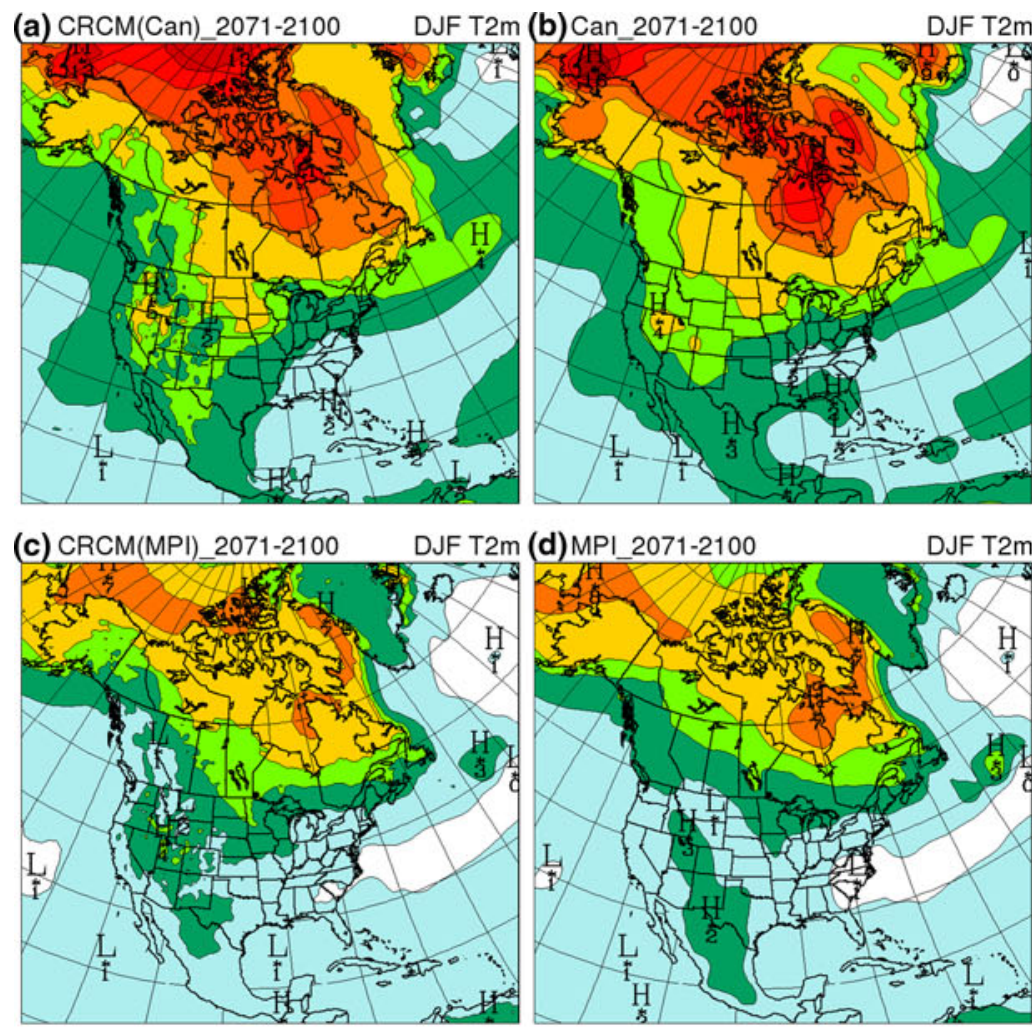

(e) $\operatorname{CRCM}($ Can)_2071-2100
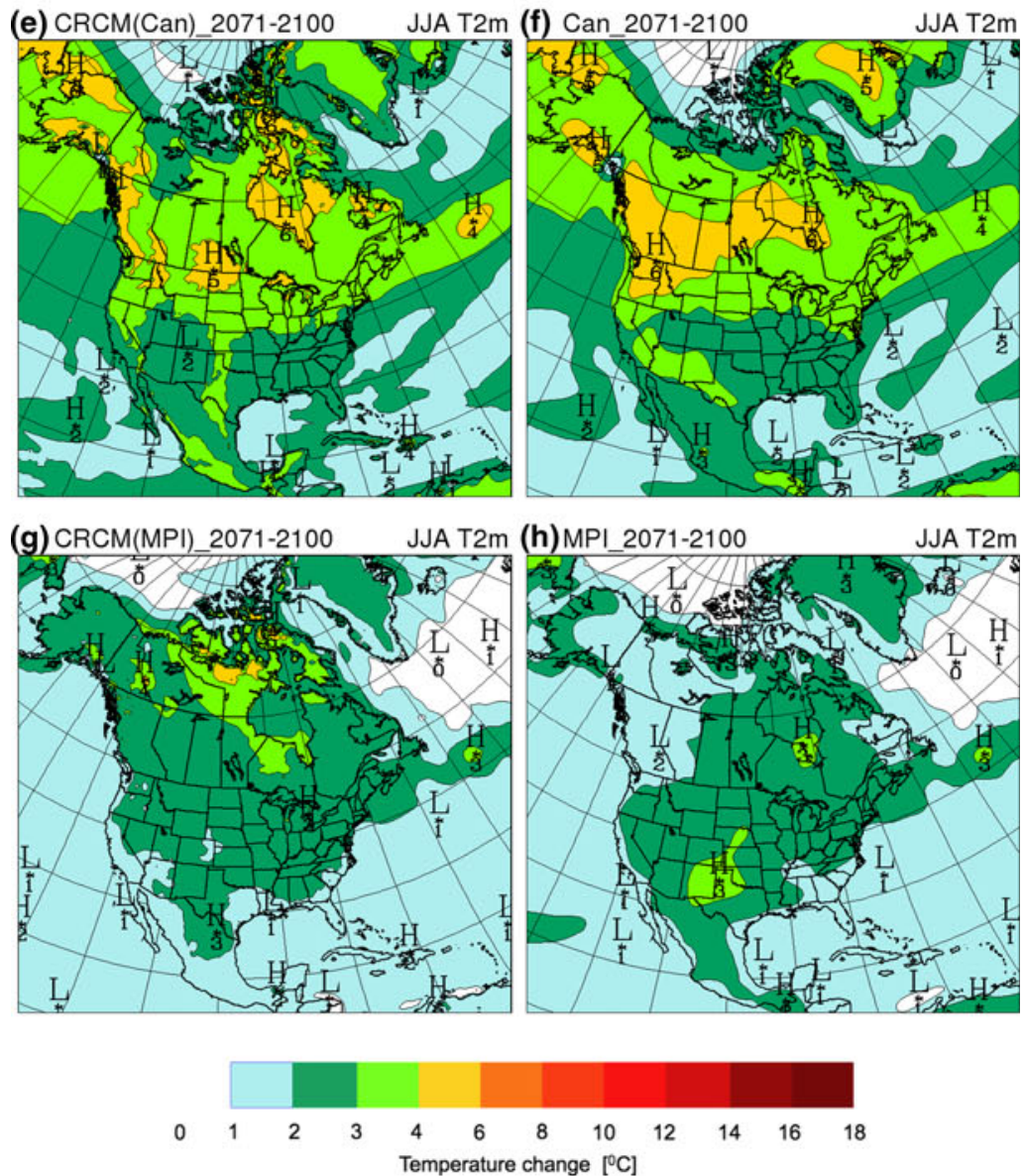
We now move to examine the transient temperature change in detail, using the Bukovsky's regionalization. The changes in spatiotemporal variability of $2 \mathrm{~m}$ temperatures for periods 2011-2040, 2041-2070 and 2071-2100 to 1981-2010 are summarized in Fig. 14 for winter (panels a-c) and summer $(\mathrm{d}-\mathrm{f}$ ) where we show the change in the mean $2 \mathrm{~m}$ temperatures for the three periods (a and d), as well as the 5th $(b, e)$ and 95th (c, f) percentiles of daily-average temperatures. As before, the spatiotemporal distributions are obtained by treating each element in a time series of daily averages in every grid point within a region as individual data. In Fig. 14 squares represent the CRCM5 and diamonds are for CGCM simulations.

First we consider the regional temperature change in winter (Fig. 14a). When the CanESM2 simulation is considered, it can be seen that the temperature increases from $2{ }^{\circ} \mathrm{C}$ in South to $6{ }^{\circ} \mathrm{C}$ in Arctic Land region in 2071-2100.
This change occurs in increments of about $1-2{ }^{\circ} \mathrm{C}$ for 2011-2040, then by additional $1{ }^{\circ} \mathrm{C}$ in the southern and quite sharply, by $3-4{ }^{\circ} \mathrm{C}$, in the northern regions for 2041-2070 and, eventually, by less than $1{ }^{\circ} \mathrm{C}$ in all regions for 2071-2100. This pattern reflects the RCP 4.5 total radiative forcing that increases till around 2070 and then stabilizes. The temperature change in the MPI-ESM-LR for 2011-2040 is similar or slightly smaller than that in the CanESM2 simulation. However, for the other two periods the MPI-ESM-LR temperature generally increases by smaller increments, eventually giving rise to quite a bit smaller total projected changes for 2071-2100; interestingly, in South, East and Great Lakes regions, the MPIESM-LR increments for 2071-2100 are larger than those for 2041-2070. Both of the CRCM5 simulations closely follow the projected changes in the corresponding CGCM simulations.
Fig. 14 Change in the mean $(\mathbf{a}, \mathbf{d}), 5$ th $(\mathbf{b}, \mathbf{e})$ and 95 th percentiles $(\mathbf{c}, \mathbf{f})$ of dailyaveraged $2 \mathrm{~m}$ temperatures, as a function of region, for $\mathbf{a}-\mathbf{c}$ DJF and d-f JJA, in 2011-2040 (blue, brown), 2041-2070 (cyan, pink) and 2071-2100 (green, yellow) with respect to 1981-2010; CRCM-Can (blue, cyan, green squares), CanESM2 (blue, cyan, green diamonds), CRCM-MPI (brown, pink, yellow squares), MPI-ESM-LR (brown, pink, yellow diamonds). Legend is split in two parts in order to fit the space
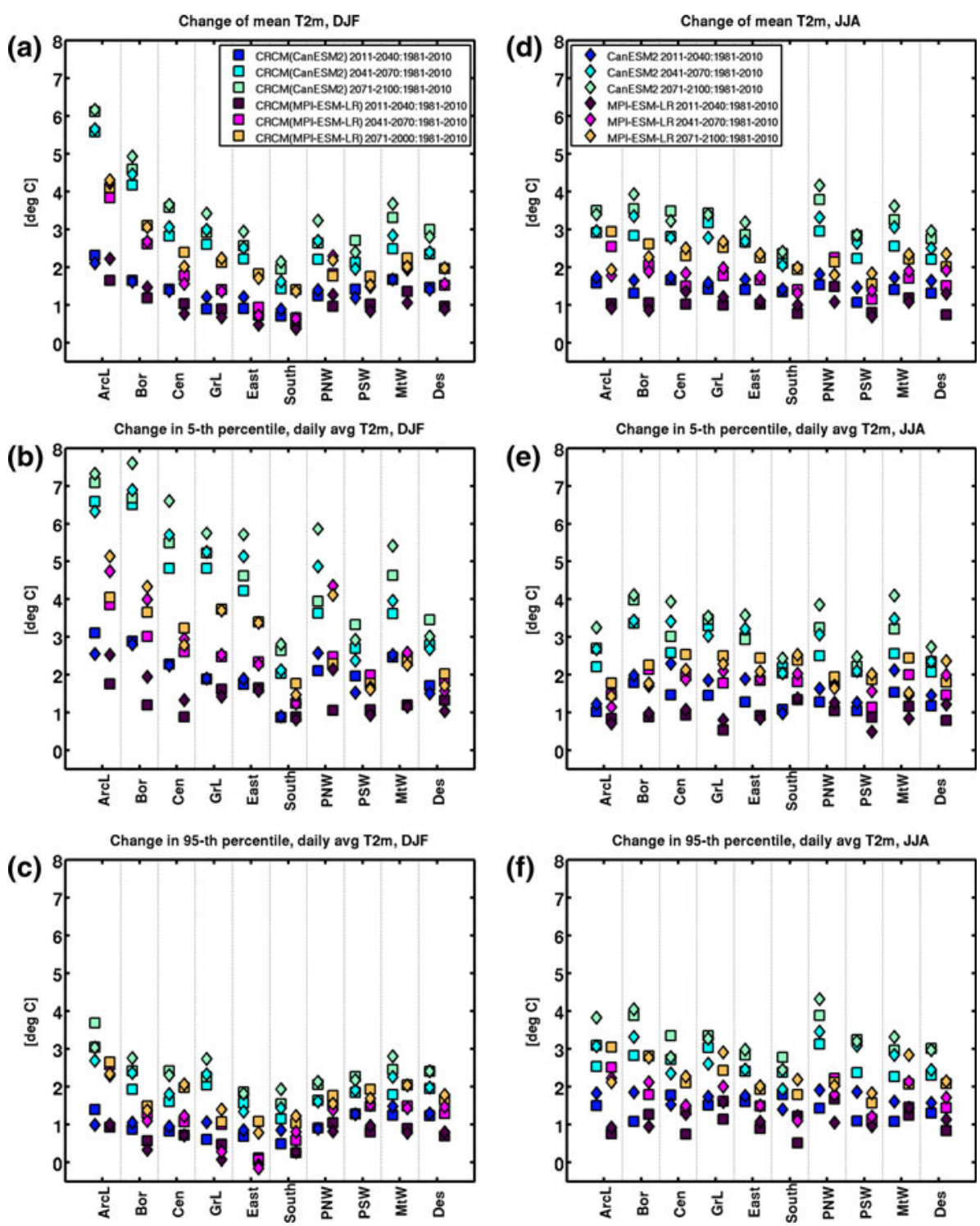
Next, we move to the 5th percentile in winter (Fig. 14b) where we can see that in all simulations the projected temperature changes are quite larger than for the mean (Fig. 14a); the exception are the southern-most regions where the change in the 5 th percentile is similar to that in the mean. The maximum temperature increase in the 5th percentile is shifted southward: while in the case of the mean the maximum is in Arctic Land region, in the case of the 5th percentile it is in Boreal region with somewhat smaller values in Arctic Land, Pacific NW, Mt West, Central, Great Lakes and East regions. It is also worth noting that along with higher climate sensitivity in the 5th percentile than in the mean, the differences among the simulations in projected changes are also larger in the 5th percentile than in the mean, including the differences between the CRCM5 and their corresponding CGCM simulations. For example, in Pacific NW region the projected warming in the CRCM-Can and CRCM-MPI simulations for $2071-2100$ is about $2{ }^{\circ} \mathrm{C}$ smaller than in their driving CGCM simulations.

When the 95th percentile in winter daily temperatures is considered (Fig. 14c), it can be seen that the projected change is generally smaller by a few degrees than in the 5th percentile and also smaller than in the mean. A smaller warming on the higher end (warm days) than warming on the lower end (cold days) by $1-2{ }^{\circ} \mathrm{C}$ was also found in Leung et al. (2004) in winter daily temperature distributions over the western US. The exception to this rule is the southern most regions (Desert and South) where the projected change is rather uniform with respect to the three statistics. In the 95th percentile, by the end of the $21 \mathrm{st}$ century the temperature increases by less then $4{ }^{\circ} \mathrm{C}$ over Arctic Land and less than $3{ }^{\circ} \mathrm{C}$ in all other regions in all simulations.

Unlike in winter, in summer regional near-surface temperatures (Fig. 14d-f), we find an almost uniform climate-change signal with respect to the mean, 5th and 95th percentile. The projected change is also quite uniform with respect to the regions, given a CGCM simulation. As in winter, the MPI-ESM-LR and CRCM-MPI simulations display smaller projected temperature changes than CanESM2 and CRCM-Can. In the case of CanESM2 the temperature increases mostly by $3-4{ }^{\circ} \mathrm{C}$ in $2071-2100$ and by $2-3{ }^{\circ} \mathrm{C}$ in the case of MPI-ESM-LR. Note also that in most of the cases the CRCM-Can projected changes tend to be smaller than in CanESM2, implying that the CRCM5 own sensitivity to the RCP4.5 radiative forcing is smaller than that of CanESM2. This also holds for winter.

We now consider projected changes in precipitation. Figure 15 displays the projected changes in the mean precipitation over the period 2071-2100 to 1981-2010, for DJF (panels a-d) and JJA (e-h), in the CRCM5 simulations (left) and the corresponding CGCM simulations (right column). The changes are presented as percentage of the 1981-2010 seasonal-mean precipitation. In winter, the CRCM-Can and CanESM2 simulations display a strong south-to-north gradient in projected relative change of precipitation, with an increase by $10-20 \%$ over most of the continent, including the Greater Antilles, and up to $50 \%$ over the Arctic. On the other hand, over Mexico (especially its Pacific coastal regions) a decrease of winter precipitation by $50 \%$ is locally found in these simulations. Although the CRCM-Can and CanESM2 display similar large-scale precipitation change patterns, there are also considerable fine-scale differences, particularly over the complex topography. For example, over the lower-elevation basins of central British Columbia and the U.S. Pacific Northwest, the CRCM-Can indicates an increase of DJF precipitation of locally more than $40 \%$, while the CanESM2 indicates almost no change. The two simulations also display different trends over southeastern California; in the CRCM-Can the projected decrease of precipitation over the Pacific coast of Mexico extends further north into California than in CanESM2. The CRCM-MPI and MPIESM-LR simulations display a smaller south-north gradient of winter relative precipitation change; over most of North America the signal is much more uniform than in the CRCM-Can and CanESM2. The former simulations' precipitation increase over the Arctic and decrease over Central America are, in general, both of quite a bit smaller magnitude than in the CRCM-Can and CanESM2, being confined to the range of $0-20 \%$, including the Arctic, although locally, such as over Alaska, the CRCM-MPI projected increase may be larger. Over the central US all four simulations produce a small climate-change signal of similar magnitude in winter. These results appear to be well inside the range of AR4 CGCMs for 2080-2099 under A1B scenario (Christensen et al. 2007a). It is also worth noting that over the Columbia Basin in the Pacific Northwest the CRCM-MPI indicates an increase of $20 \%$ while the MPI-ESM-LR shows no trend in this region. Interestingly, similar patterns of differences are also noted above when the CRCM-Can and CanESM2 were compared in the Pacific NW region, which is likely due to better-resolved orographic effects in the CRCM5.

In summer (Fig. $15 \mathrm{e}-\mathrm{h}$ ), there is much less agreement between the CanESM2 and MPI-ESM-LR and the corresponding CRCM5 simulations on precipitation change. CRCM-Can and CanESM2 project an increase of summer precipitation by about $20 \%$ over the Arctic and $10 \%$ over the US southeast. Both the CRCM-Can and CanESM2 projections display a relative increase of summer precipitation over parts of the Rocky Mountains and parts of California locally as large as $80 \%$. However, these areas receive small amounts of precipitation in summer, so this increase is not large in absolute terms. The two simulations 
Fig. 15 Same as in Fig. 13 but for precipitation
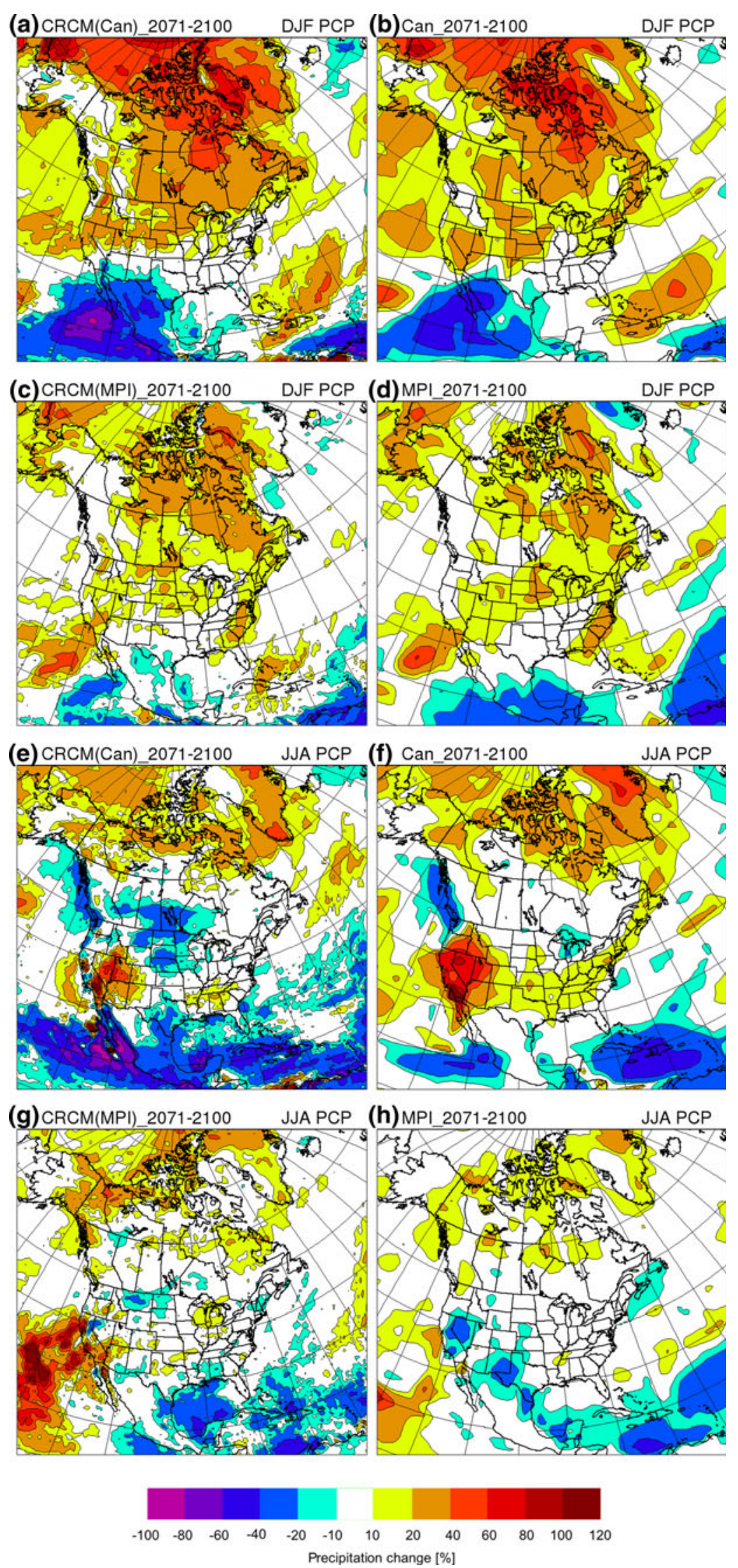
also have in common the reduction of precipitation over the northern Pacific Coast, Pacific Coast of Mexico and the Greater Antilles. The most important difference between the CRCM-Can and its driving simulation CanESM2 in summer is the reduction of precipitation over the Prairies by $10-40 \%$ in the CRCM-Can. The two models use different deep-convection parameterizations; the CanESM2 uses a mass flux scheme (Zhang and McFarlane 1995) to model the precipitation associated to deep convection, while the Kain-Fritsch scheme is used in the CRCM-Can. Using the third-generation CRCM, Plummer et al. (2006) examined the difference in projected precipitation change due to a change in the physics package and obtained rather small differences in projections over the Northern Plains. However, the two physics packages used the same deepconvection parameterization.

The CRCM-MPI and MPI-ESM-LR projected changes in summer precipitation have generally smaller magnitude than those found in the CanESM2 and CRCM-Can simulations. There is increase of 10-30\% in summer over the Arctic and some drying in the southern portions of the domain. The CRCM-MPI produces also a highly spatially variable but mainly increasing summer precipitation over the California coastal regions, locally as large as $80 \%$. This feature appears to be restricted to the ocean in the MPI-ESM-LR, not reaching the coastal regions of California. Recall that in this region the MPI-ESM-LR, and also the CRCM-MPI simulations, present huge biases in the present-climate $2 \mathrm{~m}$ temperature and precipitation, as well as a large warm SST bias over the subtropical Pacific. It is thus not surprising that the projected changes also substantially differ. We will approach this issue in more detail when we consider the projected changes of dailymean precipitation distributions over these regions.

Figure 16 summarizes by Bukovsky's regions the projected transient change of average precipitation for 2011-2040, 2041-2070 and 2071-2100 with respect to 1981-2010. In winter (Fig. 16a), a monotonic precipitation increase for the three periods is projected in Arctic Land and Boreal region, eventually giving rise to changes of almost $30 \%$ in CanESM2 and 15-20\% in MPI-ESM-LR for 2071-2100. The CRCM5 tends to somewhat increase the trends of the CanESM2 simulation in these regions. In Central, Great Lakes and East regions, the CanESM2 and MPI-ESM-LR projected changes are smaller, reaching about $15 \%$ in 2071-2100. In these regions the CanESM2 and MPI-ESM-LR closely agree in projected changes, but both the CRCM-Can and CRCM-MPI simulations tend to somewhat reduce the changes projected by their driving CGCMs by about $5 \%$. Over South, Pacific NW and AZNM regions there is a slight projected increase of precipitation but, for example, in the Pacific NW the MPIESM-LR and CRCM-MPI projected changes are the largest for 2011-2040 and afterwards the precipitation decreases. The signal might be too small to be distinguished from possible residuals of natural variability in the 30-year mean. Over Pacific SW and Mt West regions the projected changes of precipitation are positive, reaching $20 \%$ for
Fig. 16 The change in the spatiotemporal average precipitation, as a function of region, for a DJF and $\mathbf{b}$ JJA, in 2011-2040 (blue, brown), 2041-2070 (cyan, pink) and 2071-2100 (green, yellow) with respect to 1981-2010; CRCMCan (blue, cyan, green squares), CanESM2 (blue, cyan, green diamonds), CRCM-MPI (brown, pink, yellow squares), MPI-ESM-LR (brown, pink, yellow diamonds). The top and bottom rows show the same, except that they display results for different regions
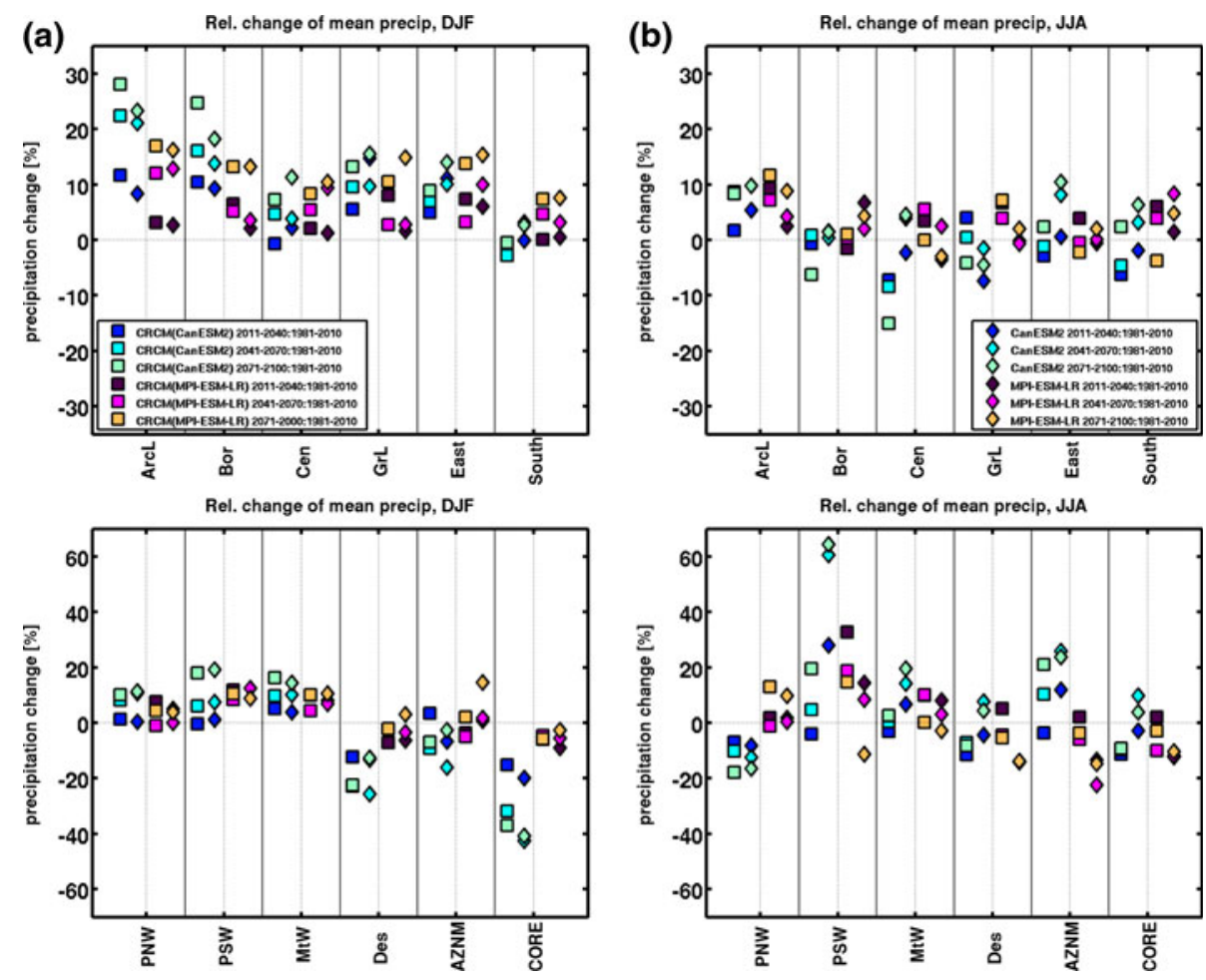
2071-2100 in the CanESM2 and $10-15 \%$ in the MPIESM-LR, while the CRCM5 follows these values closely. Finally, over Desert and especially CORE region, the CanESM2 and CRCM-Can simulations display a relatively strong drying trend, while the MPI-ESM-LR and CRCMMPI show no significant changes.

In summer (Fig. 16b), the average precipitation change signal is generally quite small, there is disagreement among the simulations on both magnitude and sign of the signal, and the projected changes are not monotonic with respect to the three 30 -year slices. It is likely that the differences among the simulations as well as those among the 30-year slices are more a result of internal model dynamics (interdecadal variability) than due to the GHG forcing. The lack of statistical significance has been noted in studies of summer precipitation projected changes (e.g., Duffy et al. 2006). Only over the Arctic Land region do all simulations agree on an increase of average precipitation by about $10 \%$. On the other hand, in Mt West region the MPI-ESMLR simulation projects first an increase in precipitation by $10 \%$ in 2011-2040 and then a precipitation decrease. The CRCM-MPI simulation follows this pattern. The CanESM2 however projects a gradual increase eventually reaching $20 \%$ in 2071-2100, while the CRCM-Can simulation projects almost no change for any of the three periods. Note in Fig. 14 that in the case of CRCM-MPI and MPIESM-LR the regions of projected precipitation decrease (south) and increase (north) appear to be rather well separated. It is noted in Christensen et al. (2007a) that the separating line between the projected precipitation increase and decrease moves north with increasing GHG concentrations. For regions near the separating line between the projected precipitation increase and decrease, such as the Mt West region, precipitation would first increase while the region is still to the north of the line, and then precipitation would decrease as the line moves northward.

In summary, the CRCM5-projected average precipitation changes exhibit quite large and spatially variable regional deviations from the corresponding changes in the driving CGCM simulations. The presence of considerable deviations of the CRCM5-projected changes from those in the corresponding CGCM simulations should be interpreted as the CRCM5 potential to add value to the driving CGCM simulations, due to a higher resolution representation of the land-surface forcing and atmospheric dynamics and physics in the CRCM5. It is not surprising that the deviations in projected precipitation changes are larger in summer, since, as we saw in Fig. 11, the temporal variability of summer daily precipitation is much more realistically represented in the CRCM5 simulations.

In order to complete the discussion of climate projections, we now examine the projected change in the spatiotemporal distribution of daily-average precipitation over Bukovsky's regions. The spatiotemporal distributions are obtained by pooling 30-year daily precipitation time series at each grid points within a region into a large single dataset. The change in the distribution is quantified as the change in the RDAD, discussed in Sect. 6, defined as follows:

$\delta P_{i}=\frac{H_{i}^{(f)}-H_{i}^{(p)}}{\sum_{i} H_{i}^{(p)}}$,

where $H_{i}^{(p)}$ and $H_{i}^{(f)}$ are the total accumulations in the intensity bin $i$ over a region, in the period 1981-2010 and 2071-2100, respectively. Note that upon summing the relative accumulations $\delta P_{i}$ over all bins $i$, we obtain the relative change in the spatiotemporal average precipitation over a region, which was shown in Fig. 16. In other words, $\delta P_{i}$ partitions the projected relative change in the regional time-average mean precipitation into the contribution of every intensity range. Also note that in principle, the changes in individual intensity bins may be large in magnitude, but if they have the opposite sign, they may cancel in the process of summing over all intensity bins, giving rise to a negligible change in the mean.

Figure 17 displays the projected regional RDAD changes for the 2071-2100 interval in winter. Except in Desert, AZNM and CORE regions, all simulations generally agree in that the projected mean change is mostly due to increased accumulations in the range of moderate to heavy precipitation. The increase is the most uniform with respect to intensity ranges in the Arctic Land region. Moving south, the higher intensities tend to have more important relative contribution. In Pacific NW, Pacific SW, South and East regions, there is almost no change in the range from 1 to $16 \mathrm{~mm} /$ day, while in the range $32-128 \mathrm{~mm} /$ day the accumulations increase by $5-10 \%$; this is of course a consequence of a projected increase in the frequency of events at this range. At the same time, the change in the relative frequency of dry days is not projected to be very large; there is a slight decrease for about $5 \%$ in the frequency of dry days in the northern regions and an increase by the same amount in the southernmost regions. No change in the midlatitude regions was found in dry days, implying that the increase in the winter mean precipitation in these regions is due to an increase of the frequency of heavy precipitation events at the expense of the frequency of light precipitation events. When the CRCM simulations are compared to the CGCM simulations in the Pacific NW and Pacific SW regions, the CRCM appears to push the corresponding CGCM-simulated RDAD changes towards higher bins. Likewise, in the South and East regions, the CRCM reduces the change in lower RDAD bins. This might be a result of better-resolved orographic effects and precipitation mesoscale systems such as the so-called "atmospheric rivers" by Dettinger et al. (2012). 

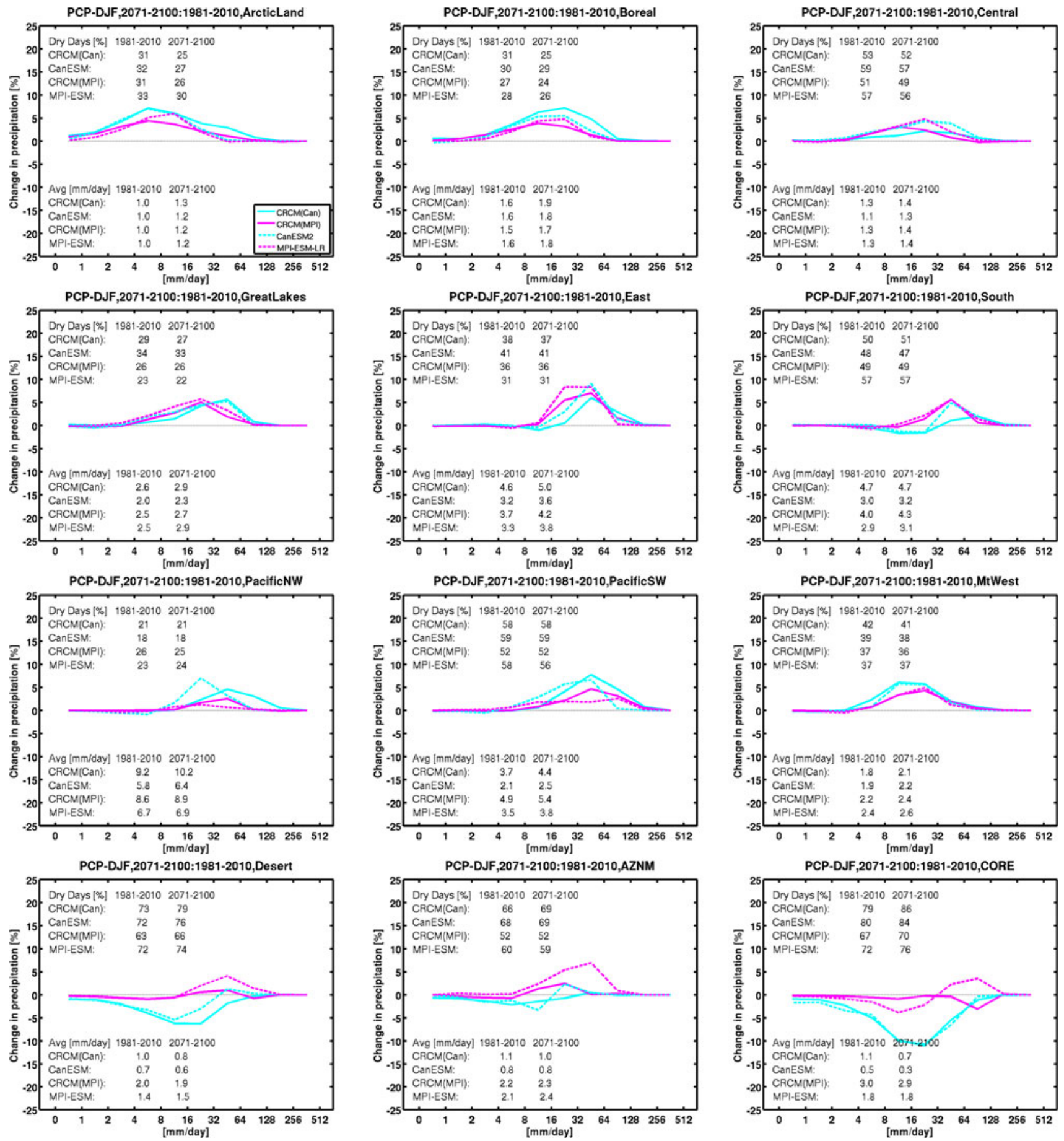

Fig. 17 Projected change in regional relative daily accumulation distributions (RDAD; Eq. 1) for DJF 2071-2100 with respect to 1981-2010 in percentage; CRCM-Can (cyan-full), CanESM2 (cyan-dashed), CRCM-MPI (pink-full) and MPI-ESM-LR simulations (pink-dashed line)

Figure 18 displays the same for summer. The inspection of the printed values shows that the relative frequency of dry days is generally not projected to change significantly in summer. As for the distributions themselves, the only region where the four simulations mostly agree on projected changes is the Arctic Land. In general, in the range of heavy precipitation the CRCM5 projected changes tend to be larger, as the CGCMs do not adequately represent distributions in this range. The projected changes in distributions are relatively small and the CGCM and CRCM5 simulations tend to disagree. The exception is the regions in the western part of the continent (Pacific NW and SW, Mt West and AZNM) where the relative changes are of a larger magnitude but they tend to have the opposite sign in 

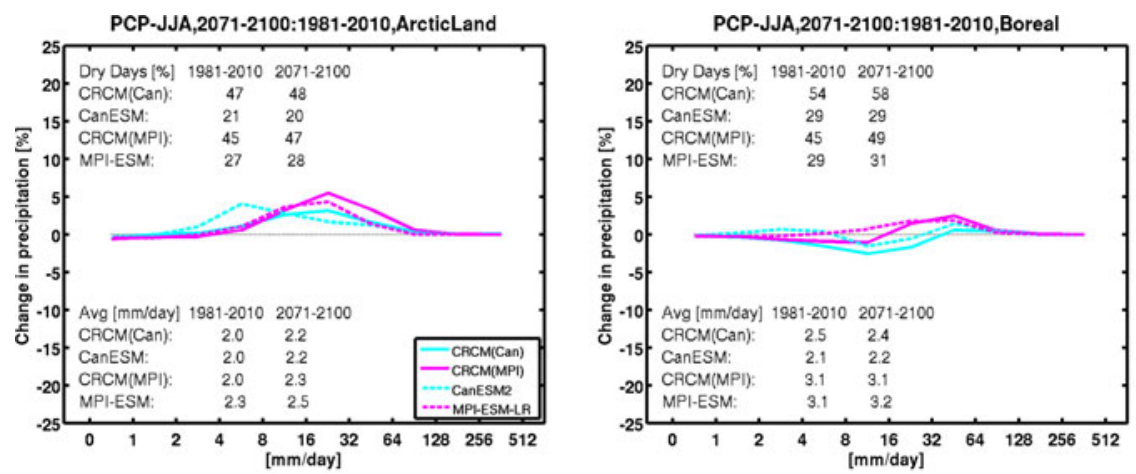

PCP-JJA,2071-2100:1981-2010,GreatLakes
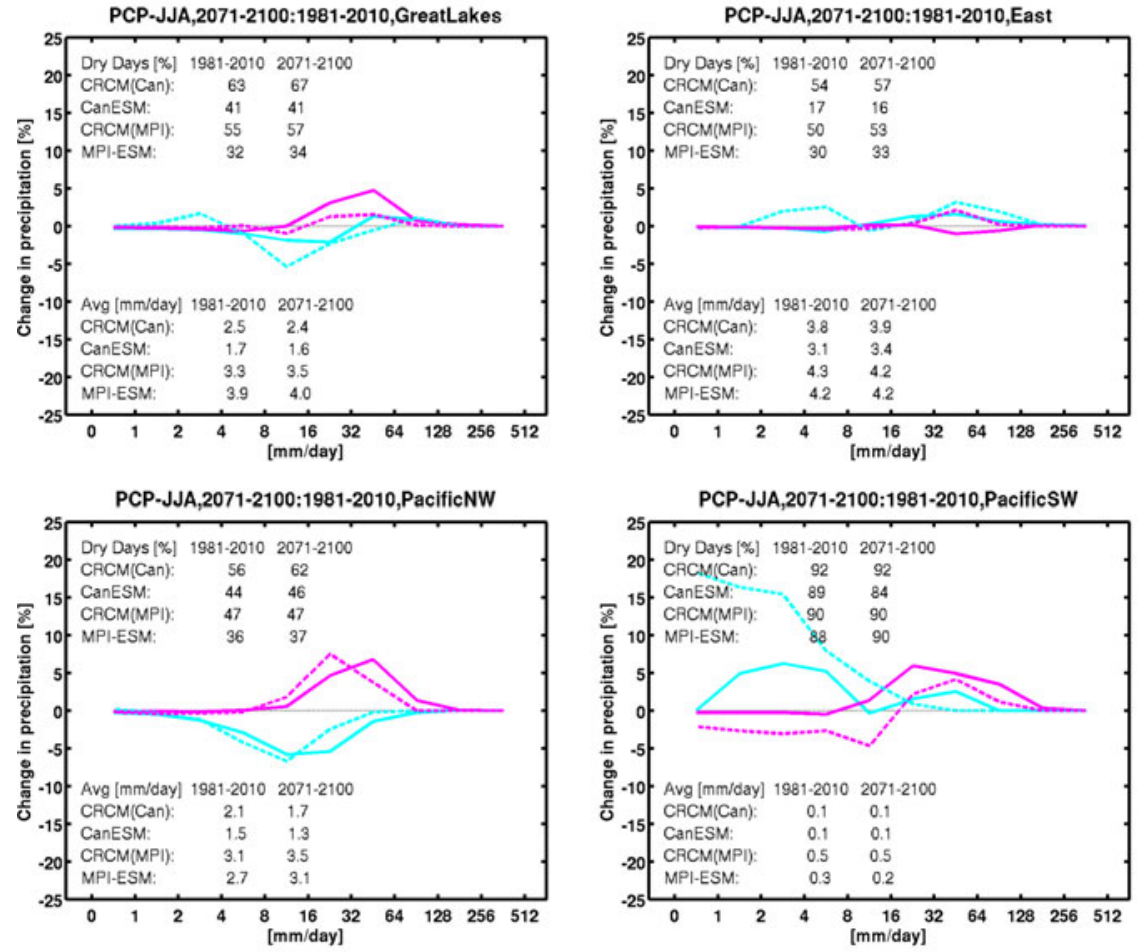

PCP-JJA,2071-2100:1981-2010,Desert
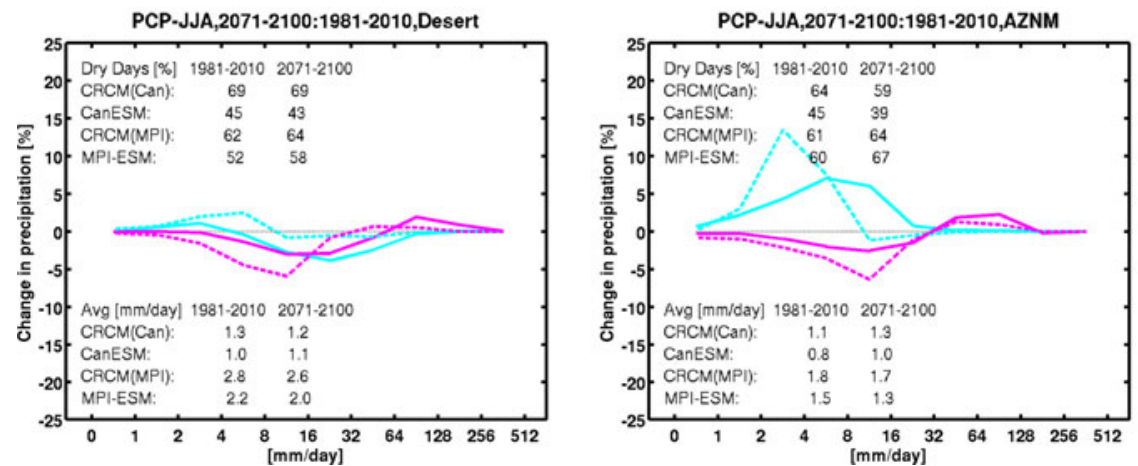

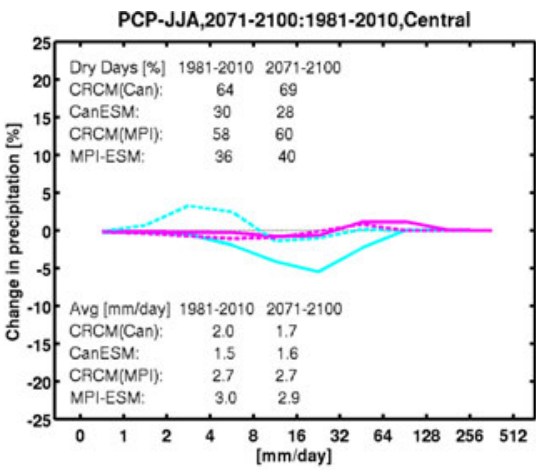

PCP-JJA,2071-2100:1981-2010,South
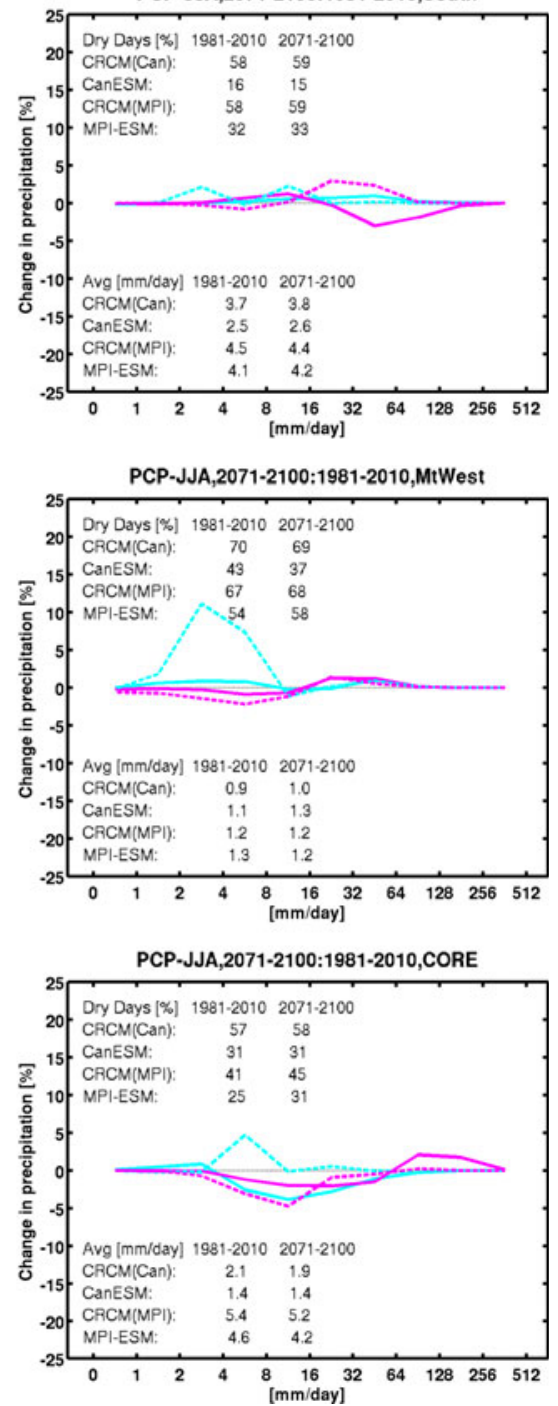

Fig. 18 Same as in Fig. 17 but for JJA daily precipitation

the CanESM2 and CRCM-Can with respect to the MPIESM-LR and CRCM-MPI, indicating that the distributions are controlled by the driving CGCMs.

In order to further examine this issue, we display in Fig. 19 the present-climate summer-average sea-level pressure (SLP) and projected summer-average changes in the four simulations for the period 2071-2100. When the CanESM2 and CRCM-Can projected changes (Fig. 19b, c) are compared with the present-climate SLP patterns (Fig. 19a) over the Pacific Ocean and West Coast, it can be seen that the projected changes indicate a weakening and northward shift of the Pacific subtropical high pressure, and 
Fig. 19 ERAINT 1989-2008

JJA-average sea-level pressure (a) and projected changes for the period 2071-2100 to 1981-2010 in: b CRCM-Can, c CanESM2, d CRCM-MPI and e MPI-ESM-LR (a) ERAINT 1989-2008 SLP

JJA

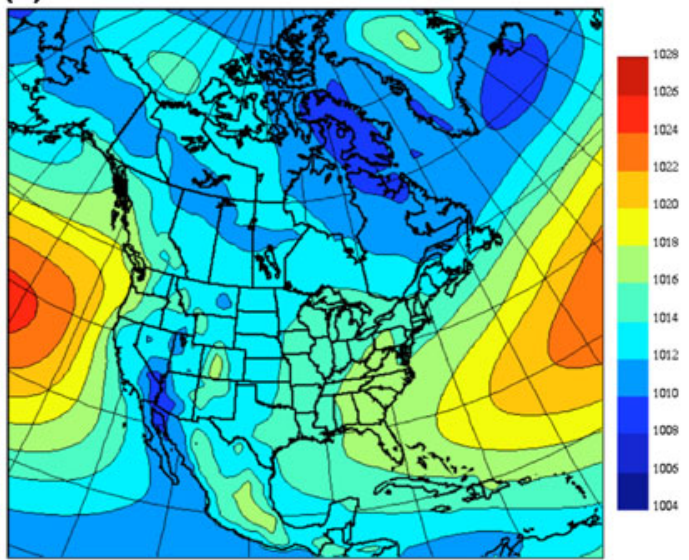

(b) $\mathrm{CRCM}$ (Can) JJA (c) CanESM2
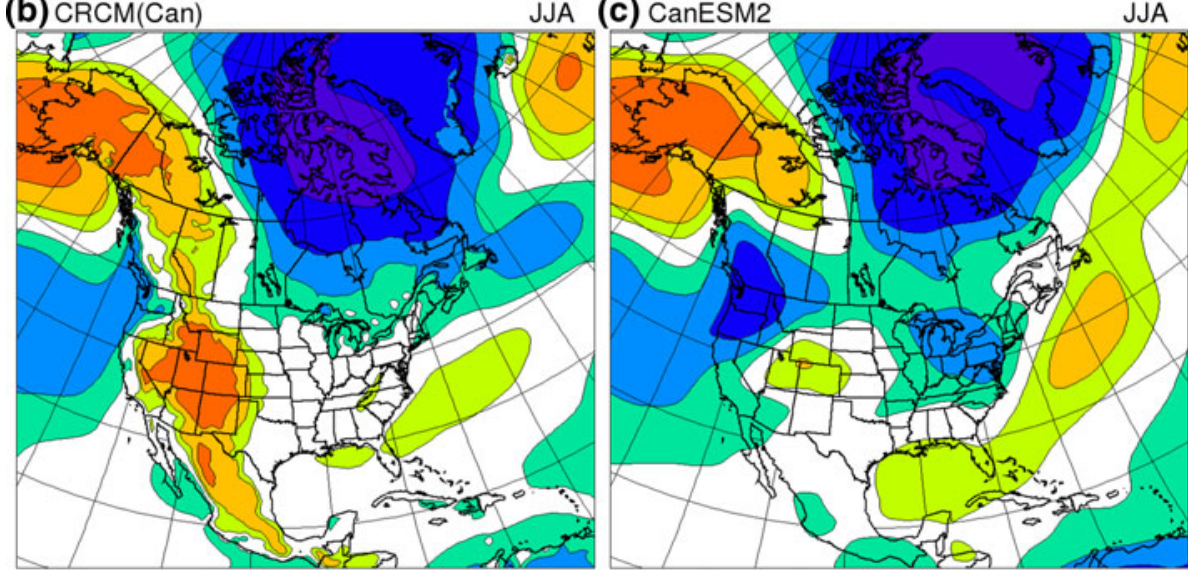

(d) $\mathrm{CRCM}(\mathrm{MPI})$ JJA (e) MPI-ESM JJA
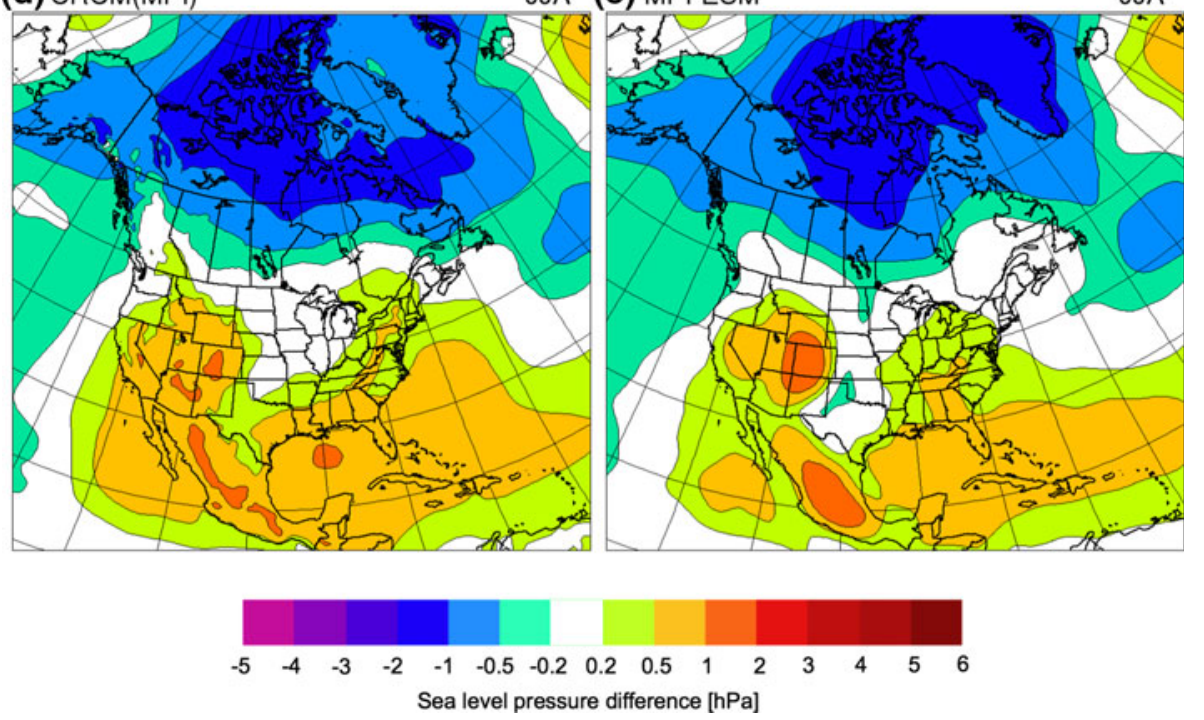

a pressure increase over the US Southwest. Consequently, this implies a weakening of the subsidence off the West Coast, a decreased zonal pressure gradient over the coastal regions of California and a reduction of the flow of dry air masses from the Pacific high, eventually allowing for the penetration of the moist air masses from the tropical Pacific farther north. Accordingly, the CRCM-Can and CanESM2 projected changes in summer precipitation over the Pacific SW, AZNM and Mt West regions are positive. However, the projected changes in the RDADs for these regions (Fig. 18) show that the mean increases only due to higher accumulations at lower intensities. At the same time, the 
CRCM-Can and CanESM2 projected SLP changes over the Pacific Ocean imply a northward shift in the storm tracks, which results in the projected decrease in summer precipitation over the Pacific NW region in these simulations (Fig. 18). The projected summer SLP changes in the CRCM-MPI and MPI-ESM-LR (Fig. 19d, e) are quite different: the SLP is projected to increase over the US southwest but also over the adjacent regions over the Pacific Ocean and to decrease over Alaska. Thus, in these simulations the subtropical anticyclone strengthens over the US Southwest and the Pacific coast of northern Mexico, implying more subsidence and resulting in projected decrease in summer precipitation over these regions (Fig. 18; Desert, AZNM and CORE regions). At the same time, the patterns of projected change of SLP over the northern Pacific Ocean in these simulations imply an intensification of the westerly flow over the Pacific NW region, resulting in an increase in summer precipitation in this region. This increase is projected to be the mostly contributed by accumulations in the heavy precipitation range, above 16 and up to $256 \mathrm{~mm}$ /day (Fig. 18; Pacific NW).

\section{Summary and conclusions}

The purpose of this study was to investigate the present climate and projected climate change as simulated by the CRCM5 in order to contribute to the CORDEX project. Three CRCM5 simulations were performed: a control reanalysis-driven simulation for the period 1959-2008 and two CGCM-driven transient climate-change simulations for the period 1950-2100 forced with CanESM2 and MPIESM-LR; the present-day control used the historical GHGs and aerosol concentrations and the future climate simulations were based on the RCP 4.5 radiative forcing scenario. The reanalysis-driven simulation was used to quantify the CRCM5 structural biases, when it is driven with nearly perfect atmospheric lateral boundary and ocean surface conditions. In addition, this simulation was used to separate the structural biases of CRCM5 from those transmitted from the driving CGCM simulations.

At continental scale, the CRCM5 simulations reproduce relatively well the near-surface temperature and precipitation over North America in the current climate. Temperature biases are mainly limited to $\pm 2{ }^{\circ} \mathrm{C}$, with the exception of a stronger cold bias during the winter season over the western and southern portions of the continent. This bias is also found in the reanalysis-driven run, implying that it originates from the CRCM5 own structural errors. Precipitation biases are relatively small over land, being mainly confined to about $25 \%$ of the observed values, which is not much larger than the observational uncertainties. However, over coastal regions, especially over California and northern Mexico, larger precipitation biases are found coinciding with the CGCMs SST biases. The reanalysisdriven CRCM5 simulation generally performs better, but there are exceptions to this rule due to the possible cancellation of CRCM5 structural biases and those transmitted from the CGCMs; this happens in the MPI-ESM-LR-driven simulation over the central and eastern parts of North America in summer.

The examination of annual cycles of monthly-average regional-average precipitation based on the regionalisation proposed by Bukovsky (2011) shows, upon neglecting some systematic biases, that the reanalysis-driven simulation is quite close to the observations, both in the most general features of the precipitation annual cycle and in reproducing finer details such as, for example over the Boreal region, the small-scale driven convective precipitation maximum in June and the large-scale driven stratiform precipitation maximum in September. The CGCMdriven simulations are somewhat less skilful at reproducing finer details in annual precipitation patterns and have larger biases especially in the coastal regions. The timing of the summer precipitation maximum related to the North American monsoon in the US southwest and northern Mexico is correctly simulated in all CRCM5 simulation, although the model has some difficulties in reproducing the correct absolute amounts. In most of the regions, the CGCM-driven CRCM5 simulations more skilfully reproduce the observed annual patterns than the driving CGCMs, although the MPI-ESM-LR also has generally very good performance.

The 5th and 95th percentile of CRCM5-simulated daily temperature distributions over Bukovsky's regions are also rather well reproduced, with biases not considerably larger than in the case of multiannual seasonal means. In addition, in most of the cases the biases in the 5th and 95th percentile of CRCM5 temperatures were smaller than those in the driving CGCMs, implying that the variability of daily temperatures is better represented in the CRCM5.

At regional and daily temporal scale, both the reanalysis- and CGCM-driven CRCM5 simulations exhibit a quite high skill at partitioning the simulated total precipitation accumulations across the range of intensities. This holds despite the fact that there are considerable biases in the total precipitation over regions and large biases in the frequency of wet and dry days. A similar conclusion was found in Leung et al. (2003) for a reanalysis-driven RCM simulation over the western U.S. This is not the case for CGCM simulations that cannot adequately represent the partition of accumulations in the range of heavy precipitation, especially in summer, when the convective precipitation has a large contribution over land. The difference between CGCM and CRCM5 summer precipitation 
distributions emphasizes the need for RCM downscaling. Due to their higher resolution, the RCM-simulated precipitation accumulations at daily temporal scale are much more realistic, which is necessary for studying the projected changes in the heavy precipitation events.

The projected climate changes were assessed as the difference between the three 30-year statistics for the periods 2011-2040, 2041-2070 and 2071-2100 with respect to 1981-2010. The projected changes in mean temperatures and precipitation fall within the range of the IPCC AR4 projected changes for North America based on the SRES A1B emission scenario. The CRCM5-projected changes are very similar to those obtained in the driving CGCMs, with some fine-scale details added by the CRCM5 due to a higher resolution representation of the topography and land-surface forcing.

For the 2071-2100 winter-average temperature changes, the largest warming of more than $10{ }^{\circ} \mathrm{C}$ is found in the CanESM2-driven simulation over the northernmost parts of the domain. The temperature climate-change signal is however much smaller in the simulation driven with the MPI-ESM-LR. In both cases, the projected warming is larger over land than over the ocean and increases with latitude over land, being only $1-2{ }^{\circ} \mathrm{C}$ over the southeastern US and much larger over northern Canada. In summer, the south-north warming gradient disappears. In the CanESM2driven simulation the maximum warming of up to $5{ }^{\circ} \mathrm{C}$ is projected over the Northern Plains and Pacific Northwest, while in the MPI-ESM-driven simulation there is a more uniform warming pattern of about $2-3{ }^{\circ} \mathrm{C}$ over land.

All simulations agree in projecting considerably larger warming in the 5 th percentile than in the multiannual mean of daily average temperatures in winter, especially over the northern and central regions of the continent. This feature can be related to the fact that on average, the Arctic regions warm up the most. The cold waves over the central parts of the continent in winter are mostly due to the intrusions of the Arctic air masses; these cold waves are likely to become milder due to the large warming in their source region, resulting in a large increase in the temperatures' 5 th percentile over the central parts of North America. In addition, the increase of the 95th percentile of winter daily temperatures in the northern parts of the continent is found to be smaller than the increase of the multi-annual mean, which is likely related to the fact that over low latitudes as well as over the Pacific and Atlantic Ocean, the projected mean temperature change in winter is relatively small. Warm periods over the Arctic and subarctic regions in winter are mostly due to the advection of warm air masses originating from lower latitudes and oceans. On the other hand, the projected changes in the 5th and 95th percentiles of summer temperatures are found to closely follow the change in the mean in all simulations.
The projected changes in average precipitation in winter for 2071-2100 are not large; the increase of precipitation of about $0-20 \%$ is projected over most of the continent except Central America where precipitation is projected to decrease. The CRCM5 and CGCM simulations all agree in this general pattern although the CRCM5 simulations display important mesoscale differences with respect to their driving CGCMs. The increase of winter precipitation over the western, southern and eastern coastal regions, as well as over the Great Lakes, is found in all simulations to be mainly due to an increase in the frequency of days with heavy precipitation. This might be due to the intensification or an increase in frequency of winter storms, but this topic is beyond the scope of this paper. In summer, the projected precipitation changes are rather small and very uncertain; only over the northernmost regions of the continent the simulations agree on an increase of precipitation of about $10 \%$. In other regions, large differences are found between the two CRCM5 simulations, especially over the western half of the continent, where the simulations disagree on both magnitude and sign of the projected changes in summer precipitation. The uncertainties in the CGCMprojected changes in the synoptic-scale circulation over the Pacific Ocean, such as the position and strength of the subtropical high pressure, are likely to be the main cause of the large uncertainties in the CRCM5-projected changes in summer precipitation over western North America.

Acknowledgments This research was funded by the Canadian Foundation for Climate and Atmospheric Sciences (CFCAS), the Québec's Ministère du Développement Économique, Innovation et Exportation (MDEIE), the Natural Sciences and Engineering Research Council of Canada (NSERC), Hydro-Québec, the Ouranos Consortium on Regional Climatology and Adaptation to Climate Change, the Mathematics of Information Technology and Complex Systems (MITACS) Network of Centres of Excellence, and the Canada Research Chairs programme. The calculations were made possible through the CLUMEQ Consortium, on the Colosse and Guillimin high-performance computing platforms; CLUMEQ is part of the Compute Canada national HPC platform and a member of the Calcul Québec regional HPC platform. The authors thank Mr Georges Huard and Mrs Nadjet Labassi for maintaining an efficient and userfriendly local computing facility. The authors are also grateful to the following collaborators at Environment Canada: Mr Michel Desgagné for his work in developing a nested version of GEM, Dr Diana Verseghy for allowing to use the code of CLASS 3.5, Mr Richard Harvey for helping with CLASS, and specially Dr Bernard Dugas for his unwavering support on developing CRCM5 since the beginning of this work more than a decade ago. This study would not have been possible without the access to valuable data from ERA-Interim, CRU, UDEL, GPCP and TRMM, as well as the outputs from CanESM2 and MPI-ESM-LR models.

Open Access This article is distributed under the terms of the Creative Commons Attribution License which permits any use, distribution, and reproduction in any medium, provided the original author(s) and the source are credited. 


\section{References}

Adams DK, Comrie AC (1997) The North American monsoon. Bull Am Meteor Soc 78:2197-2213

Arakawa A, Lamb WR (1977) Computational design of the basic dynamical processes of the UCLA general circulation model. In: General circulation models of the atmosphere (A78-10662 01-47). Academic Press Inc, New York, pp 173-265

Arora VK, Boer GJ (2010) Uncertainties in the 20th century carbon budget associated with land use change. Global Chang Biol 16:3327-3348

Arora VK, Boer GJ, Christian JR, Curry CL, Denman KL, Zahariev K, Flato GM, Scinocca JF, Merryfield WJ, Lee WG (2009) The effect of terrestrial photosynthesis down-regulation on the 20th century carbon budget simulated with the CCCma earth system model. J Clim 22:6066-6088

Arora VK, Scinocca JF, Boer GJ, Christian JR, Denman KL, Flato GM, Kharin VV, Lee WG, Merryfield WJ (2011) Carbon emission limits required to satisfy future representative pathways of greenhouse gases. Geophys Res Lett 38:L05805

Bélair S, Mailhot J, Girard C, Vaillancourt P (2005) Boundary-layer and shallow cumulus clouds in a medium-range forecast of a large-scale weather system. Mon Weather Rev 133:1938-1960

Benoit R, Côté J, Mailhot J (1989) Inclusion of a TKE boundary layer parameterization in the Canadian regional finite-element model. Mon Weather Rev 117:1726-1750

Brovkin V, Raddatz T, Reick CH, Clauseen M, Gayler V (2009) Global biogeophysical interactions between forest and climate. Geophys Res Let 36:L07405

Bukovsky MS (2011) Masks for the Bukovsky regionalization of North America, Regional Integrated Sciences Collective, Institute for Mathematics Applied to Geosciences, National Center for Atmospheric Research, Boulder, CO. Downloaded 2012-0703. http://www.narccap.ucar.edu/contrib/bukovsky/

Castro CL, Pielke RA, Leoncini G (2005) Dynamical downscaling: an assessment of value added using a regional climate model. J Geophys Res 110:D05108. doi:10.1029/2004JD004721

Christensen JH, Hewitson B, Busuioc A, Chen A, Gao X, Held I, Jones R, Kolli RK, Kwon W-T, Laprise R, Magaña Rueda V, Mearns L, Menéndez CG, Räisänen J, Rinke A, Sarr A, Whetton P (2007a) Regional climate projections. In: Solomon S, Qin D, Manning M, Chen Z, Marquis M, Averyt KB, Tignor M, Miller HL (eds) Climate change 2007: the physical science basis. Contribution of working group I to the fourth assessment report of the intergovernmental panel on climate change. Cambridge University Press, Cambridge

Christensen JH, Carter T, Rummukainen M, Amanatidis G (2007b) Evaluating the performance and utility of regional climate models: the PRUDENCE project. Climatic Chang 81:1-6

Christian JR, Arora VK, Boer GJ, Curry CL, Zahariev K, Denman KL, Flato GM, Lee WG, Merryfield WJ, Roulet NT, Scinocca JF (2010) The global carbon cycle in the Canadian Earth System Model (CanESM1): preindustrial control simulation. J Geophys Res 115:G03014

Côté J, Gravel S, Méthot A, Patoine A, Roch M, Staniforth A (1998) The operational CMC-MRB global environmental multiscale (GEM) model. Part I: design considerations and formulation. Mon Weather Rev 126:1373-1395

Davies HC (1976) A lateral boundary formulation for multi-level prediction models. Q J R Meteorol Soc 102(432):405-418

de Elía R, Caya D, Côté H, Frigon A, Biner S, Giguère M, Paquin D, Harvey R, Plummer D (2008) Evaluation of uncertainties in the CRCM-simulated North American climate. Clim Dyn 30:113-132
De Sales F, Xue Y (2011) Assessing the dynamic downscaling ability over South America using the Intensity-Scale verification technique. Int J Climatol 31:1205-1221

Dee DP, Uppala SM, Simmons AJ et al (2011) The ERA-Interim reanalysis: configuration and performance of the data assimilation system. Q J R Meteorol Soc 137:553-597. doi: 10.1002/qj.828

Delage Y (1997) Parameterising sub-grid scale vertical transport in atmospheric models under statically stable conditions. Boundary-Layer Meteor 82:23-48

Delage Y, Girard C (1992) Stability functions correct at the free convection limit and consistent for both the surface and Ekman layers. Boundary-Layer Meteor 58:19-31

Dettinger MD, Ralph FM, Hughes M, Das T, Neiman P, Cox D, Estes G, Reynolds D, Hartman R, Cayan D, Jones L (2012) Design and quantification of an extreme winter storm scenario for emergency preparedness and planning exercises in California. Nat Hazards 60:1085-1111. doi:10.1007/s11069-011-9894-5

Di Luca A, de Elía R, Laprise R (2012a) Potential for added value in precipitation simulated by high-resolution nested regional climate models and observations. Clim Dyn 38:1229-1247

Di Luca A, de Elía R, Laprise R (2012b) Potential for added value in temperature simulated by high-resolution nested RCMs in present climate and in the climate change signal. Clim Dyn. doi: 10.1007/s00382-012-1384-2

Di Luca A, de Elía R, Laprise R (2012c) Potential for small scale added value of RCM's downscaled climate change signal. Clim Dyn. doi:10.1007/s00382-012-1415-z

Duffy PB, Arritt RW, Coquard J, Gutowski W, Han J, Iorio J, Kim J, Leung L-R, Roads J, Zeledon E (2006) Simulations of present and future climates in the western United States with four nested regional climate models. J Clim 19:873-895. doi:10.1175/JCLI3669.1

Feser F (2006) Enhanced detectability of added value in limited-area model results separated into different spatial scales. Mon Weather Rev 134:2180-2190

Gent PR, Bryan FO, Danabasoglu G, Doney SC, Holland WR, Large WG, McWilliams JC (1998) The NCAR climate system model global ocean component. J Climate 11:1287-1306

Giorgetta MA, Roeckner E, Mauritsen T, Stevens B, Crueger T, Esch M, Rast S, Kornblueh L, Schmidt H, Kinne S, Möbis B, Krismer T, Reick C, Raddatz T, Gayler V (2012) The atmospheric general circulation model ECHAM6-model description. http://www.mpimet. mpg.de/en/science/models/echam.html. Accessed 30 July 2012

Giorgi F, Mearns LO (1999) Introduction to special section: regional climate modeling revisited. J Geophys Res 104(D6):6335-6352

Giorgi F, Jones C, Asrar G (2009) Addressing climate information needs at the regional level: the CORDEX framework. WMO Bull 58(3):175-183

Hernández-Díaz L, Laprise R, Sushama L, Martynov A, Winger K, Dugas B (2012) Climate simulation over CORDEX Africa domain using the fifth-generation Canadian regional climate model (CRCM5). Clim Dyn. doi:10.1007/s00382-012-1387-z

Huffman GJ, Adler RF, Morrissey MM, Curtis S, Joyce R, McGavock B, Susskind J (2001) Global precipitation at one-degree daily resolution from multi-satellite observations. J Hydrometeor 2:36-50

Huffman GJ, Adler RF, Bolvin DT, Gu G, Nelkin EJ, Bowman KP, Hong Y, Stocker EF, Wolff DB (2007) The TRMM multisatellite precipitation analysis (TMPA): quasi-global, multiyear, combinedsensor precipitation estimates at fine scales. J Hydrometeor 8:38-55

Jungclaus JH, Keenlyside N, Botzet M, Haak H, Luo JJ, Latif M, Marotzke J, Mikolajewicz U, Roeckner E (2006) Ocean circulation and tropical variability in the coupled model ECHAM5/MPI-OM. J Clim 19:3952-3972 
Kain JS, Fritsch JM (1990) A one-dimensional entraining/detraining plume model and application in convective parameterization. J Atmos Sci 47:2784-2802

Kanamitsu M, Ebisuzaki W, Woollen J, Yang SK, Hnilo JJ, Fiorino M, Potter GL (2002) NCEP-DOE AMIP-II reanalysis (R-2). B Am Meteorol Soc 83:1631-1643

Kuo HL (1965) On formation and intensification of tropical cyclones through latent heat release by cumulus convection. J Atmos Sci 22:40-63

Laprise R (1992) The Euler equation of motion with hydrostatic pressure as independent coordinate. Mon Weather Rev 120:197-207

Laprise R (2005) A foreword to "high-resolution climate modelling: assessment, added value and applications". In: Bärring, Laprise R (ed) High-resolution climate modelling: assessment, added value and applications extended abstracts of a WMO/WCRPsponsored regional-scale climate modelling workshop, Lund, Sweden, 29 March-2 April 2004. Lund University electronic reports in physical geography, pp 12-16 http://www.nateko. lu.se/ELibrary/Lerpg/5/Lerpg5Article.pdf

Laprise R (2008) Regional climate modeling. J Comput Phys 227(7):3641-3666

Laprise R, de Elía R, Biner S, Lucas-Picher P, Diaconescu E, Leduc M, Alexandru A, Šeparović L (2008) Challenging some tenets of regional climate modeling. Meteor Atmos Phys 100(1-4):3-22

Laprise R, Hernández-Díaz L, Tete K, Sushama L, Šeparović L, Martynov A, Winger K, Valin M (2013) Climate projections over CORDEX Africa domain using the fifth-generation Canadian Regional Climate Model (CRCM5). Clim Dyn. doi:10.1007/s00382-012-1651-2

Leung LR, Qian Y, Bian X (2003) Hydroclimate of the western United States based on observations and regional climate simulation of 1981-2000. Part I: seasonal statistics. J Climate 16:1892-1911

Leung LR, Qian Y, Bian X, Washington WM, Han J, Roads JO (2004) Mid-century ensemble regional climate change scenarios for the western United States. Clim Chang 62:75-113

Li J, Barker HW (2005) A radiation algorithm with correlated-k distribution. Part I: local thermal equilibrium. J Atmos Sci 62:286-309

Marsland SJ, Haak H, Jungclaus JH, Latif M, Roeske F (2003) The Max-Planck-Institute global ocean/sea ice model with orthogonal curvilinear coordinates. Ocean Model 5:91-127

Martynov A, Sushama L, Laprise R, Winger K, Dugas B (2012) Interactive lakes in the Canadian regional climate model, version 5: the role of lakes in the regional climate of North America. Tellus A 64:16226. doi:10.3402/tellusa.v64i0.16226

Martynov A, Laprise R, Sushama L, Winger K, Šeparović L, Dugas B (2013) Reanalysis-driven climate simulation over CORDEX North America domain using the Canadian Regional Climate Model, version 5: model performance evaluation. Clim Dyn. doi:10.1007/s00382-013-1778-9

Masson V, Champeaux J-L, Chauvin F, Meriguet C, Lacaze R (2003) A global database of land surface parameters at 1-km resolution in meteorological and climate models. J Climate 16:1261-1282

McFarlane NA (1987) The effect of orographically excited gravitywave drag on the circulation of the lower stratosphere and troposphere. J Atmos Sci 44:1175-1800

McGregor JL (1997) Regional climate modeling. Meteor Atmos Phys 63(1):105-117

Mearns LO, Gutowski WJ, Jones R, Leung L-Y, McGinnis S, Nunes AMB, Qian Y (2009) A regional climate change assessment program for North America. EOS 90:311-312

Meinshausen M, Smith S et al. (2011) The RCP greenhouse gas concentrations and their extension from 1765 to 2500. Clim Chang (Special Issue on RCPs)
Mironov D, Heise E, Kourzeneva E, Ritter B, Schneider N, Terzhevik A (2010) Implementation of the lake parameterisation scheme FLake into the numerical weather prediction model COSMO. Boreal Environ Res 15:218-230

Mitchell TD, Jones PD (2005) An improved method of constructing a database of monthly climate observations and associated highresolution grids. Int J Climatol 25:693-712. doi:10.1002/joc.1181

Monette A, Sushama L, Khaliq MN, Laprise R, Roy R (2012) Projected changes to precipitation extremes for Northeast Canadian watersheds using a multi-RCM ensemble. J Geophys Res 117(D13):D13106

Nikulin G, Jones C, Samuelsson P, Giorgi F, Sylla MB, Asrar G, Büchner M, Cerezo-Mota R, Christensen OB, Déqué $M$, Fernandez J, Hänsler A, van Meijgaard E, Sushama L (2012) Precipitation climatology in an ensemble of CORDEX-Africa regional climate simulations. J Clim. doi:10.1175/JCLI-D$11-00375.1$

Pierce DW, Barnett TP, Santer BD, Gleckler PJ (2009) Selecting global climate models for regional climate change studies. Proc Nat Acad Sci USA 106(21):8441-8446

Plummer DA, Caya D, Frigon A, Côté H, Giguère M, Paquin D, Biner S, Harvey R, de Elía R (2006) Climate and climate change over North America as simulated by the Canadian RCM. J Clim 19:3112-3132

Prömmel K, Geyer B, Jones JM, Widmann M (2010) Evaluation of the skill and added value of a reanalysis-driven regional simulation for Alpine temperature. Int J Climatol 30:760-773. doi:10.1002/joc. 1916

Roeckner E, Baeuml G, Bonaventura L, Brokopf R, Esch M, Giorgetta M, Hagemann S, Kirchner I, Kornblueh L, Manzini E, Rhodin A, Schlese U, Schulzweida U, Tompkins A (2003) The general circulation model ECHAM5. Part I: Model description. Report 349, Max-Planck-Institut for Meteorology, Hamburg

Rummukainen M (2010) State-of-the-art with regional climate models. WIREs Clim Chang 1(1):82-96

Salathe EP Jr, Steed R, Mass CF, Zahn PH (2008) A high-resolution climate model for the U.S. Pacific Northwest: mesoscale feedbacks and local responses to climate change. J Clim 21:5708-5726

Scinocca JF, McFarlane NA, Lazare M, Li J, Plummer D (2008) Technical note: the CCCma third generation AGCM and its extension into the middle atmosphere. Atmos Chem Phys 8:7055-7074

Stevens B, Gonzales-Rouco JF, Beltrami H (2008) North American climate of the last millennium: underground temperatures and model comparison. J Geophys Lett 113:F01008, 15

Sturm M, Holmgren J, König M, Morris K (1997) The thermal conductivity of seasonal snow. J Glaciol 43:26-41

Sundqvist H, Berge E, Kristjansson JE (1989) Condensation and cloud parameterization studies with a mesoscale numerical weather prediction model. Mon Weather Rev 117:1641-1657

Sushama L, Laprise R, Caya D, Frigon A, Slivitzky M (2006) Canadian RCM projected climate-change signal and its sensitivity to model errors. Int J Climotol 26:2141-2159

Takle ES, Gutowski WJ, Arritt RW, Pan Z, Anderson CJ, da Silva RR, Caya D, Chen S-C, Giorgi F, Christensen JH, Hong S-Y, Juang H-MH, Katzfey J, Lapenta WM, Laprise R, Liston GE, Lopez P, McGregor J, Pielke RA, Roads JO (1999) Project to intercompare regional climate simulations (PIRCS): description and initial results. J Geophys Res 104(D16):19443-19461

Taylor KE, Stouffer RJ, Meehl GA (2012) An overview of CMIP5 and the experiment design. Bull Am Meteor Soc 93:485-498

Vera C, Higgins W, Amador J, Ambrizzi T, Garreaud R, Gochis D, Gutzler D, Lettenmaier D, Marengo J, Mechoso CR, NoguesPaegle J, Silva Dias L, Zhang C (2006) Toward a unified view of the American monsoon systems. J Clim 19:4977-5000 
Verseghy DL (1991) CLASS—a Canadian land surface scheme for GCMs: I. Soil model. Int J Climatol 11:111-133

Verseghy DL (2009) CLASS-The Canadian land surface scheme (Version 3.4) - technical documentation (version 1.1). Internal report, Climate Research Division, Science and Technology Branch, Environment Canada, 183 pp

von Salzen K, McFarlane NA, Lazare M (2005) The role of shallow convection in the water and energy cycles of the atmosphere. Clim Dyn 25:671-688

von Storch H, Langenberg H, Feser F (2000) A spectral nudging technique for dynamical downscaling purposes. Mon Weather Rev 128(10):3664-3673

Wang Y, Leung LR, McGregor JL, Lee DK, Wang WC, Ding YH, Kimura F (2004) Regional climate modeling: progress, challenges and prospects. J Meteor Soc Japan 82:1599-1628

Wetzel P, Winguth A, Maier-Reimer E (2005) Sea-to-air CO2 fluxes from 1948 to 2003. Global Biogeochem Cycles 19:GB2005

Willmott CJ, Matsuura K (1995) Smart interpolation of annually averaged air temperature in the United States. J App Meteorol 34:2577-2586

Winterfeldt J, Weisse R (2009) Assessment of value added for surface marine wind speed obtained from two regional climate models. Mon Weather Rev 137:2955-2965. doi:10.1175/2009MWR2704.1
Yang D, Kane D, Zhang Z (2005) Bias corrections of long-term (1973-2004) daily precipitation data over the northern regions. J Geophys Lett 32:L19501. doi:10.1029/2005GL024057

Yeh KS, Côté J, Gravel S, Méthot A, Patoine A, Roch M, Staniforth A (2002) The CMC-MRB global environmental multiscale (GEM) model. Part III: nonhydrostatic formulation. Mon Weather Rev 130:339-356

Zadra A, Roch M, Laroche S, Charron M (2003) The subgrid-scale orographic blocking parameterization of the GEM Model. Atmos-Ocean 41:155-170

Zadra A, Caya D, Côté J, Dugas B, Jones C, Laprise R, Winger K, Caron L-P (2008) The next Canadian regional climate model. Phys Canada 64:74-83

Zadra A, McTaggart-Cowan R, Roch M (2012) Recent changes to the orographic blocking. Seminar presentation, RPN, Dorval, Canada, 30 March 2012. http://collaboration.cmc.ec.gc.ca/science/ rpn/SEM/dossiers/2012/seminaires/2012-03-30/Seminar_201203-30_Ayrton-Zadra.pdf. Accessed 19 July 2012

Zhang GJ, McFarlane NA (1995) Sensitivity of climate simulations to the parameterization of cumulus convection in the CCC-GCM. Atmos-Ocean 3:407-446 